\title{
Charge Transport in Two-Photon Semiconducting Structures for Solar Fuels
}

Guohua Liu, ${ }^{[a, b]}$ Kang Du, ${ }^{[a]}$ Sophia Haussener, ${ }^{[c]}$ and Kaiying Wang ${ }^{*[a]}$

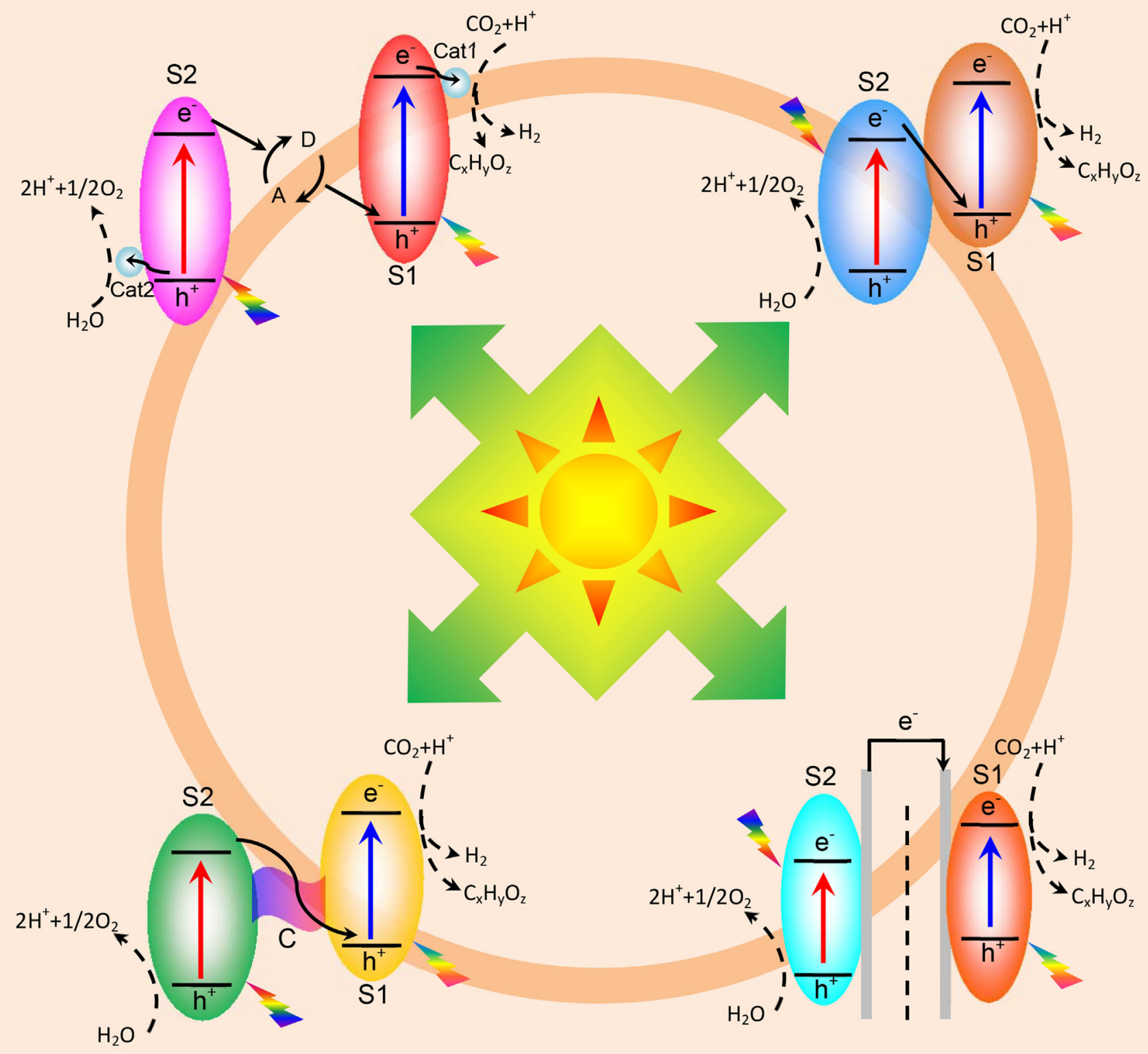


Semiconducting heterostructures are emerging as promising light absorbers and offer effective electron-hole separation to drive solar chemistry. This technology relies on semiconductor composites or photoelectrodes that work in the presence of a redox mediator and that create cascade junctions to promote surface catalytic reactions. Rational tuning of their structures and compositions is crucial to fully exploit their functionality. In this review, we describe the possibilities of applying the two-photon concept to the field of solar fuels. A wide range of strategies including the indirect combination of two semiconductors by a redox couple, direct coupling of two semiconductors, multicomponent structures with a conductive me- diator, related photoelectrodes, as well as two-photon cells are discussed for light energy harvesting and charge transport. Examples of charge extraction models from the literature are summarized to understand the mechanism of interfacial carrier dynamics and to rationalize experimental observations. We focus on a working principle of the constituent components and linking the photosynthetic activity with the proposed models. This work gives a new perspective on artificial photosynthesis by taking simultaneous advantages of photon absorption and charge transfer, outlining an encouraging roadmap towards solar fuels.

\section{Introduction}

As the population increases and industrial growth continues, the energy demands of our society continue to rise. Nowadays, our major energy resources are still derived from limited and nonrenewable fossil fuels, such as coal, oil, and natural gas. ${ }^{[1]}$ Their production and consumption are problematic. The byproducts and chemicals used in the extraction and refinement of fossil fuels cause significant harm to the environment. The combustion of fossil fuels results in severe problems ranging from air and water pollution to global warming. Therefore, renewable energy sources are urgently needed to liberate our dependence on fossil fuels.

Solar energy provides a sustainable and clean resource. The challenge is to develop efficient methods to harvest and store solar energy ${ }^{[2]}$ This has stimulated studies to find materials capable of transforming solar energy into chemical fuels. Photochemical fuel production by water splitting or $\mathrm{CO}_{2}$ reduction represents an attractive approach. ${ }^{[3]}$ In this method, semiconductor photocatalysts or photoelectrodes (PEs) with assisting catalysts are integrated in photocatalytic (PC) or photoelectrochemical (PEC) devices. ${ }^{[4]}$ The reactions are realized if sequential steps are accomplished: light harvesting to generate electron-hole pairs, charge separation and migration to the surface of the catalyst, and catalytic reaction between the charge carriers and the reactants. ${ }^{[3 a, 5]}$ The overall efficiency is dependent on both the thermodynamics and the kinetics of the processes.

Photochemical conversion of solar energy is a fundamental research and technology challenge. ${ }^{[6]}$ The basic problem lies in

\section{[a] Dr. G. Liu, K. Du, Prof. K. Wang}

Department of Micro and Nano Systems Technology

University College of Southeast Norway

Horten, 3184 (Norway)

E-mail:Kaiying.Wang@hbv.no

[b] Dr. G. Liu

School of Energy and Environment

Anhui University of Technology

Maanshan, 243002 (PR China)

[c] Dr. S. Haussener

Institute of Mechanical Engineering

Ecole Polytechnique Federale de Lausanne

1015 Lausanne (Switzerland) the coupling of the light-harvesting modules, which involves the catalysis of transient electron excited states to typically slow, multielectron, proton-coupled fuels. ${ }^{[3 e, 7]}$ The technology challenge is integration of the complicated machinery responsible for this process, particularly the assembling and spatial structuring of the various components. ${ }^{[6,8]}$ Nature photosynthesis (NPS) provides a two-photon paradigm for doing this with molecular-based materials. ${ }^{[3,9]}$ To mimic the process, various structures have been proposed to simulate NPS through two separate semiconductors and a redox couple. The preferential attachment of redox species to a particular semiconductor surface is either an oxidation reaction or a reduction reaction. ${ }^{[10]}$ Recently, advanced structures for fast charge transfer have been used for the process. For example, two different semiconductors through a heterojunction have been shown to induce swift electron transfer between materials, ${ }^{[11]}$ ternarycomponent structures with a solid-state electron mediator are able to realize a vectorial electron-transfer path, ${ }^{[12]}$ and various composite photoanodes ${ }^{[13]}$ and cathodes ${ }^{[14]}$ have been constructed for fuel generation. PEC devices employing multijunction photovoltaics $(\mathrm{PVs})^{[15]}$ or consisting of hydrogen- and oxygen-evolving electrodes ${ }^{[16]}$ are also reported.

Although these efforts have been summarized in excellent reviews from specific aspects, for example, two-step solution contact systems, ${ }^{[17]}$ composite photocatalysts and $\mathrm{PEs},{ }^{[3 f, 4 b, 5 a, 18]}$ and solar-fuel devices, ${ }^{[19]}$ the integration of materials for both photon absorption and charge transport remains poorly understood. ${ }^{[20]}$ We believe that a comprehensive overview on ways to introduce the two-photon strategy for solar fuels is timely to promote further developments in this exciting field. In this work, we provide insight into two-photon semiconducting structures to understand interfacial carrier dynamics. Models are extracted from the literature to elucidate the mechanism of charge transport and to rationalize the experimental observations. We examine the physical explanations and attempt to distinguish ambiguities behind the models. Special focus is put on the techniques used to couple the materials and the working principle of the constituent components. Links between their performance and the proposed models are highlighted. 
Guohua Liu received his Ph.D. degree in the Engineering of Thermophysics from the Chinese Academy of Sciences in 2010. He obtained his second Ph.D. degree in Micro and Nano Systems Technology at the University College of Southeast Norway (HSN) in 2013. He is currently a professor of Power Engineering at the Anhui University of Technology and a postdoctoral fellow working under the supervision of Prof. Kaiying Wang at HSN. His research in-

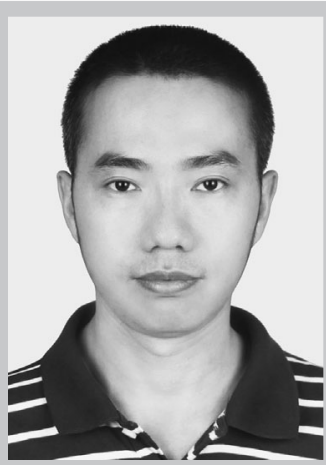
terests are centered on the development and assembly of nanostructured materials for energy applications.

Kang $\mathrm{Du}$ is currently a $\mathrm{PhD}$ candidate at the University College of Southeast Norway (HSN) under the supervision of Prof. Kaiying Wang. He received his M.Sc. degree in Micro and Nano System Technology in 2014 at HSN, Norway. His present scientific interests focus on nanomaterials and photocatalysts for energy conversion and applications.

Dr. Sophia Haussener is an assistant professor and the head of the Laboratory of Renewable Energy Science and Engineering at École polytechnique fédérale de Lausanne (EPFL), Switzerland. She has worked in collaboration with numerous international partners on highly multi-disciplinary projects conducting investigations of transport phenomena in complex multi-phase media relevant to energy conversion technologies. A special focus lies on solar-driven energy conversion processes based on solar thermal, thermochemical, and electrochemical processes.

Kaiying Wang received his Ph.D. degree in Condensed Matter Physics from the Institute of Physics, Chinese Academy of Sciences, in 1995. He was a postdoctoral researcher at the University of New Orleans, USA. He joined the University College of Southeast Norway in 2007 as an associate professor and was then promoted to professor in 2010. His research interests focus on microfabrication and nanotechnology, functional thin films, mag-
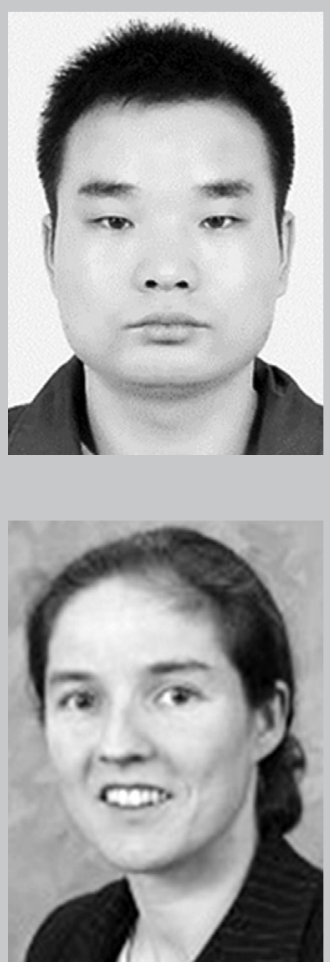

netic and superconductive materials, nanostructure characterization, and nanodevices for environmental and energy applications.

\section{Concept, Models, and Benefit of Two- Photon Structures}

Plants use sunlight as an energy source and $\mathrm{CO}_{2}$ and water as feedstock to split water as molecular oxygen, which is accompanied by the reduction of $\mathrm{CO}_{2}$ to carbohydrates. ${ }^{[9 a]}$ The reactions occur over two distinct stages. The light reaction occurs through a stepwise electron-transfer process to accumulate sufficient energy for the chemical reaction (Scheme $1 a),{ }^{[3 b, 9 a, 21]}$ for which two photosystems (PSI and PSII) collect solar energy through an assembly of light-harvesting chlorophylls and power electrons to a higher electronic state inside the reaction center. At the donor side of PSIl, water oxidation occurs on a manganese calcium oxide cluster. Electrons are extracted from water and are further donated to the lower oxidized form of P680. P680 is a pigment that absorbs $\lambda=680 \mathrm{~nm}$ light in PSIl. Absorption of a photon excites P680 to P680*, at which the electrons are promoted to an actively reducing species. $\mathrm{P} 680^{*}$ donates its electron to the quinone--cytochrome $f$ chain with proton pumping. The electron from cytochrome $f$ is donated to PSI, which converts P700 into P700* (P700 is a pigment that absorbs $\lambda=700 \mathrm{~nm}$ light in PSI).The electrons along
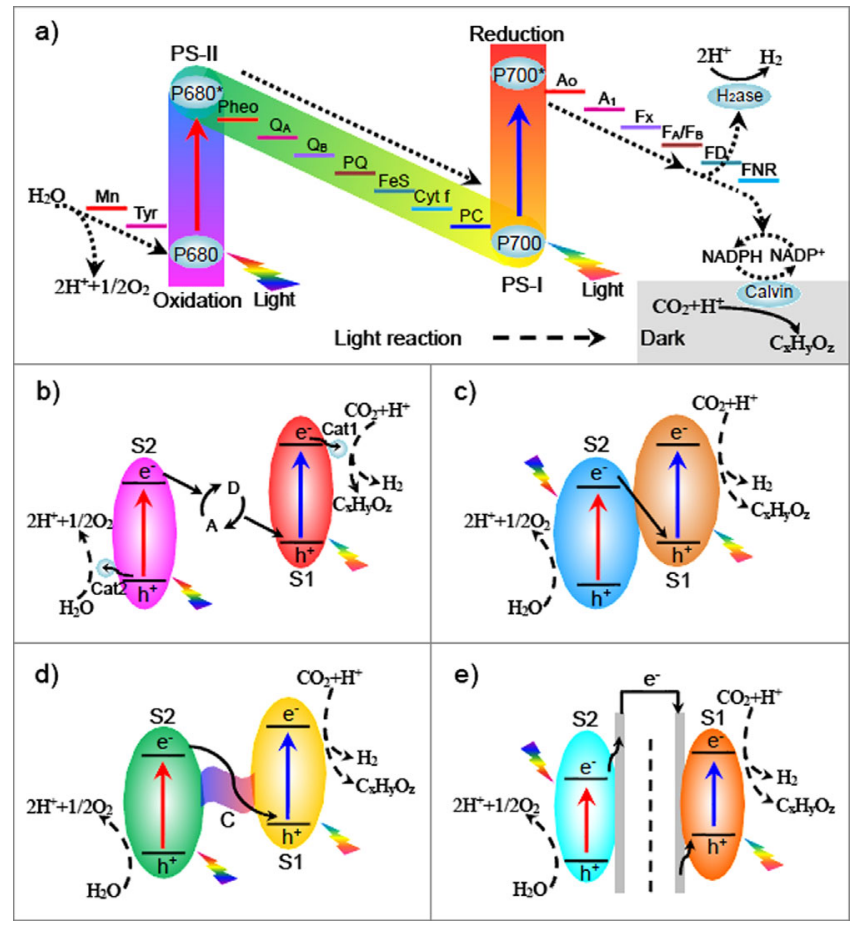

Scheme 1. a) Z-Scheme in natural photosynthesis for charge separation. P680: pigment that absorbs $\lambda=680 \mathrm{~nm}$ light in photosystem II; $\mathrm{P} 680^{*}$ is the excited state of $\mathrm{P} 680$; P700: pigment that absorbs $\lambda=700 \mathrm{~nm}$ light in photosystem I; P700* is the excited state of P700. Mn is manganese calcium oxide cluster; Tyr is tyrosine in PSII; Pheo is pheophytin, the primary electron acceptor of PSII; $Q_{A}$ is primary plastoquinone electron acceptor; $Q_{B}$ is secondary plastoquinone electron acceptor; $P Q$ is plastoquinone; $F e S$ is Rieske iron sulfur protein; Cyt $f$ is cytochrome $f ; P C$ is plastocyanin; $A_{O}$ is primary electron acceptor of PSI; $A_{1}$ is phylloquinone; $F_{X}, F_{A}$ and $F_{B}$ are three separate iron sulfur centers; $F_{D}$ is ferredoxin; FNR is nicotinamide adenine dinucleotide phosphate (NADP) reductase (adapted from refs. [3b, 21a, c]). Artificial two-photon structures of b) solution contact, c) direct contact, d) multicomponent, and e) photoelectrochemical cells. 
with others are transferred to nicotinamide adenine dinucleotide phosphate $\left(\mathrm{NADP}^{+}\right)$to form NADPH. Lastly, the dark reactions occur, during which the products of the light reaction form the $\mathrm{C}-\mathrm{C}$ covalent bonds of carbohydrates. In this process, pigments absorbing a wide range of the visible spectrum convert light into chemical energy at PSII. Charge recombination is prevented by the presence of a transport chain, which drives electrons to PSI. Additional light harvesting takes place at PSI, which provides more energy to the electrons for their final purpose. This excitation cascade with electrons shuttled through the transport chain initiates the concept of twophoton structures. ${ }^{[21 c, 22]}$

Artificial two-photon structures are analogous to the electron-transport chain in NPS. According to the charge-extraction scheme, the structures are classified into four models: indirect combination of two semiconductors by redox couples (S1-A/DS2) (Scheme $1 \mathrm{~b}$ ), direct coupling of two semiconductors (S1S2) (Scheme 1 c), multicomponent structure with a solid conductive mediator (S1-C-S2) (Scheme 1d), and related PEs and two-photon cells (i.e., PEC) (Scheme 1e). Here, the symbol $S$ represents the semiconductor, $A / D$ is the redox couple, and $C$ represents the conductive material. The band gaps and band positions for a variety of semiconducting materials are depicted in Figure 1. ${ }^{[23]}$ For $\mathrm{H}_{2}$ evolution and $\mathrm{CO}_{2}$ reduction, the position of the conduction band (CB) edge should be higher than the redox potential of $\mathrm{H}_{2} / \mathrm{H}_{2} \mathrm{O}$ or $\mathrm{CH}_{4} / \mathrm{CO}_{2}\left(\mathrm{CH}_{3} \mathrm{OH} / \mathrm{CO}_{2}, \mathrm{HCHO} /\right.$ $\mathrm{CO}, \mathrm{HCOOH} / \mathrm{CO}_{2}$, or $\left.\mathrm{CO} / \mathrm{CO}_{2}\right)$, whereas the position of the valence band (VB) edge should be lower than the redox potential of $\mathrm{O}_{2} / \mathrm{H}_{2} \mathrm{O} .^{[3 a, c, 24]}$ The core of this concept is to steer charge transport between various materials and species. The engineering of energy bands and the interfaces of structures play important roles in the design of materials. The ultimate goal is to enhance light absorption and charge transfer to accelerate the photosynthetic reaction.

The essence of a two-photon structure lies in the coupling of different materials to efficiently capture and stabilize the energy of solar radiation to drive multielectron chemistry. ${ }^{[10 b, 11 b, 16]}$ The electron transfer is balanced through an electron relay material between the absorbers. The process utilizes lower energy photons of the solar spectrum and increases the choices available for combinations of the materials. As long as the excited-state oxidation potential at the oxygen-evolving site ( $\mathrm{S} 2$ in Scheme 1) is more negative than the excited-state reduction potential at the hydrogen-evolving site (S1), there is no further potential requirement for these states. ${ }^{[3 \mathrm{~b}, 18 \mathrm{1}]}$ The system features spatial separation of charge carriers and enhances the stability of the catalyst against photocorrosion. The electrons aggregated in the CB of S1 produce an electron-rich region that suppresses photooxidation. Aggregation of the holes in the VB of S2 produces a hole-rich region, which protects $\mathrm{S} 2$ from photoreduction.

\section{Principle, Materials, and Performance of Two-Photon Structures}

\subsection{Indirect combination of two semiconductors by a redox couple (photocatalytic systems)}

The structure represents a system with two separate semiconductors in a solution redox mediator (Figure $2 \mathrm{a}$ ). ${ }^{[10 a]}$ Each semiconductor is responsible for one half-reaction, and the soluble redox mediator helps electron transfer between the materials. ${ }^{[17,25]}$ Forward reactions occurring on the surface of S1 include reduction of protons by the $\mathrm{CB}$ electrons and oxidation
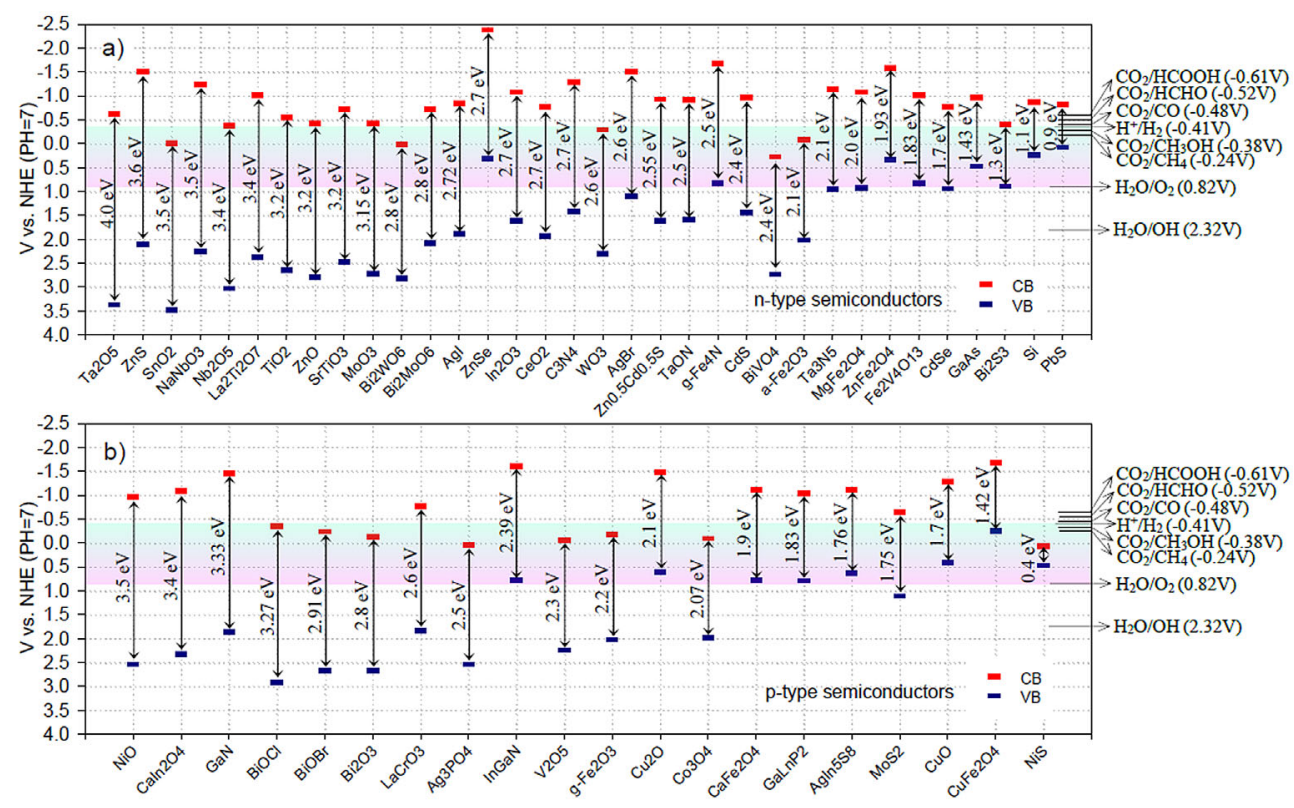

Figure 1. Band gaps and band positions of a) n-type semiconductors and b) p-type semiconductors relative to the redox potentials of various compounds involved in water splitting and $\mathrm{CO}_{2}$ reduction. Values were taken from references given in the article. Note: The CB potential of a semiconductor material in aqueous solution usually exhibits a $\mathrm{pH}$ dependence described according to $E_{\mathrm{CB}}=E_{\mathrm{CB}(\mathrm{pH} 0)}^{0}-0.059 \mathrm{pH}$. The redox potentials of water also have the same linear $\mathrm{pH}$ dependence with a slope of $0.059 \mathrm{~V}$ per $\mathrm{pH}$. 


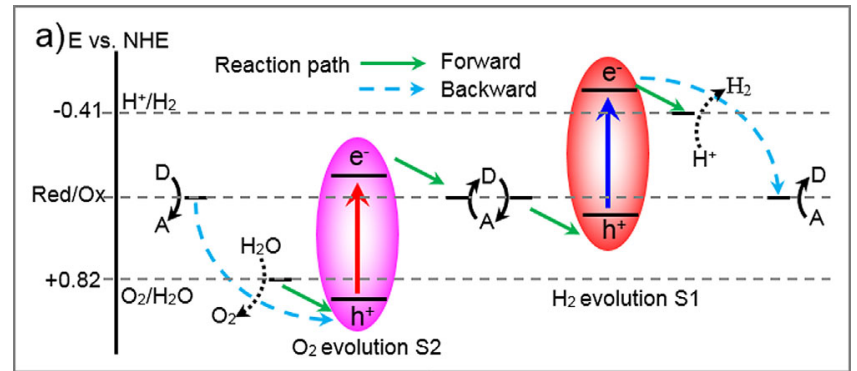

b)

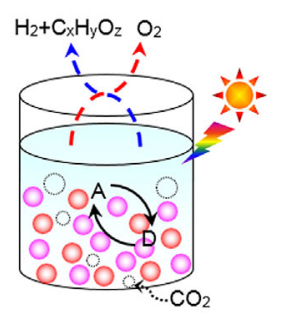

c)

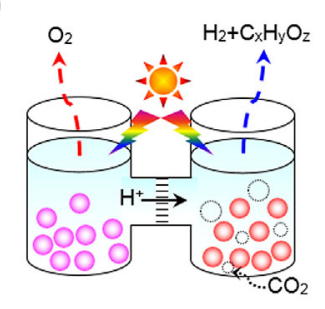

Figure 2. a) Energy diagrams of a solution contact system (adapted from ref. [10a]). b) Photocatalysts mixed in a conventional reactor. c) Twin reactor for product separation.

of the electron donor (D) by VB holes to yield the corresponding electron acceptor (A). The forward reaction on S2 is water oxidation, which occurs with the VB holes, and the A generated by $\mathrm{S} 1$ is converted into its reduced form (i.e., D). Thus, a cycle of redox pairs occurs and fuel production is fulfilled. The properties of the semiconductor, the cocatalyst (cat1 and cat 2 in Scheme $1 \mathrm{~b}$ ), and the redox couple are key factors affecting the activity.

\subsubsection{Semiconductors and cocatalysts}

Since Bard introduced the concept of pairing semiconductors for water splitting, ${ }^{[26]}$ many efforts have been made to develop new materials. ${ }^{[17]}$ Many metal oxides and (oxy)nitrides have been reported for $\mathrm{H}_{2}$ or $\mathrm{O}_{2}$ evolution under UV/Vis light irradiation. ${ }^{[17 \mathrm{~b}]}$ The combination of $\mathrm{Pt}-\mathrm{TaON}\left(\mathrm{H}_{2}\right.$ evolution) and $\mathrm{PtO}_{x} /$ $\mathrm{WO}_{3}\left(\mathrm{O}_{2}\right)$ through the $\mathrm{IO}_{3}{ }^{-} \mathrm{I}^{-}$redox couple shows water splitting with an apparent quantum yield (AQY) of $0.5 \%$ under the illumination of $\lambda=420 \mathrm{~nm}$ UV light. Fuel production is stable, and stoichiometric amounts of $\mathrm{H}_{2}$ and $\mathrm{O}_{2}$ are produced within $60 \mathrm{~h} .{ }^{[27]}$ Between $\lambda=520$ and $600 \mathrm{~nm}, \mathrm{RuO}_{2}$-loaded TaON nanoparticles (NPs) ${ }^{[10 a]}$ and Ir-loaded rutile $\mathrm{TiO}_{2} / \mathrm{Ta}_{3} \mathrm{~N}_{5}$ (oxy)nitrides ${ }^{[28]}$ show functionality for $\mathrm{O}_{2}$ evolution in the presence of the $\mathrm{IO}_{3}^{-} / \mathrm{I}^{-}$redox mediator. By extending the absorption wavelength further to $\lambda=660 \mathrm{~nm}, \mathrm{BaZrO}_{3} / \mathrm{BaTaO}_{2} \mathrm{~N}$ with Pt NPs can be used as a water reduction promoter with either $\mathrm{PtO}_{x} / \mathrm{WO}_{3}$ or $\mathrm{TiO}_{2}$ rutile as the $\mathrm{O}_{2}$ evolution catalyst. ${ }^{[29]}$ It is anticipated that nanosheets such as $\mathrm{g}-\mathrm{C}_{3} \mathrm{~N}_{4}, \mathrm{BiVO}_{4}$, and $\mathrm{WO}_{3}$ can be used and optimized to build more efficient systems under visible light.

The oxide $\mathrm{SrTiO}_{3}$ exhibits high stability, but it alone cannot split water under visible light. Pairing $\mathrm{Ru} / \mathrm{Na}, \mathrm{V}-\mathrm{SrTiO}_{3}$, and $\mathrm{Ru}$ / $\mathrm{Rh}-\mathrm{SrTiO}_{3}$ with the aid of the $\mathrm{IO}_{3}^{-} / \mathrm{I}^{-}$mediator results in water splitting owing to narrowing of the band gap of the oxide by adjusting the impurity levels of the $\mathrm{V} 3 \mathrm{~d}$ and $\mathrm{Rh} 4 \mathrm{~d}$ states in the forbidden band. These intermediate energy levels act either as electron acceptors or donors that allow $\mathrm{Ru} / \mathrm{Rh}-\mathrm{SrTiO}_{3}$ to reduce $\mathrm{H}_{2} \mathrm{O}$ to $\mathrm{H}_{2}$ and the holes in the $\mathrm{VB}$ of $\mathrm{Na}, \mathrm{V}-\mathrm{SrTiO}_{3}$ to oxidize $\mathrm{H}_{2} \mathrm{O}$ to produce $\mathrm{O}_{2} \cdot{ }^{\left[{ }^{[0]}\right.}$ Inorganic modification and organic dyes are normally employed to tune the energy levels of the semiconductors for visible-light absorption. As organic dye sensitizers, NKX 2677 can be loaded on $\mathrm{Pt}$ (in)/ $\mathrm{H}_{4} \mathrm{Nb}_{6} \mathrm{O}_{17}$ for $\mathrm{H}_{2}$ evolution and $\mathrm{WO}_{3}$ for $\mathrm{O}_{2}$ evolution with the $\mathrm{IO}_{3}^{-} / \mathrm{I}^{-}$redox couple between them; $\mathrm{H}_{2}$ evolution proceeds at a steady rate of approximately $8 \mu \mathrm{molh}^{-1}$. ${ }^{[31]}$ Rapid electron injection from the anchored dyes into the semiconductor is responsible for this high performance.

Inorganic noble metals ( $\mathrm{Pt}, \mathrm{Rh}$ ) and several metal oxides $\left(\mathrm{NiO}_{x}, \mathrm{RuO}_{2}\right)$ are important cocatalysts to collect charge carriers. They are dispersed on a photocatalyst surface to provide active sites and to reduce the activation energy (Scheme 1 b). ${ }^{[4 a, 32]}$ The $\mathrm{SrTiO}_{3}: \mathrm{Rh}$ system loaded with various cocatalysts ( $\mathrm{Ni}, \mathrm{Ru}, \mathrm{Rh}, \mathrm{Pt}$, and $\mathrm{Au}$ ) has been explored for $\mathrm{H}_{2}$ evolution in the $\mathrm{Fe}^{3+} / \mathrm{Fe}^{2+}$ electron-mediator solution. ${ }^{[32 \mathrm{~b}]}$ The activity using a Ru cocatalyst is as high as that using a Pt cocatalyst. The backwards reaction of water formation from $\mathrm{H}_{2}$ and $\mathrm{O}_{2}$ and the reduction of $\mathrm{Fe}^{3+}$ ions by $\mathrm{H}_{2}$ do not proceed in the system. The $\left(\mathrm{Ru} / \mathrm{SrTiO}_{3}: \mathrm{Rh}\right)-\left(\mathrm{Fe}^{3+} / \mathrm{Fe}^{2+}\right)-\left(\mathrm{BiVO}_{4}\right)$ system shows a quantum yield of $0.3 \%$ with stable activity for more than $70 \mathrm{~h}$. The way in which the catalyst is synthesized is also an important factor affecting the $A Q Y$; it increases from 0.4 to $3.9-4.2 \%$ at $\lambda=$ $420 \mathrm{~nm}$ if $\mathrm{SrTiO}_{3}: \mathrm{Rh}$ is synthesized by the hydrothermal and polymerizable complex method instead of a solid-state reaction. ${ }^{[33]}$

\subsubsection{The redox couple and engineering aspect}

Redox mediators inhibit the unfavorable recombination of electrons and holes, which is analogous to the transport chain in NPS. They transfer electrons from the $\mathrm{O}_{2}$ evolution catalyst (OEC) to the hydrogen evolution catalyst (HEC) and are in direct contact with the catalyst surface. Many transition-metal complexes have been accepted as electron mediators including $\mathrm{IO}_{3}^{-} / \mathrm{I}^{-}, \quad \mathrm{Fe}^{3+} / \mathrm{Fe}^{2+}, \quad\left[\mathrm{Co}(\mathrm{bpy})_{3}\right]^{3+/ 2+} \quad$ bpy $=2,2^{\prime}$-bipyridyl), $\left[\mathrm{Co}(\text { phen })_{3}\right]^{3+/ 2+}$ (phen =1,10-phenanthroline), and $\mathrm{NO}_{3}^{-} /$ $\mathrm{NO}_{2}{ }^{-} \cdot{ }^{[17 b, 34]}$ The most common redox couples are $\mathrm{IO}_{3}{ }^{-} / \mathrm{l}$ and $\mathrm{Fe}^{3+} / \mathrm{Fe}^{2+}$, the former of which is used over a wide range of $\mathrm{pH}$ conditions and has no absorption in the visible-light region. lodide salts (e.g., Nal) are used to initiate water splitting. By increasing the concentration of $\mathrm{Nal}$, the efficiency of $\mathrm{I}^{-}$oxidation by the VB holes for a HEC is increased, which results in water reduction to give more $\mathrm{H}_{2}$. In the case of the $\mathrm{Fe}^{3+} / \mathrm{Fe}^{2+}$ couple, the situation is similar, but the available $\mathrm{pH}$ range is limited to acidic conditions, because iron ions undergo precipitation to give iron hydroxide under neutral conditions. The cobalt complexes $\left[\mathrm{Co}(\mathrm{bpy})_{3}\right]^{3+/ 2+}$ and $\left[\mathrm{Co}(\text { phen })_{3}\right]^{3+/ 2+}$ have been shown to be effective mediators. Their activity depends on the solution $\mathrm{pH}$, and the highest activity is obtained under neutral $\mathrm{pH}$ conditions. ${ }^{[34]}$ Nevertheless, all redox mediators absorb light to some extent and have limited long-term stability.

Nanoparticle photocatalysts are often mixed with an aqueous solution in a single reactor (Figure $2 \mathrm{~b}$ ). ${ }^{[19 \mathrm{c}]}$ In this reactor, 
the backwards reaction occurs and separation of the products causes extra expense. A two-compartment system connected by a Pt wire with bromide and iron ions as electron mediators was proposed for water splitting in 1998. ${ }^{[35]}$ Fuel production was then achieved in a dual-bed operation with $\mathrm{O}_{2}$ evolution on $\mathrm{WO}_{3}$ and $\mathrm{H}_{2}$ evolution on $\mathrm{Pt} / \mathrm{SrTiO}_{3}: \mathrm{Rh}$ in an aqueous $\mathrm{Fe}^{2+}$ $/ \mathrm{Fe}^{3+}$ solution. ${ }^{[36]}$ Twin reactors also have been designed for $\mathrm{CO}_{2}$ reduction. ${ }^{[37]}$ Here, a fuel-evolving catalyst and an oxidation reaction catalyst are placed in different compartments of the reactor that are separated by a proton-exchange membrane (PCM, Figure $2 \mathrm{c}$ ). Comparing the single catalyst Pt/CuAl$\mathrm{GaO}_{4}$ system with the dual catalyst $\mathrm{Pt} / \mathrm{SrTiO}_{3}: \mathrm{Rh}$ and Pt/CuAl$\mathrm{GaO}_{4}$ system in $\mathrm{Fe}^{2+} / \mathrm{Fe}^{3+}$ solution, the dual-catalyst system shows a photoreduction quantum efficiency of $0.0051 \%$, which is more than double the efficiency of the single-catalyst system. ${ }^{[37 b]}$ These reactors offer a viable prototype for engineering applications.

\subsection{Direct coupling of two semiconductors (photocatalytic systems)}

Loading one semiconductor onto another creates a semiconductor junction. ${ }^{[5,18 b, 23]}$ The band offsets and the electronic structure/affinity and work functions of the materials define the charge dynamics. According to energy level and band-gap alignment, the junctions are classified as injection sensitization (Figure $3 a, b$ ), $p-n$ junction (Figure $3 c, d$ ), staggered (Figure $3 c, d$ ), straddling junction (Figure $3 e$ ), and direct Z-scheme (Figure $3 \mathrm{f}$ ). These structures provide an offset of band edges that promotes spatial separation of the charges by transferring electrons in the higher $C B$ to the lower $C B$ and/or holes in the lower VB to the higher VB.

\subsubsection{Injection sensitization}

Injection sensitization happens in a system with a wide-bandgap semiconductor (S2) and a narrow-band-gap semiconductor (S1). The narrow-band-gap sensitizer is excited under visi-
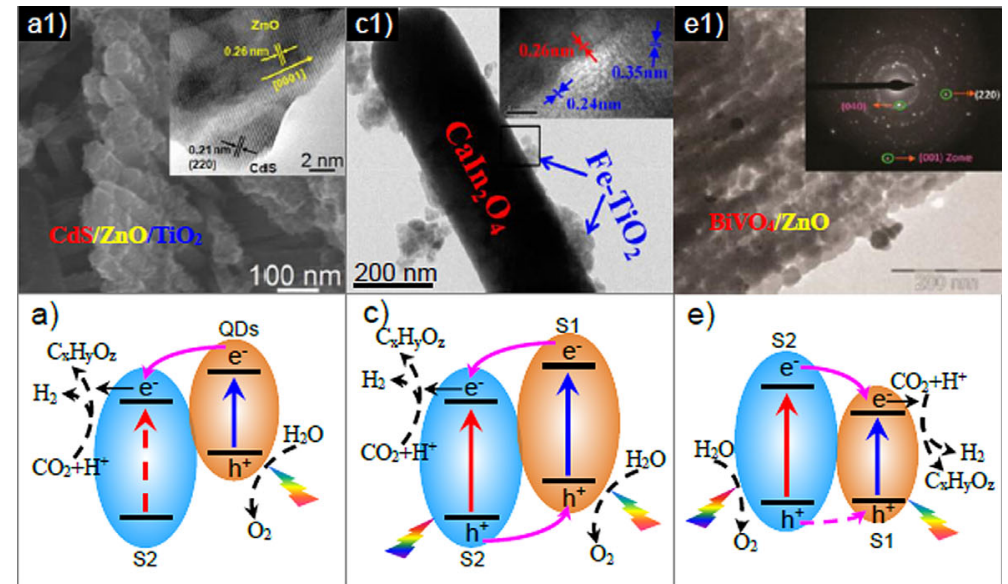

e)
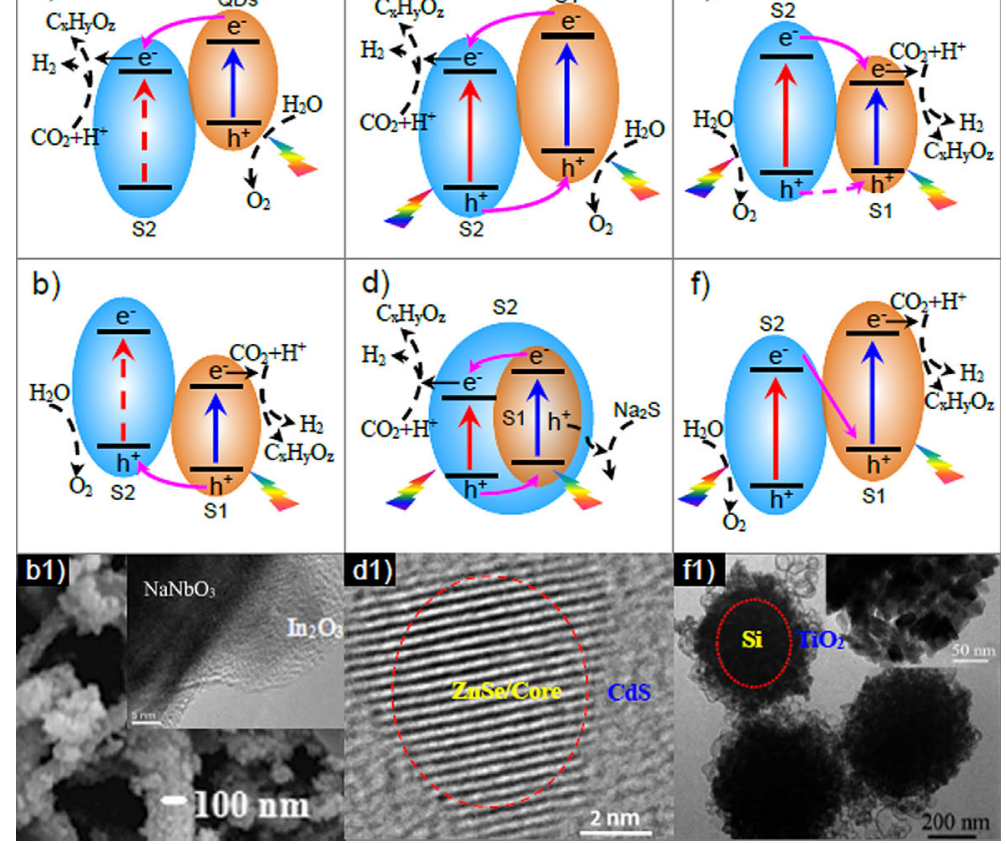

Figure 3. a) Electron-injection sensitization and its example a1) SEM and HRTEM images of A-TiO $/ 2$ nO/CdS (adapted from ref. [42], copyright 2014 Nature Publishing Group). b) Hole-injection sensitization and its example b1) SEM and TEM images of $\ln _{2} \mathrm{O}_{3} / \mathrm{NaNbO}_{3}$ rods (adapted from ref. [44], copyright 2010 American Chemical Society). c) The p-n junction and its example c1) TEM and HRTEM images of Caln $\mathrm{O}_{4} / \mathrm{Fe}^{-T i O_{2}}$ composite (reprinted with permission from ref. [11b], copyright 2014 American Chemical Society). d) Core-shell staggered junction and its example d1) TEM images of ZnSe/CdS nanocrystals (reprinted with permission from ref. [80], copyright 2012 American Chemical Society). e) Straddling junction and its example, e1) TEM images and SAED pattern of $\mathrm{BiVO}_{4} / \mathrm{ZnO}$ (adapted from ref. [81], copyright 2014 American Chemical Society). f) Direct Z-scheme and its example, f1) SEM and TEM images of Si/TiO 2 nanospheres (adapted from ref. [100a], copyright 2014 American Chemical Society). 
ble light and generates electrons and holes (Figure $3 a, b) .{ }^{[38]}$ The CB energy level of S2 is lower than that of the sensitizer (Figure $3 \mathrm{a}$ ). Therefore, the electrons in the sensitizer can migrate to the $C B$ of S2. For instance, the band gap of CdS is approximately $2.40 \mathrm{eV}$, and the $\mathrm{CB}$ and $\mathrm{VB}$ energy levels are approximately -0.50 and $1.90 \mathrm{eV}$ versus normal hydrogen electrode (NHE). The electrons of CdS are transferred from the VB to the $\mathrm{CB}$, whereas $\mathrm{TiO}_{2}$ cannot be photoexcited under visible light because of its large band gap. ${ }^{[39]}$ As a result, the electrons of $\mathrm{CdS}$ are injected into the $\mathrm{CB}$ of $\mathrm{TiO}_{2}$, because the $\mathrm{CB}$ potential of $\mathrm{CdS}$ is more negative than that of $\mathrm{TiO}_{2}(\approx-0.26 \mathrm{eV})$. The holes remain in the VB of CdS owing to the lower positive potential of the $C B$.

Photoexcited electrons of $\mathrm{CdS}$ have been reported to inject into diverse nanostructures, such as elongated nanocrystals $(\mathrm{NCs}){ }^{[39]}$ porous or layered materials, ${ }^{[40]}$ and tubular semiconductor hosts. ${ }^{[41]}$ The $\mathrm{H}_{2}$ production rate of $\mathrm{CdS} /$ elongated $\mathrm{TiO}_{2}$ NCs reaches $3.85 \mathrm{mmolh}^{-1} \mathrm{~g}^{-1}$ if the $\mathrm{Cd} / \mathrm{Ti}$ molar ratio is $0.17 .^{[39]}$ The $\mathrm{H}_{2}$ generation rate of the CdS NPs with layered titanate nanosheets $\left(\approx 1.0 \mathrm{mmolg}^{-1} \mathrm{~h}^{-1}\right)$ is higher than that of their reference $\left(\approx 0.13 \mathrm{mmolg}^{-1} \mathrm{~h}^{-1} \text { for bulk } \mathrm{CdS} / \mathrm{TiO}_{2}\right)^{\left[{ }^{[40 a]}\right.}$ Strong electronic coupling between the $2 \mathrm{D}$ layered titanate nanosheets and the CdS NPs leads to a high visible-light harvesting ability, an increased charge lifetime, and expansion of the surface area. Decorating CdS NPs approximately $2-5 \mathrm{~nm}$ in size inside $\mathrm{TiO}_{2}$ nanotubes (TNTs) not only promotes the $\mathrm{H}_{2}$ evolution activity but also enhances the stability of $\mathrm{CdS}{ }^{[41 \mathrm{~b}, \mathrm{c}]}$ CdS-coated TNTs undergo rapid deactivation after a reaction time of $4 \mathrm{~h}$. However, the activity is stable for $13 \mathrm{~h}$ if $\mathrm{CdS}$ is confined within the TNTs. Figure 3 a1 shows hierarchical structured CdS-sensitized 1D ZnO nanorods (NRs) on a 2D $\mathrm{TiO}_{2}$ nanosheet; it exhibits better $\mathrm{H}_{2}$ evolution performance $\left(\approx 13.3 \mu \mathrm{mol} \mathrm{h}^{-1} \mathrm{~cm}^{-2}\right)$ than $\mathrm{CdS}$-sensitized $1 \mathrm{D} \mathrm{ZnO} / \mathrm{TiO}_{2} \mathrm{NRs}^{[42]}$ This is due to efficient light harvesting and effective charge transport through the connected 3D network.

Hole injection is an inverse process to the electron injection, in which excitation of the sensitizer results in transfer of the holes to the $\mathrm{VB}$ of the semiconductor for the oxidation reaction (Figure $3 \mathrm{~b}$ ). For $\mathrm{Ag}_{3} \mathrm{PO}_{4} / \mathrm{SrTiO}_{3}{ }^{[43]}$ and $\ln _{2} \mathrm{O}_{3} / \mathrm{NaNbO}_{3} \mathrm{NR}$ composites, ${ }^{[44]}$ the $\mathrm{CB}$ edge of the sensitizer (i.e., $\mathrm{Ag}_{3} \mathrm{PO}_{4}$ or $\ln _{2} \mathrm{O}_{3}$ ) is lower than that of the parent catalyst, whereas the $V B$ edge of the catalyst is higher than that of the sensitizer. Under visible light, electrons in the sensitizer are excited to its $C B$, which leaves holes in the VB. The holes of the sensitizer are transported to the catalyst (i.e., $\mathrm{SrTiO}_{3}$ or $\mathrm{NaNbO}_{3}$ ) through the interface, whereas the electrons retain in the $C B$ of the sensitizer. ${ }^{[44,45]} \mathrm{O}_{2}$ evolution has shown that a small amount of $\mathrm{SrTiO}_{3}$ brings about an increase in the activity of $\mathrm{Ag}_{3} \mathrm{PO}_{4}$. The $\mathrm{AQY}$ reaches $16.2 \%$ if the molar ratio of $\mathrm{SrTiO}_{3} / \mathrm{Ag}_{3} \mathrm{PO}_{4}$ is approximately $5 \%{ }^{[43]} \ln _{2} \mathrm{O}_{3}$ exhibits a low activity for $\mathrm{H}_{2}$ evolution in $\mathrm{CH}_{3} \mathrm{OH}$ solution $\left(1.7 \mu \mathrm{molg}^{-1} \mathrm{~h}^{-1}\right)$, and almost no $\mathrm{H}_{2}$ is formed over $\mathrm{NaNbO}_{3}$ (Figure 3 b1). ${ }^{[44]}$ However, their combination with an In molar percentage of 0.25 improves the $\mathrm{H}_{2}$ formation rate to $16.4 \mu \mathrm{molg}^{-1} \mathrm{~h}^{-1}$, which is approximately one order of magnitude higher than that of $\ln _{2} \mathrm{O}_{3}$ alone.

Injection-sensitized catalysts have also been applied for $\mathrm{CO}_{2}$ reduction, such as $\mathrm{CdS}, \mathrm{Bi}_{2} \mathrm{~S}_{3}{ }^{[46]} \mathrm{PbS}^{[47]}$ and $\mathrm{AgBr}^{[48]}$ coupled with $\mathrm{TiO}_{2}, \mathrm{ZnTe}$ decorated with $\mathrm{ZnO}^{[49]}$ and $\mathrm{SrTiO}_{3}{ }^{[50]} \mathrm{CdS}$ - or $\mathrm{Bi}_{2} \mathrm{~S}_{3}$-sensitized TNTs show selective reduction of $\mathrm{CO}_{2}$ into methanol. The yields of methanol on TNTs, CdS/TNTs, and $\mathrm{Bi}_{2} \mathrm{~S}_{3}$ /TNTs catalysts are $102.5,159.5$, and $224.6 \mu \mathrm{molL}^{-1}$, respectively. ${ }^{[46]}$ The selectivity arises from the potentials of the $\mathrm{CBs}$ of $\mathrm{Bi}_{2} \mathrm{~S}_{3}$ and $\mathrm{CdS}$, which are more negative than those of the six-electron reduction of $\mathrm{CO}_{2}, \mathrm{H}_{2} \mathrm{CO}_{3}$, and $\mathrm{CO}_{3}{ }^{2-}$ to methanol in water. Thus, regardless of whether $\mathrm{CO}_{2}$ is in the form of $\mathrm{H}_{2} \mathrm{CO}_{3}$ or $\mathrm{CO}_{3}{ }^{2-}$ in water, it is reduced to methanol. The spectral range of light absorption depends on the band gap, which can be tuned by adjusting the size of the photocatalyst. ${ }^{[51]} \mathrm{PbS}$ NPs with diameters of 3,4 , and $5 \mathrm{~nm}$ have been used to sensitize $\mathrm{TiO}_{2}$ doped with $\mathrm{Cu}$ cocatalysts for $\mathrm{CO}_{2}$ conversion. ${ }^{[4]}$ Although the $\mathrm{CB}$ edge of bulk $\mathrm{PbS}$ is slightly lower than that of $\mathrm{TiO}_{2}$, quantum confinement shifts the $\mathrm{CB}$ edge of the smaller PbS NPs to higher energies, which enables electron injection into $\mathrm{TiO}_{2}$. The activity is clearly dependent on the size of PbS. The conversion rates of $\mathrm{CO}_{2}$ over the composites with 3,4 , and $5 \mathrm{~nm} \mathrm{PbS}$ are reported to be $0.45,1.12$, and $0.60 \mu \mathrm{mol} \mathrm{g}^{-1} \mathrm{~h}^{-1}$, all of which are higher than the conversion rate over $\mathrm{Cu} / \mathrm{TiO}_{2}$. This is because smaller PbS NPs facilitate electron-hole separation, whereas particles with larger diameters extend the visible absorption owing to the smaller band gap.

\subsubsection{P-n junction}

The $p$-n junction is an interface between $p$-type and n-type semiconductors. Within the interface, the energy bands are bent and the Fermi levels are equilibrated to reach a new equilibration between diffusion and migration, which results in the formation of a space-charge region. The built-in potential in the space-charge region allows effective separation of the charges (Figure 3c). ${ }^{[18 b, 24,52]} \mathrm{n}$-Type $\mathrm{TiO}_{2}$ has been coupled with various $\mathrm{p}$-type semiconductors to form these junctions, for example, $\mathrm{CuFe}_{2} \mathrm{O}_{4} / \mathrm{TiO}_{2},{ }^{[53]} \mathrm{Cu}_{2} \mathrm{O} / \mathrm{TiO}_{2},{ }^{[54]} \mathrm{CuO}_{x} / \mathrm{TiO}_{2}{ }^{[55]} \mathrm{Caln}_{2} \mathrm{O}_{4} / \mathrm{Fe}-$ $\mathrm{TiO}_{2}{ }^{[11 \mathrm{bl}]}$ and $\mathrm{CuO} / \mathrm{TiO}_{2-x} \mathrm{~N}_{x}{ }^{[56]}$ Figure $3 \mathrm{c} 1$ presents a TEM image of a Caln ${ }_{2} \mathrm{O}_{4} \mathrm{NR}$ with a tunable $\mathrm{Fe}-\mathrm{TiO}_{2}$ content. The composite leads to a $\mathrm{H}_{2}$ evolution rate of $280 \mu \mathrm{molg}^{-1} \mathrm{~h}^{-1}$, which is 12.3 times higher than that of pure $\mathrm{Caln}_{2} \mathrm{O}_{4}$ and 2.2 times higher than that of pure $\mathrm{Fe}^{-\mathrm{TiO}_{2}} \cdot{ }^{[11 \mathrm{~b}]}$ The enhanced rate is attributed to increased surface area, enhanced visible-light absorption, and efficient charge separation across the interface. Porous $\mathrm{Cu}_{2} \mathrm{O} / \mathrm{TiO}_{2}$ offers more reaction active sites than their composite particles for $\mathrm{CO}_{2}$ conversion. The formation rate of $\mathrm{CH}_{4}$ is $28.4 \mathrm{ppm} \mathrm{g}^{-1} \mathrm{~h}^{-1}$, which is approximately 12,9 , and 7.5 times higher than that of the pure $\mathrm{TiO}_{2}, \mathrm{Pt} / \mathrm{TiO}_{2}$, and commercial P25 powders. ${ }^{[54]}$ As nitrogen atoms enter the lattice $\mathrm{TiO}_{2}$, they make the band edges more compatible for charge transfer. The $\mathrm{CuO}-\mathrm{TiO}_{2-x} \mathrm{~N}_{x}$ composite with a hollow nanotube structure shows a high $\mathrm{CH}_{4}$ formation rate of $41.3 \mathrm{ppm} \mathrm{g}^{-1} \mathrm{~h}^{-1}$ from $\mathrm{CO}_{2}$ reduction. ${ }^{[56]}$

By depositing p-type NiS NPs onto n-type CdS NRs, the $\mathrm{H}_{2}$ generation rate becomes higher than that of $1 \mathrm{wt} \%$ Pt-loaded CdS NRs. ${ }^{[57]}$ The assembly of NiS NPs on the surface of CdS NRs results in the formation of a large number of $p-n$ junctions that reduce charge recombination. The optimal NiS loading is $5 \mathrm{~mol} \%$, and the corresponding $\mathrm{H}_{2}$ rate reaches 
$1131 \mu \mathrm{mol} \mathrm{g}^{-1} \mathrm{~h}^{-1}$. However, cadmium suffers from photocorrosion and is toxic. The emerging perovskite $n-\mathrm{La}_{2} \mathrm{Ti}_{2} \mathrm{O}_{7} / \mathrm{p}-\mathrm{LaCrO}_{3}$ evolves $267.6 \mathrm{mmolh}^{-1}$ of $\mathrm{H}_{2}$, whereas $\mathrm{LaCrO}_{3}$ photocatalyst

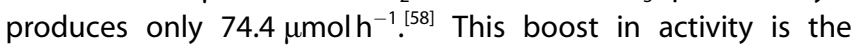
result of the low recombination rate of the charge carriers and visible-light activation of $\mathrm{La}_{2} \mathrm{Ti}_{2} \mathrm{O}_{7}$. A nanodiode of $\mathrm{p}-\mathrm{CaFe}_{2} \mathrm{O}_{4}$ $(\approx 1.9 \mathrm{eV})$ and $\mathrm{n}-\mathrm{PbBi}_{2} \mathrm{Nb}_{1.9} \mathrm{~W}_{0.1} \mathrm{O}_{9}(\approx 2.75 \mathrm{eV})$ has also been constructed. ${ }^{[59]}$ This composite shows enhanced activity for both $\mathrm{H}_{2}$ production in methanol solution and water oxidation in $\mathrm{AgNO}_{3}$ solution. Similar bulk junctions of $\mathrm{CaFe}_{2} \mathrm{O}_{4} / \mathrm{MgFe}_{2} \mathrm{O}_{4}$ (2.0 eV) have also been reported. ${ }^{[60]}$ The $\mathrm{H}_{2}$ evolution rate of the $\mathrm{RuO}_{2} / \mathrm{MgFe}_{2} \mathrm{O}_{4} / \mathrm{CaFe}_{2} \mathrm{O}_{4} / \mathrm{Pt}$ composite remains almost the same after several runs with a quantum yield of $10.1 \%$. This performance comes from the effect of the junction, for which the p-type and n-type semiconductors are dispersed from each other.

\subsubsection{Staggered alignment}

For staggered band-gap heterostructures, both the $C B$ and VB edges of S1 are higher than those of S2 (Figure $3 c, d$ ). The energy gradient existing at the interface tends to separate electrons and holes on different sides; the electrons are confined to the $C B$ of $S 2$ and the holes are confined to the VB of $S 1$. Band bending resulting from the difference in the chemical potentials of the semiconductors also contributes to a built-in field. It remains under debate as to whether this occurs through electron transfer owing to favorable energetics of the relative positions of the $\mathrm{CBs}$ or through band bending at the interface. ${ }^{[5 c, 18 b, 23,61]}$ As a result, spatially localized charges across the junction can participate in redox reactions. The disadvantage of this structure is weak redox ability after charge transfer.

One wide-band-gap semiconductor coupling to another narrow-band-gap semiconductor results in the formation of a junction, and this occurs in $\mathrm{TiO}_{2} / \mathrm{CeO}_{2}{ }^{[62]} \mathrm{TiO}_{2} / \mathrm{ZnO}{ }^{[63]} \mathrm{Ta}_{2} \mathrm{O}_{5} /$ $\mathrm{In}_{2} \mathrm{O}_{3}{ }^{[64]} \mathrm{Cu}_{2} \mathrm{O} / \mathrm{g}-\mathrm{C}_{3} \mathrm{~N}_{4}{ }^{[65]} \mathrm{In}_{2} \mathrm{O}_{3} / \mathrm{g}-\mathrm{C}_{3} \mathrm{~N}_{4}{ }^{[66]} \mathrm{N}-\mathrm{TiO}_{2} / \mathrm{g}-\mathrm{C}_{3} \mathrm{~N}_{4}{ }^{[67]} \mathrm{ZnO} /$ $\mathrm{g}-\mathrm{C}_{3} \mathrm{~N}_{4}{ }^{[68]} \mathrm{TiO}_{2} / \mathrm{SnO}_{2}{ }^{[69]}$ and $\mathrm{TiO}_{2} / \mathrm{Nb}_{2} \mathrm{O}_{5}{ }^{[70]}$ Incorporation of $\mathrm{In}_{2} \mathrm{O}_{3}$ improves the thermal stability of mesoporous $\mathrm{Ta}_{2} \mathrm{O}_{5}$ and leads to a composite with a reduced band gap. The composite promotes electron transfer from the CB of $\ln _{2} \mathrm{O}_{3}$ to the CB of $\mathrm{Ta}_{2} \mathrm{O}_{5}$, and the inverse transfer of the holes retards the recombination probability. A $\mathrm{H}_{2}$ evolution rate of approximately $92 \mu \mathrm{mol} \mathrm{g}^{-1} \mathrm{~h}^{-1}$ is detected with a stability of approximately $30 \mathrm{~h} .{ }^{[64]}$ Recent studies focus on new photosystems such as metal nitrides and carbon nitrides. $\mathrm{Fe}_{4} \mathrm{~N} / \mathrm{Fe}_{2} \mathrm{O}_{3}$ structures improve the separation of charges and enhance the water-splitting reaction. ${ }^{[71]}$ First-principles analyses have revealed that the properties originate from particle-size-dependent changes in the band structure. The proximity of the VB potential of the component promotes the entrapment of hole carriers, and the defect-induced interband-gap energy states lead to effective charge separation. $\mathrm{g}-\mathrm{C}_{3} \mathrm{~N}_{4}$ is a metal-free semiconductor, and its $\mathrm{CB}$ band edge $(-1.20 \mathrm{eV}$ vs. NHE at $\mathrm{pH} 7)$ is more negative than that of $\mathrm{TiO}_{2}(-0.29 \mathrm{eV})$, which implies that its photoexcited electrons have stronger reducibility, and this allows it to reduce $\mathrm{CO}_{2}$ to $\mathrm{CH}_{3} \mathrm{OH}$. $\mathrm{ZnO}$ with a $\mathrm{CB}$ potential of $-0.44 \mathrm{eV}$ has moderate ability to absorb $\mathrm{CO}_{2}$. Loading $\mathrm{ZnO}$ on porous g-
$\mathrm{C}_{3} \mathrm{~N}_{4}$ markedly increases the activity. Under sunlight for $1 \mathrm{~h}$, the generation rates of ethanol, methane, methanol, and CO reach 2.5, 5.4, 19.0, and $38.7 \mu \mathrm{mol} \mathrm{g} \mathrm{cat}^{-1}$. The optimal sample shows a $\mathrm{CO}_{2}$ conversion rate of $45.6 \mu \mathrm{mol} \mathrm{g}^{-1} \mathrm{~h}^{-1}$, which is 4.9 times higher than that of $\mathrm{g}-\mathrm{C}_{3} \mathrm{~N}_{4}$ and 6.4 times higher than that of $\mathrm{P} 25{ }^{[68]}$ An optimal concentration exists because if the loading of $\mathrm{ZnO}$ is too high it blocks the active sites on $\mathrm{g}-\mathrm{C}_{3} \mathrm{~N}_{4}$.

Multiple interfaces increase the complexity of charge transport, as in the $\mathrm{Cu}_{2} \mathrm{O} @ \mathrm{SnO}_{2} @ \mathrm{Fe}_{2} \mathrm{O}_{3}{ }^{[72]} \mathrm{V}_{2} \mathrm{O}_{5} / \mathrm{BiVO}_{4} / \mathrm{TiO}_{2}{ }^{[73]}$ and $\mathrm{ZnS} / \mathrm{CdS} @ \mathrm{Fe}_{2} \mathrm{O}_{3}{ }^{[74]} \quad$ composites. One-dimensional $\mathrm{Cu}_{2} \mathrm{O} @ \mathrm{SnO}_{2} @ \mathrm{Fe}_{2} \mathrm{O}_{3}$ core-double shells present a tubelike morphology and has broad spectral response to sunlight owing to the combination of a narrow-band-gap material (e.g., n- $\mathrm{Fe}_{2} \mathrm{O}_{3}$, $\approx 2.2 \mathrm{eV}$ or $\mathrm{p}-\mathrm{Cu}_{2} \mathrm{O}, \approx 3.6 \mathrm{eV}$ ) with wide-band-gap $\mathrm{n}-\mathrm{SnO}_{2}$ $(\approx 3.6 \mathrm{eV}){ }^{[72]}$ The band structures of $\mathrm{Cu}_{2} \mathrm{O}$ or $\mathrm{Fe}_{2} \mathrm{O}_{3}$ and $\mathrm{SnO}_{2}$ match well with each other; the $\mathrm{CB}$ edge of $\mathrm{Cu}_{2} \mathrm{O}$ or $\mathrm{Fe}_{2} \mathrm{O}_{3}$ is higher than that of $\mathrm{SnO}_{2}$, and the $\mathrm{VB}$ edge of $\mathrm{Cu}_{2} \mathrm{O}$ or $\mathrm{Fe}_{2} \mathrm{O}_{3}$ is lower than that of $\mathrm{Cu}_{2} \mathrm{O}$. Consequently, photoexcited electrons are transported to the surface of $\mathrm{SnO}_{2}$, whereas the holes migrate to the surface of $\alpha-\mathrm{Fe}_{2} \mathrm{O}_{3}$ or $\mathrm{Cu}_{2} \mathrm{O}$. Apart from charge transfer, stability is another key issue, in particular for longterm applications. Coating photoactive $\mathrm{CdS}$ and/or ZnS onto a magnetic $\mathrm{Fe}_{2} \mathrm{O}_{3}$ core results in stable and recyclable catalysts. $\mathrm{CdS} / \mathrm{Fe}_{2} \mathrm{O}_{3}, \mathrm{ZnS} / \mathrm{Fe}_{2} \mathrm{O}_{3}$, and $\mathrm{ZnS} / \mathrm{CdS} @ \mathrm{Fe}_{2} \mathrm{O}_{3}$ core-shell catalysts can be synthesized by a co-precipitation method. ZnS/ $\mathrm{CdS} @ \mathrm{Fe}_{2} \mathrm{O}_{3}$ evolves a higher volume of $\mathrm{H}_{2}$ and is more stable than the other counterparts. The maximum $\mathrm{H}_{2}$ production is $4129 \mu \mathrm{mol}$, which gives rise to a quantum efficiency of $19 \%$ at $\lambda=510 \mathrm{~nm}^{[74]}$ In this case, vectorial charge transfer is presumed over all the components for separation of charges, which thus enhances the activity.

Incorporating one or more elements into a parent semiconductor results in the formation of a homogenous solid solution, for example, mixing $\mathrm{ZnS}$ and $\mathrm{CdS}$ results in $\mathrm{Cd}_{1_{-x}} \mathrm{Zn}_{x} \mathrm{~S}$. The band gap of the solid solution can be adjusted by tuning the $\mathrm{Zn} / \mathrm{Cd}$ concentration ratio. Thus, coupling the solid solution with other materials, for example, $\mathrm{Pt} / \mathrm{Cd}_{1-x} \mathrm{Zn}_{x} \mathrm{~S} / \mathrm{ZnO} / \mathrm{Zn}(\mathrm{OH})_{2}^{[75]}$ $\mathrm{Cd}_{0.5} \mathrm{Zn}_{0.5} \mathrm{~S} / \mathrm{g}-\mathrm{C}_{3} \mathrm{~N}_{4}{ }^{\left[{ }^{[76]}\right.}$ and $\mathrm{CdS} / \mathrm{Ba}_{1-\mathrm{x}} \mathrm{Zn}_{\mathrm{x}} \mathrm{TiO}_{3}{ }^{[77]}$ offers a flexible technique for band-gap engineering. The activity of $1 \% \mathrm{Pt} /$ $\mathrm{Cd}_{0.2} \mathrm{Zn}_{0.8} \mathrm{~S} / \mathrm{ZnO} / \mathrm{Zn}(\mathrm{OH})_{2}$ exceeds that of $1 \% \mathrm{Pt} / \mathrm{Cd}_{0.1} \mathrm{Zn}_{0.9} \mathrm{~S}$ by a factor of $2 .{ }^{[78]}$ The highest $\mathrm{H}_{2}$ production of approximately $2256 \mu \mathrm{mol} \mathrm{g}^{-1} \mathrm{~h}^{-1}$ is achieved by $\mathrm{Pt} / \mathrm{Cd}_{1-x} \mathrm{Zn} \mathrm{n}_{x} \mathrm{~S} / \mathrm{Zn}(\mathrm{OH})_{2}$ owing to the fact that its electron reduction potential for zinc hydroxide is higher than that of $\mathrm{ZnO} .^{[75]}$ For the CdSe@ZnTe coreshell structure, one of the carriers is confined in the ZnTe core, and it is not accessible for surface reactions. However, if the thickness of the outer layer is modified with an appropriate charge-accepting moiety, the confined carriers can tunnel to the surface and can be regenerated by a scavenging agent. ${ }^{[79]}$ The hole-scavenging surfactant facilitates transfer of core-localized holes to the surface, even for shells exceeding $7 \mathrm{~nm}$ in thickness (Figure $3 \mathrm{~d}, \mathrm{~d} 1$ ). ${ }^{[80]}$ The transfer of charge carries from the $\mathrm{ZnSe}$ core to the surface of the CdS shell is approximately one order of magnitude faster than the recombination time, which indicates that most of the absorbed energy is available to drive the catalytic reactions. 


\subsubsection{Straddling alignment}

For a straddling band-gap alignment structure (Figure $3 \mathrm{e}$ ), both the VB and CB edges of S1 are localized within the energy gap of S2. Photoexcited electrons are transferred from CB2 to CB1, and the holes are transferred from VB2 to VB1. All charge carriers are accumulated on S1, which does not affect the activity. ${ }^{[23]}$ However, the potential difference between the materials is asymmetric in most cases. Specifically, the CB band edges of $\mathrm{ZnO}$ and $\mathrm{BiVO}_{4}$ are situated at -0.38 and $+0.32 \mathrm{eV}$ versus $\mathrm{NHE}$ at $\mathrm{pH} 7$, whereas the $\mathrm{VB}$ edges of $\mathrm{BiVO}_{4}$ and $\mathrm{ZnO}$ are at +2.78 and $+2.84 \mathrm{eV}$. The $\mathrm{CB}$ potential of $\mathrm{BiVO}_{4}$ is much more positive $(+0.7 \mathrm{eV})$ than that of $\mathrm{ZnO}$, whereas the $\mathrm{VB}$ of $\mathrm{BiVO}_{4}$ is slightly more negative $(\approx-0.06 \mathrm{eV})$ than the $\mathrm{VB}$ of $\mathrm{ZnO}$. Thus, there is a greater tendency for the electrons to flow from $\mathrm{ZnO}$ to $\mathrm{BiVO}_{4}$. As there is not much difference in the VB levels, the impetus for holes to flow into $\mathrm{BiVO}_{4}$ is low (Figure $3 \mathrm{e}, \mathrm{e} 1) .{ }^{[81]}$ This facilitates charge transfer, and the mechanism supports the design of $\mathrm{V}_{2} \mathrm{O}_{5} / \mathrm{BiVO}_{4}{ }^{[82]} \mathrm{Bi}_{2} \mathrm{~S}_{3} / \mathrm{CdS}{ }^{[83]}$ and $\mathrm{TiO}_{2} / \mathrm{SrTiO}_{3}{ }^{[84]}$ composites. The $\mathrm{Bi}_{2} \mathrm{~S}_{3} / \mathrm{CdS}$ composite has been shown to catalyze the reaction of $\mathrm{CO}_{2}$ with $\mathrm{H}_{2} \mathrm{O}$ to give methanol in a yield of $613 \mu \mathrm{molg}^{-1}$; this value is approximately threefold higher than the yield given by the $\mathrm{CdS}$ parent and twofold higher than the yield produced by $\mathrm{Bi}_{2} \mathrm{~S}_{3}{ }^{[83]}$ The $\mathrm{TiO}_{2} /$ $\mathrm{SrTiO}_{3}$ catalyst produces approximately 4.9 times more $\mathrm{H}_{2}$ than $\mathrm{TiO}_{2}$ and 2.1 times more than $\mathrm{SrTiO}_{3}{ }^{[84 \mathrm{~b}]}$

For core-shell NCs with a narrow band core, electron-hole pairs near the interface tend to be confined in the core. The separation and transfer of charges from the core to the outer shell surface is a challenging issue. In the cases of ZnS@CdS and ZnS@CdSe NCs, the surface-trap states are passivated by the $\mathrm{ZnS}$ shell. The confined electrons and holes with high energy in the core might tunnel through the shell to the outer surface. ${ }^{[85]}$ A similar transfer has been observed in CdS@CdSe $\mathrm{NCs}$, in which charge-carrier tunneling produces a 10-fold increase in $\mathrm{H}_{2}$ evolution over the $\mathrm{CdSe}$ core $\mathrm{NCs}$ alone. ${ }^{[86]}$ The inverted straddling-band-gap structure is found in a material with a narrower band gap grown epitaxially around the core material with a higher band gap, ${ }^{[87]}$ and the charges are rationally driven to the shell by the built-in potential. For this reason, $\mathrm{In}_{2} \mathrm{~S}_{3} @ \mathrm{In}_{2} \mathrm{O}_{3}$ core-shells present a $\mathrm{H}_{2}$ evolution rate of approximately $61.4 \mu \mathrm{mol} \mathrm{g}^{-1} \mathrm{~h}^{-1}$.88] On the other hand, chemical etching can be used to open the shell to expose the core to the external environment. The resulting morphology is desirable, as it can enable both the reductive and oxidative reactions to run simultaneously on different surfaces. The hydrogen production activity of CdSe@CdS can be improved three-to-fourfold by etching treatment. ${ }^{[89]}$

\subsubsection{Direct Z-scheme}

In the direct Z-scheme, a large number of defects aggregate at the semiconductor/semiconductor contact interface. The energy levels of the interface are quasicontinuous and show properties similar to those of conductors with low electric resistance. Thus, the contact interface serves as the center for charge recombination. The band alignment of the two semi- conductors in the direct Z-scheme presents a staggered edge position, and the $C B$ and VB of each semiconductor do not satisfy redox potential requirements for an overall reaction, but they can perform half-reactions separately (Figure $3 \mathrm{f}$ ). ${ }^{[18 a, 38 a, 90]}$ According to charge transfer, the electrons are required to combine with the same quantity of holes. The ideal case is that S1 and S2 produce the same number of charge carriers. This can be coordinated by tuning the mass ratio of the materials. ${ }^{[\mathrm{bb}, 18 \mathrm{a}]}$ Whereas a broad contact interface promotes charge recombination, a balanced distribution of incident photons maximizes light absorption. Thus, architectural diversity in material systems also requires an optimal mass ratio. ${ }^{[1]}$ The clear advantage of this separation lies in the availability of powerful reductive electrons and oxidative holes.

The direct Z-scheme has been successful in the design of catalysts. The $1 \mathrm{wt} \%$ Pt-loaded $(\mathrm{ZnO})_{1} /(\mathrm{CdS})_{0.2}$ catalyst shows the highest $\mathrm{H}_{2}$ evolution rate of $1805 \mu \mathrm{mol} \mathrm{g}^{-1} \mathrm{~h}^{-1}$ among different reference structures; this value is 14 times higher than that of the CdS catalyst and 40 times higher than that of the $\mathrm{ZnO}$ catalyst. ${ }^{[11 \mathrm{c}, 92]}$ Relative to particles, $\mathrm{CdS} / \mathrm{ZnO}$ nanowire arrays effectively trap light by extending the path length. The photoexcited electrons in a low $\mathrm{CB}$ of $\mathrm{ZnO}$ are injected into a higher VB of CdS and recombine with the holes to realize desirable reverse carrier transfer. The $\mathrm{H}_{2}$ evolution rate is approxi-

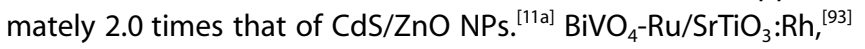

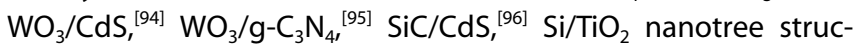
tures, ${ }^{[97]}$ and rutile/anatase $\mathrm{TiO}_{2}$ composites ${ }^{[91 \mathrm{~b}]}$ follow this Zscheme mechanism. In the $\mathrm{Ru} / \mathrm{SrTiO}_{3}: \mathrm{Rh}_{-} \mathrm{BiVO}_{4}$ system, interparticle electron transfer occurs from $\mathrm{BiVO}_{4}$ to $\mathrm{Ru} / \mathrm{SrTiO}_{3}: \mathrm{Rh}^{\text {[93b] }}$ The impurity level $\left(\mathrm{Rh}^{3+} / \mathrm{Rh}^{4+}\right)$ formed by doping in the forbidden gap of $\mathrm{SrTiO}_{3}$ serves as a mediator and assists in electron transfer. The direct Z-scheme is also thought to exist at the anatase/rutile interface. ${ }^{[91 \mathrm{~b}, 98]}$ The $\mathrm{TiO}_{2}$ sample composed of $45 \mathrm{wt} \%$ rutile phase and $55 \mathrm{wt} \%$ anatase phase exhibits a $\mathrm{H}_{2}$ production rate of $324 \mu \mathrm{molh}^{-1}$.

A few studies report direct Z-schemes for $\mathrm{CO}_{2}$ reductio$\mathrm{n},{ }^{[912,99]}$ one of which involves the $\mathrm{CuO} / \mathrm{TiO}_{2}$ composite. The electrons of $\mathrm{CuO}$ are used for $\mathrm{CO}_{2}$ conversion, and the holes from $\mathrm{TiO}_{2}$ are consumed by the sacrificial reagent methanol. The interface favors the combination of holes from $\mathrm{CuO}$ and electrons from $\mathrm{TiO}_{2}$. The optimal rate of methyl formate formation is reported to be approximately $1600 \mu \mathrm{mol} \mathrm{g}^{-1} \mathrm{~h}^{-1}$. ${ }^{\text {99b] }}$ The $\mathrm{CB}$ band edge of $\mathrm{ZnFe}_{2} \mathrm{O}_{4}$ lies at $-1.5 \mathrm{eV}$ versus $\mathrm{NHE}$ at $\mathrm{pH} 7$, which is higher than that of $\mathrm{TiO}_{2}$ and is more negative than the redox potential of $\mathrm{CO}_{2} / \mathrm{HCOOH}$. The $\mathrm{VB}$ position of $\mathrm{TiO}_{2}$ lies at $2.7 \mathrm{eV}$, which is more positive than that of the anodic oxidation of cyclohexanol. Thus, coupling $\mathrm{TiO}_{2}$ with $\mathrm{ZnFe}_{2} \mathrm{O}_{4}$ is thermodynamically favorable for $\mathrm{CO}_{2}$ reduction. The junction has higher activity than either pure $\mathrm{ZnFe}_{2} \mathrm{O}_{4}$ or $\mathrm{TiO}_{2}$, and the composite with a $9.78 \% \mathrm{ZnFe}_{2} \mathrm{O}_{4}$ content exhibits the highest yield. ${ }^{\text {[91a] }}$ The $\mathrm{Si}(\mathrm{S} 1) / \mathrm{TiO}_{2}(\mathrm{~S} 2)$ composite (Figure $3 \mathrm{f} 1$ ) also presents activity in the conversion of $\mathrm{CO}_{2}$ into methanol. ${ }^{[100]}$ In this system, the potential barrier at the $\mathrm{Si} / \mathrm{TiO}_{2}$ interface reflects holes back into the $\mathrm{TiO}_{2}$ layer, and the holes move toward the $\mathrm{TiO}_{2}$ /electrolyte interface and oxidize $\mathrm{OH}^{-}$to oxygen. The electrons in $\mathrm{Si}$ moving to the surface trigger the $\mathrm{CO}_{2}$ reducing reaction. 


\subsection{Multicomponent structures with a solid conductive me-} diator (photocatalytic systems)

In this structure, two semiconductors are bridged with a solid electron mediator or conductor (Scheme $1 \mathrm{~d}$ ). The conductor shows a stronger ability for charge transfer than the solid contact interface among the semiconductors. ${ }^{[18,101]}$ In theory, any conductor, including metals and graphene oxide, can serve as the conductive mediator.

\subsubsection{Metal electron mediator}

Metals in multicomponent structures can be functionalized as storage centers (Figure $4 \mathrm{a}$ ) and/or recombination centers (Figure $4 b, c)$, which contribute to charge separation and to enhancing interfacial carrier transport. ${ }^{[12 a, 18 a, 102]}$ The metallic components may also enhance light absorption through a plasmonic effect (Figure $4 d-f$ ). ${ }^{[103]}$ With these mechanisms, the structures have the capability to generate holes with strong oxidation power and electrons with strong reduction power.

\subsubsection{Electron capture center (Schottky junction)}

Metal semiconductor catalysts are often prepared by loading metallic nanoclusters on a semiconductor surface. Contact of the metal with an n-type semiconductor creates a Schottky junction, at which the work function of the metal is slightly higher than that of the semiconductor. Upon excitation, photoexcited electrons from the semiconductor are transferred across the Schottky junction to the metal, which results in a shift in the Fermi level of the metal towards a new equilibrium (Figure 4a). ${ }^{[102,104]}$ In this manner, the metal acts like an electron sink to enable separation of electrons and holes, which thus extends the lifetime of the holes on the semiconductor surface for the oxidation reaction. Besides, the metal components provide active sites to reduce the overpotential for surface chemical reactions.

Typical cases of this type include $\mathrm{CdS} / \mathrm{TiO}_{2} / \mathrm{Pt}{ }^{[102,104 b, 105]}$ $\mathrm{Agln}_{5} \mathrm{~S}_{8} / \mathrm{TiO}_{2} / \mathrm{Pt}_{1}{ }^{[106]} \mathrm{TNT} / \mathrm{CdS} / \mathrm{Pt}_{1}{ }^{[107]} \mathrm{CdS} / \mathrm{PdS} / \mathrm{Pt}_{1}^{[108]} \mathrm{CdS} / \mathrm{TiO}_{2} /$ $\mathrm{Au}_{1}^{[109]} \mathrm{TiO}_{2} / \mathrm{In}_{2} \mathrm{O}_{3} / \mathrm{Pt}_{1}^{[110]} \mathrm{CdS} / \mathrm{BN} / \mathrm{Pt}^{[111]}$ and $\mathrm{IrO}_{2}$ or $\mathrm{CoO}_{x} / \mathrm{Ta}_{3} \mathrm{~N}_{5} /$ $\mathrm{Pt}^{[112]}$ These systems show high activities that far exceed those of one- and two-component systems. The effects of Pt and PdS co-loaded on a metal sulfide [e.g., $\mathrm{CdS}$ or $\mathrm{ZnO}_{1-x} \mathrm{~S}_{x}$
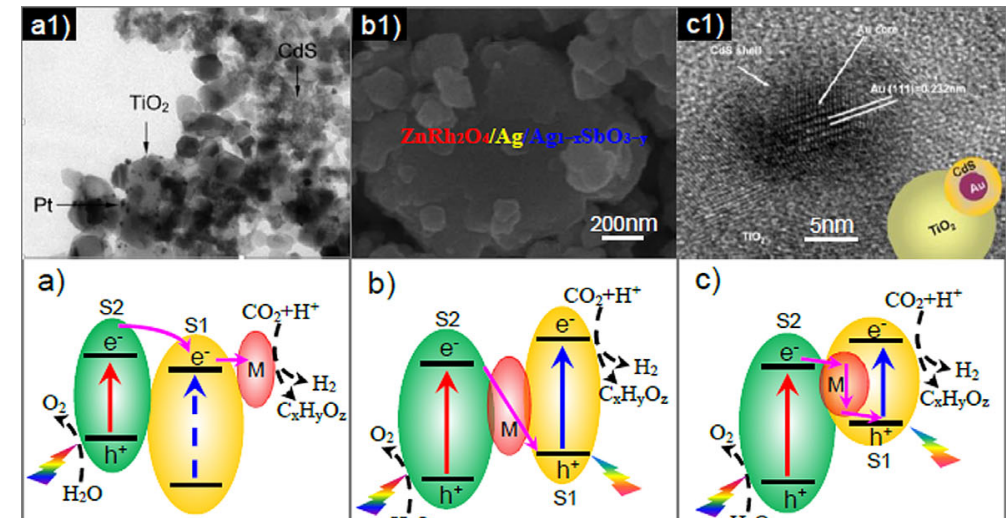

b)

c)

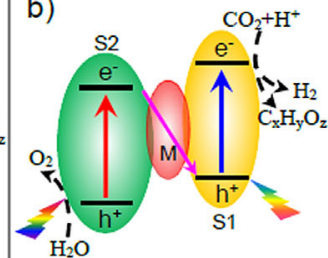

C) $\quad \mathrm{CO}_{2}+\mathrm{H}^{+}$

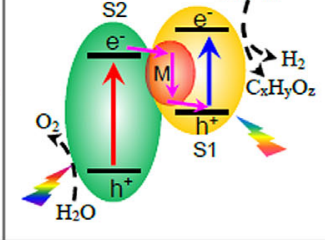

d)
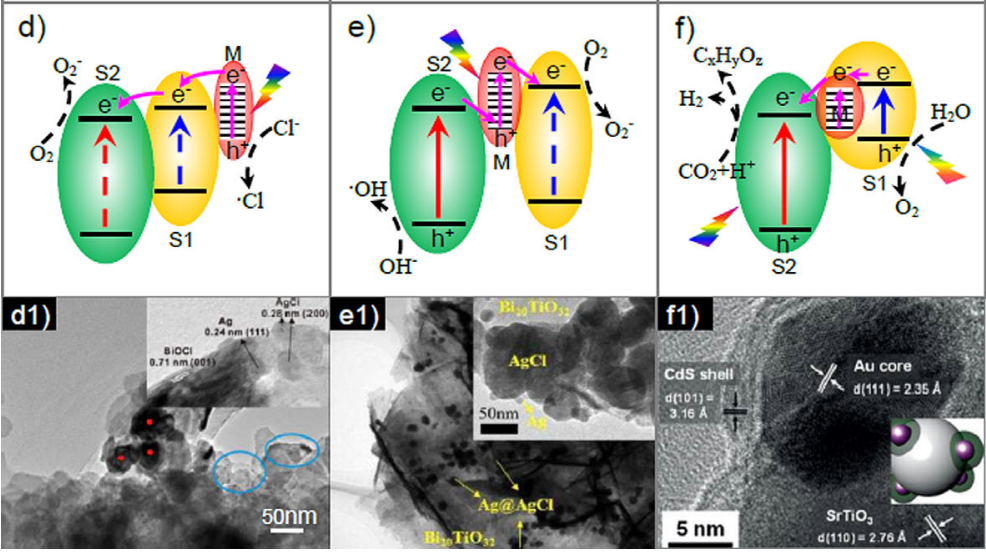

Figure 4. a) Metal acts as an electron capture center and its example, a1) TEM image of $\mathrm{CdS} /\left(\mathrm{Pt}_{-} \mathrm{TiO}_{2}\right)$ (reprinted with permission from ref. [105a], copyright 2008 Royal Society of Chemistry). b) Metal acts as an electron recombination center and its example, b1) $\mathrm{SEM}_{\mathrm{images}}$ of $\mathrm{ZnRh} \mathrm{O}_{4} / \mathrm{Ag} / \mathrm{AgSbO}_{3}(\mathrm{reprinted}$ with permission from ref. [133], copyright 2014 American Chemical Society). c) Metal acts as an electron recombination center in core-shell structures and its example, c1) HRTEM image of $\mathrm{CdS} / \mathrm{Au} / \mathrm{N}-\mathrm{TiO}_{2}$ heterostructures (reprinted with permission from ref. [137], copyright 2014 Elsevier). d-f) Metal acts as a plasmonic effect in parallel structures and their examples, d1) TEM and HRTEM images of Ag/AgCl/BiOCl (adapted from ref. [149i], copyright 2012 American Chemical Society); e1) TEM images of Ag-AgCl@ $\mathrm{Bi}_{20} \mathrm{TiO}_{32}$ photocatalysts (reprinted with permission from ref. [149d], copyright 2013 American Chemical Society); f1) HRTEM image of the interface region of $\mathrm{SrTiO}_{3}$ and $\mathrm{Au} @ \mathrm{CdS}$ (adapted from ref. [149e], copyright 2014 Wiley-VCH). 
$\mathrm{ZnIn}_{2} \mathrm{~S}_{4}, \mathrm{ZnGa}_{2} \mathrm{~S}_{4},(\mathrm{Culn})_{0.8} \mathrm{Zn}_{1.82} \mathrm{~S}$ ] have been studied for $\mathrm{H}_{2}$ evolution. ${ }^{[108]}$ The activities of the catalysts follow the order Pt/ $\mathrm{MS}<\mathrm{PdS} / \mathrm{MS}<\mathrm{Pt} / \mathrm{PdS} / \mathrm{MS}$, and the best $\mathrm{H}_{2}$ evolution rate of approximately $8800 \mu \mathrm{molh}^{-1}$ is obtained from the $\mathrm{Pt} / \mathrm{PdS} / \mathrm{CdS}$ catalyst. The activity indicates that PdS acts as an effective cocatalyst for oxidation, whereas Pt functions as an electron-trapping center for proton reduction. In principle, microporous zeolite $\mathrm{Y}$ loaded with $\mathrm{Pt}, \mathrm{TiO}_{2}, \mathrm{CdS}$, and $\mathrm{Pt} / \mathrm{TiO}_{2} \mathrm{NPs}$ are proposed for water splitting. The zeolites help to prevent aggregation of the nanoparticles and stabilize the structure, and provide access for the solution species to the zeolite-bound particles. ${ }^{[102]}$ An additional study validates the use of $\mathrm{Pt} / \mathrm{CdS} /$ $\mathrm{TiO}_{2}$ composites within a hierarchically reticular structure, as $\mathrm{H}_{2}$ is generated at a rate of approximately $118 \mu \mathrm{molh}^{-1}$ on this catalyst. ${ }^{[105 b]}$ Notably, the location of Pt on the catalyst is a critical factor affecting the efficiency, as the rate increases by a factor of 3-30 for $\mathrm{CdS} /\left(\mathrm{Pt}-\mathrm{TiO}_{2}\right)$ relative to that for $\mathrm{Pt}-(\mathrm{CdS}) /$ $\mathrm{TiO}_{2}$ (Figure $\left.4 \mathrm{a} 1\right) .^{[104 b, 105 a]}$

Rational integration of a light-absorber, hole and electron acceptor is important for charge transfer. The $\mathrm{ZnSe} / \mathrm{CdS} / \mathrm{Pt}^{[113]}$ and $\mathrm{CdSe} / \mathrm{CdS} / \mathrm{Pt}^{[104 a]}$ hybrids are formed by coupling several crystalline materials. The three components with unique functionalities are assembled to form a linear energy gradient. The photoexcited carriers are steered to be localized in nonadjacent parts of the NR, the holes reside in the semiconductors, and the electrons reside in the metal domains. ${ }^{[113 b]}$ Spatial localization of the carriers suppresses backwards recombination, which leads to efficient harvesting of visible light through injection of electrons into metallic Pt. Lian et al. have examined the rate of elementary electron-hole separation and the recombination steps in CdSe/CdS-Pt and CdS-Pt NRs. ${ }^{[104 a]}$ The electron-transfer efficiencies to $\mathrm{Pt}$ are near $100 \%$ and hole transfer is the bottleneck step. The hole-transfer rates to the electron donor can be correlated with the quantum efficiency of $\mathrm{H}_{2}$ generation.

Loading $\mathrm{MgO}$ on a Pt-TiO 2 photocatalyst can enhance $\mathrm{CO}_{2}$ reduction. ${ }^{[114]}$ The role of $\mathrm{MgO}$ is to attract $\mathrm{CO}_{2}$ molecules onto the catalyst surface to destabilize the chemical bonds of $\mathrm{CO}_{2}$ by the enriched area of electrons near the Pt nanoparticles. However, maintaining long-term stability of the catalyst is a challenge, as CO easily poisons Pt nanoparticles. One strategy to avoid poisoning is to use bimetallic alloys. Coaxial $\mathrm{SrTiO}_{3} / \mathrm{TiO}_{2}$ nanotube arrays loaded with $\mathrm{Au}-\mathrm{Cu}$ bimetallic alloy NPs have been designed to reduce $\mathrm{CO}_{2}$ into $\mathrm{CO}$ and hydrocarbons. ${ }^{[115]}$ It is found that $\mathrm{Au}_{3} \mathrm{Cu} / \mathrm{SrTiO}_{3} / \mathrm{TNTs}$ is the most reactive catalyst in the alloy family. A CO production rate of $3.77 \mathrm{mmolg}^{-1} \mathrm{~h}^{-1}$ and a total hydrocarbon of $725.4 \mu \mathrm{mol} \mathrm{g}^{-1} \mathrm{~h}^{-1}$ are obtained. In the reaction, $\mathrm{N}_{2} \mathrm{H}_{4} \cdot \mathrm{H}_{2} \mathrm{O}$ as the $\mathrm{H}$ source and electron donor offers a reducing atmosphere to protect the surface $\mathrm{Cu}$ atoms against oxidation, which thus maintains the alloying effect for high activity and stability.

\subsubsection{Electron recombination center (ohmic junction)}

The interface between semiconductors contains an ample amount of defects that hamper charge transfer. Insertion of a conductor between the semiconductors forms an ohmic con- tact with low contact resistance. ${ }^{[18 a, 101 b]}$ The work function of the ohmic metal layer should match the band positions of the semiconductors, so that the photoexcited electrons from the CB of S2 recombine with the holes from the VB of S1 through the contact (Figure $4 b, c$ ). Although one photon is lost during this recombination, it reduces the distance of electron transfer and the remaining carriers can promote the redox reactions. In addition to physical separation of the redox sites, the ohmic junction offers net photon energies for the reactions by partial overlap of two band gaps.

Metals in the $\mathrm{CdS} / \mathrm{Ag} / \mathrm{TNT}_{1}^{[116]} \quad \mathrm{Bi}_{2} \mathrm{WO}_{6} / \mathrm{Ag} / \mathrm{N}-\mathrm{TiO}_{2}{ }^{[117]}$ $\mathrm{SrTiO}_{3}: \mathrm{La}-\mathrm{Rh} / \mathrm{Ir} / \mathrm{CoO}_{x}-\mathrm{Ta}_{3} \mathrm{~N}_{5}{ }^{[118]} \quad \mathrm{SrTiO}_{3}: \mathrm{La}-\mathrm{Rh} / \mathrm{Au} / \mathrm{BiVO}_{4}{ }^{[119]}$ $\mathrm{SrTiO}_{3}: \mathrm{La}-\mathrm{Rh} / \mathrm{Au} / \mathrm{BiVO}_{4}: \mathrm{Mo}^{[120]}$ and $\mathrm{CeO}_{2} / \mathrm{Pt} / \mathrm{SiO}_{2}{ }^{[121]}$ composites have been functionalized as electron relay or recombination centers (Figure $4 \mathrm{~b}$ ). The high photocurrent of $\mathrm{CdS} / \mathrm{Ag} / \mathrm{TNTs}$ might be due to the efficient electron traps formed at the CdS-Ag junction. ${ }^{[116 a]}$ However, Xie et al. believe that two-step excitation between $\mathrm{CdS}$ and $\mathrm{TiO}_{2}$ with $\mathrm{Ag}$ as a mediator induces electron vectorial transfer. ${ }^{[116 b]}$ The $\mathrm{La}-\mathrm{Rh}: \mathrm{SrTiO}_{3} / \mathrm{Ir} / \mathrm{CoO}_{x}{ }^{-}$ $\mathrm{Ta}_{3} \mathrm{~N}_{5}$ material exhibits a rate of $\mathrm{H}_{2}$ evolution that is 3.8 times higher than that of the $\mathrm{SrTiO}_{3}: \mathrm{Rh}$ system. Introduction of $\mathrm{Au}$ as a mediator in the $\mathrm{SrTiO}_{3}: \mathrm{La}-\mathrm{Rh} / \mathrm{Au} / \mathrm{BiVO}_{4}$ system results in a catalyst with high activity for overall water splitting. The activity using particulate semiconductors immobilized onto Au layers is approximately 6 times higher than that of a powder suspension and 20 times higher than that of the $\mathrm{La}-\mathrm{Rh}: \mathrm{SrTiO}_{3} / \mathrm{BiVO}_{4}$ system without metal layers. ${ }^{[110-120]}$ The performance comes from the presence of a metallic conductor (e.g., Ir, Au layer), which serves as an electron shuttle to transfer electrons from one semiconductor to another effectively.

As one constituent element of the photocatalysts is same as the metallic mediator, such as in $\mathrm{W}_{18} \mathrm{O}_{49} / \mathrm{Ag} / \mathrm{AgCl}_{1}{ }^{[122]} \mathrm{Cu}_{2} \mathrm{O} / \mathrm{Ag} /$ $\mathrm{AgBr}-\mathrm{Al}_{2} \mathrm{O}_{3}{ }^{[123]} \mathrm{AgBr} / \mathrm{Ag} / \mathrm{TiO}_{2},{ }^{[124]} \mathrm{TNT} / \mathrm{Ag} / \mathrm{AgBr}^{[125]} \mathrm{AgBr} / \mathrm{Ag} /$ $\mathrm{Bi}_{2} \mathrm{WO}_{6}{ }^{[126]} \mathrm{AgBr} / \mathrm{Ag} / \mathrm{g}-\mathrm{C}_{3} \mathrm{~N}_{4}{ }^{[127]} \mathrm{AgBr} / \mathrm{Ag} / \mathrm{Bi}_{2} \mathrm{MoO}_{6}{ }^{[128]} \quad \mathrm{Ag}_{3} \mathrm{PO}_{4} /$ $\mathrm{Ag} / \mathrm{Agl}{ }_{,}^{[129]} \mathrm{Ag}_{3} \mathrm{PO}_{4} / \mathrm{Ag} / \mathrm{WO}_{3-x,}{ }^{[130]} \mathrm{Agl} / \mathrm{Ag} / \mathrm{AgBr},{ }^{[131]}$ and $\mathrm{AgBr} /$ $\mathrm{Ag} / \mathrm{MoO}_{3}{ }^{[132]}$ there exists a concentration equilibrium between the metal and its ions. The intimate contact interface between the conductor and the catalyst presents low electric resistance that is beneficial for the formation of an ohmic contact. For example, water splitting has been performed on $\mathrm{ZnRh}_{2} \mathrm{O}_{4} / \mathrm{Ag}$ / $\mathrm{Ag}_{1-x} \mathrm{SbO}_{3-y}$ in which zinc rhodium oxide and defective silver antimonate act as the $\mathrm{H}_{2}$ and $\mathrm{O}_{2}$ evolution catalysts and $\mathrm{Ag}$ acts as an electron mediator for electron transfer (Figure 4b1). ${ }^{[133]}$ Another case is $\mathrm{Ag}_{3} \mathrm{PO}_{4} / \mathrm{Ag} / \mathrm{g}-\mathrm{C}_{3} \mathrm{~N}_{4}{ }^{[134]}$ in which metallic Ag NPs are involuntary formed on the interface under irradiation owing to photodecomposition of AgX. The optimal sample shows a $\mathrm{CO}_{2}$ conversion rate of $57.5 \mu \mathrm{molg}^{-1} \mathrm{~h}^{-1}$, which is 6.1 times higher than that of $\mathrm{g}-\mathrm{C}_{3} \mathrm{~N}_{4}$ and 10.4 times higher than that of P25. Different from the in situ generation of the electron mediator, the catalyst can be inversely formed from a chemical reaction of the metallic mediator. As in the preparation of the $\mathrm{ZnO} / \mathrm{Cd} / \mathrm{CdS}$ and $\mathrm{WO}_{3} / \mathrm{W} / \mathrm{PbBi}_{2} \mathrm{Nb}_{1.9} \mathrm{Ti}_{0.1} \mathrm{O}_{9}$ catalysts, ${ }^{[124 b, 135]} \mathrm{CdS}$ and $\mathrm{WO}_{3}$ are synthesized from surface sulfurization of the metal core of $\mathrm{Cd}$ and surface oxidation of the W cluster to form a seamless contact interface between the materials. 
The core-shell CdS@Au/TiO ${ }_{2}$ structure with an electron transfer mediator (i.e., $\mathrm{Au}$ ) exhibits high activity owing to stepwise electron transfer driven by two-step excitation of $\mathrm{TiO}_{2}$ and CdS. ${ }^{[12 a]}$ Following this work, a series of composites including $\mathrm{CdS} @ \mathrm{Au} / \mathrm{TiO}_{2}{ }^{[136]} \mathrm{CdS} @ \mathrm{Au} / \mathrm{N}-\mathrm{TiO}_{2}{ }^{[137]}$ and $\mathrm{CdS} @ \mathrm{M} / \mathrm{TiO}_{2}(\mathrm{M}=\mathrm{Au}$, $\mathrm{Ag}, \mathrm{Pt}, \mathrm{Pd}){ }_{1}{ }^{[138]} \mathrm{CdS} @ A u / T N F\left(\mathrm{TiO}_{2}\right.$ nanofibers)${ }_{,}{ }^{[139]}$ and CdS@Au/ $\mathrm{TiO}_{1.96} \mathrm{C}_{0.04}{ }^{[140]}$ have been developed. The module (Figure 4 $\mathrm{c} 1$ ) increases charge separation and prolongs electron-hole lifetimes. The incorporated porous $\mathrm{CdS} @ \mathrm{Au} / \mathrm{N}-\mathrm{TiO}_{2}$ contributes to a $\mathrm{H}_{2}$ evolution rate of approximately $9.2 \mu \mathrm{molh}^{-1}$, which is approximately 270 times higher than that of $\mathrm{Au} / \mathrm{N}-\mathrm{TiO}_{2} \cdot{ }^{[137]} \mathrm{To}$ determine the effects of the core-shell and the role of the $\mathrm{TiO}_{2}$ nanostructures, Au-deposited $\mathrm{CdS} / \mathrm{TNF}$ and commercial $\mathrm{TiO}_{2}$ (P25) have been examined as references. ${ }^{[139]}$ The amount of $\mathrm{H}_{2}$ produced by CdS@Au/TNF higher than that produced by CdS/ TNF, CdS/Au/TNF, and CdS@Au/P25. However, these systems are not real two-photon systems, because $\mathrm{TiO}_{2}$ only generates electrons under UV light. Biomimetic systems such as CdS@Au/ $\mathrm{TiO}_{1.96} \mathrm{C}_{0.04}$ consisting of two visible-light components produce four times the amount of $\mathrm{H}_{2}$ as that produced by $\mathrm{CdS@Au/}$ $\mathrm{TiO}_{2} \cdot{ }^{[140]}$ Photoluminescence studies have revealed that the $\mathrm{Au}$ core captures electrons from the $\mathrm{CB}$ of $\mathrm{TiO}_{1.96} \mathrm{C}_{0.04}$ and accelerates electron transfer to the VB of $\mathrm{CdS}$, which allows the electrons to be shuttled to a higher energy level, and this produces a substantial amount of $\mathrm{H}_{2}$ on the $\mathrm{CdS}$ surface.

Other composites, such as $\mathrm{CdS} @ \mathrm{Au} / \mathrm{ZnO}{ }^{[141]} \mathrm{ZnO} /$ $\mathrm{CdS} @ \mathrm{Cd}^{[142]} \mathrm{Cu}_{2} \mathrm{O} @ \mathrm{Pt} / \mathrm{TiO}_{2},{ }^{[143]} \mathrm{CdS} @ \mathrm{Pt} / \mathrm{TiO}_{2}{ }^{[144]} \mathrm{Cr}_{2} \mathrm{O}_{3} @ \mathrm{Rh} /$ $\mathrm{GaN}: \mathrm{ZnO}{ }^{[145]}$ and CdS@Au/g- $\mathrm{C}_{3} \mathrm{~N}_{4}{ }^{[146]}$ have been further examined. Pt NPs loaded $\mathrm{ZnO} / \mathrm{CdS} @ \mathrm{Cd}$ exhibits a $\mathrm{H}_{2}$ evolution rate of $1.92 \mu \mathrm{molh}^{-1}$, which is 5.1 times higher than that exhibited by $\mathrm{Pt}$-loaded $\mathrm{ZnO} / \mathrm{CdS}$. To understand the size effect of the core, $\mathrm{Cr}_{2} \mathrm{O}_{3} @ \mathrm{Rh} / \mathrm{GaN}: \mathrm{ZnO}$ has been examined for water splitting. ${ }^{[145 b]}$ The size of the poly-protected Rh NPs can be controlled to fall within the range of 1.7 to $7.7 \mathrm{~nm}$ by changing the nucleation rate of the polyol synthesis. The activity of the catalyst with the smaller $\mathrm{Rh}$ core is higher than that with a larger $\mathrm{Rh}$ core. In another case, the $\mathrm{Cu}_{2} \mathrm{O} @ \mathrm{Pt} / \mathrm{TiO}_{2}$ structure with a Pt content of approximately $0.9 \mathrm{wt} \%$ and a mean Pt NP size of approximately $3.1 \mathrm{~nm}$ has been prepared, in which the $\mathrm{Cu}_{2} \mathrm{O}$ shell provides sites for preferential activation and conversion of $\mathrm{CO}_{2}$ in the presence of $\mathrm{H}_{2} \mathrm{O}$, whereas the Pt core extracts electrons from $\mathrm{TiO}_{2}$. The rate of formation of $\mathrm{CH}_{4}$ is $33 \mu \mathrm{mol} \mathrm{g}^{-1} \mathrm{~h}^{-1}$, which is approximately 3.0 times higher than that over $\mathrm{Pt} / \mathrm{TiO}_{2}$ and 3.8 times higher than that over $\mathrm{Cu}$ / $\mathrm{TiO}_{2} \cdot{ }^{[143]}$ The conversion of $\mathrm{CO}_{2}$ and water vapor has also been explored by using $\mathrm{Cu}_{x} \mathrm{O} / \mathrm{Pt} / \mathrm{N}-\mathrm{TNT}$, in which TNT offers a thin wall to facilitate effective carrier transfer. ${ }^{[147]}$

\subsubsection{Plasmonic effect}

Interest in introducing nanoscale metals into photocatalysis comes from their light-harvesting and electromagnetic field concentrating properties induced by surface plasmon resonance (SPR), which refers to coherent oscillations of the free electrons on the metal surface against the restoring force of positive nuclei. ${ }^{[103 a]}$ The SPR resonant wavelength and intensity depend on size, shape, composition, and dielectric environ- ment of the plasmon metals. ${ }^{[103]}$ SPR enhances photocatalysis in three ways: by increasing light absorption, by increasing charge separation through either direct electron transfer or plasmon-induced resonance energy transfer, and by reducing charge recombination by plasmon-mediated electromagnetic field. However, it is hard to differentiate the plasmonic effects from other potential factors such as cocatalytic effect or enhanced charge separation by the metal/semiconductor junction. ${ }^{[148]}$

It has been demonstrated that $\mathrm{Ag}, \mathrm{Au}$, and $\mathrm{Cu}$ NPs respond to visible light by the SPR effect. ${ }^{[149]}$ The compounds BiOX (X= $\mathrm{Cl}, \mathrm{Br}$ ) have good catalytic activities. To further improve their activities, $\mathrm{Ag} / \mathrm{AgCl}$ and $\mathrm{Ag} / \mathrm{AgBr}$ have been integrated with $\mathrm{BiOCl}$ and $\mathrm{BiOBr}$. The roles of $\mathrm{Ag}$ in the systems have been identified by quantification experiments involving trapping of the active species and superoxide radicals. ${ }^{[149]}$ Given that the absorption edges of $\mathrm{AgCl}$ and $\mathrm{BiOCl}$ correspond to $\lambda=382$ and $360 \mathrm{~nm}$, they cannot be photoexcited under visible light, but Ag absorbs visible light owing to the SPR effect and its dipolar character. The absorbed photons generate an electron and hole, and then the electron is transferred to the $C B$ of $\mathrm{AgCl}$ and further moves to the $\mathrm{CB}$ of $\mathrm{BiOCl}$ (SPR effect in Figure $4 d, d 1$ ). In contrast, the absorption edges of $\mathrm{AgBr}$ and $\mathrm{BiOBr}$ are $\lambda=490$ and $427 \mathrm{~nm}$. Therefore, the electrons flow as $\mathrm{BiOBr} \rightarrow \mathrm{Ag} \rightarrow \mathrm{AgBr}$ in the $\mathrm{AgBr} / \mathrm{Ag} / \mathrm{BiOBr}$ structure (electron relay in Figure $4 \mathrm{C}$ ). To take advantage of the features of both SPR and electron trapping, converting $\mathrm{CO}_{2}$ into hydrocarbons has been conducted by using $\mathrm{Ag}, \mathrm{Pt}$, or bimetallic $\mathrm{Ag}-\mathrm{Pt}$ and core-shell $\mathrm{SiO}_{2} @ \mathrm{Ag} \mathrm{NPs}$ coupled with a $\mathrm{TiO}_{2}$ catalyst. ${ }^{[149 f]} \mathrm{A}$ selectivity for $\mathrm{CH}_{4}$ of approximately $80 \%$ is achieved by tuning the bimetallic Ag-Pt cocatalysts. If both bimetallic catalysts and $\mathrm{SiO}_{2} @ \mathrm{Ag} \mathrm{NPs}$ are used, the product yield is enhanced more than sevenfold over that obtained in the presence of native $\mathrm{TiO}_{2}$.

In plasmonic Z-scheme systems (Figure $4 \mathrm{e}$ ) such as $\mathrm{AgCl} /$ $\mathrm{Ag} / \mathrm{H}_{2} \mathrm{WO}_{4} \cdot \mathrm{H}_{2} \mathrm{O}$ nanoplates, ${ }^{[149 \mathrm{c}]} \mathrm{AgCl} / \mathrm{Ag} / \mathrm{Bi}_{20} \mathrm{TiO}_{32} \mathrm{NCs}$ (Figure $4 \mathrm{e} 1)^{\left[{ }^{[149 d]}\right.} \mathrm{AgCl} / \mathrm{Ag} / \mathrm{Bi}_{2} \mathrm{MoO}_{6}$ nanosheets, ${ }^{[149 a]} \mathrm{AgCl} / \mathrm{Ag} / \alpha / \beta$ $\mathrm{Bi}_{2} \mathrm{O}_{3}{ }^{[1499]}$ and $\mathrm{AgCl} / \mathrm{Ag} / \gamma$-TaON hollow spheres, ${ }^{[149 \mathrm{~h}]}$ the metal NPs serve as the electron mediator as well as the plasmonic sensitizer. Specifically, under visible-light irradiation, $\mathrm{AgCl}$ with a large band gap energy $\left(E_{\mathrm{g}}\right)$ of $3.25 \mathrm{eV}$ cannot be photoexcited, whereas materials with relatively small band gaps (e.g., $\mathrm{H}_{2} \mathrm{WO}_{4} \cdot \mathrm{H}_{2} \mathrm{O}, \mathrm{Bi}_{20} \mathrm{TiO}_{32}, \mathrm{Bi}_{2} \mathrm{MoO}_{6} \alpha / \beta-\mathrm{Bi}_{2} \mathrm{O}_{3}$, and $\left.\gamma-\mathrm{TaON}\right)$ respond to visible light. Metallic $\mathrm{Ag}$ also absorbs visible light owing to the SPR effect and its dipolar character. The photoexcited electrons in the $\mathrm{CB}$ of a material with a small band gap combine with the holes in the highest occupied orbital of metallic Ag. The photoexcited electrons in the lowest unoccupied orbital of plasmonic $\mathrm{Ag}$ migrate to the $\mathrm{CB}$ of $\mathrm{AgCl}$. Such electron transfer from $\mathrm{Ag}$ to the semiconductor is expected to facilitate charge transfer.

Core-shell $\mathrm{Cu}_{2} \mathrm{O} @ \mathrm{Cu}$ NPs inside TNTs also shows a plasmonic effect (Figure $4 \mathrm{f}$ ). ${ }^{[149 b, e]}$ The metal $\mathrm{Cu}$ core plays three roles: one, it lowers the resistance to electron transport from excited $\mathrm{Cu}_{2} \mathrm{O}$ to the TNTs; two, it behaves as an electron storage center for charge separation; three, it enhances the photocatalytic properties of the TNTs under visible light. The maximum 
amount of $\mathrm{H}_{2}$ evolved is $45.56 \mu \mathrm{molh}{ }^{-1}$, which is approximately 12 times higher than that evolved over pure TNTs. The drawback of a bare plasmonic structure lies in fast decay of hot electrons. Their ultrafast decay across Au NPs can be overcome by coupling with $\mathrm{CdS}$ quantum dots (QDs) and by a Schottky junction with perovskite $\mathrm{SrTiO}_{3} \mathrm{NPs}$ (Figure 4 f1). ${ }^{[149 e]}$ The $\mathrm{CdS} @ \mathrm{Au} / \mathrm{SrTiO}_{3}$ catalyst shows an impressive $\mathrm{H}_{2}$ generation rate of approximately $29.1 \mu \mathrm{molh}^{-1}$, in contrast to a rate of $5.0 \mu \mathrm{molh}^{-1}$ offered by $\mathrm{Au} / \mathrm{CdS} / \mathrm{SrTiO}_{3}$, on which $\mathrm{CdS}$ and $\mathrm{Au}$ NPs are individually deposited on the $\mathrm{SrTiO}_{3}$ surface. These instances are consistent with the electron-relay model (Figure $4 b, c)$, except that the electron mediator also takes responsibility for light harvesting. Notably, both the band gap of the semiconductor and the wavelength of incident light define the role of the metal.

\subsubsection{Graphene electron mediator}

Graphene possesses a 2D structure, exceptional conductivity, superior mobility of charge carriers, large surface area, and excellent optical transmittance. ${ }^{[150]}$ Its work function is $4.42 \mathrm{eV}$, and such a high energy level is beneficial to electron transport from the semiconductor to graphene. A series of semiconductor(s) and/or metals have been coupled with graphene to form multicomponent catalysts. ${ }^{[151]}$ Although the mechanism is not fully understood, graphene in the composites is considered to promote electron shuttling from the light-absorbing semiconductor to the catalyst, to extend light absorption, and to provide a large surface area for the chemical reactions.

\subsubsection{Semiconductor-metal composites}

Since it was reported that shuttling of $\mathrm{TiO}_{2}$ photoelectrons to spatially separated Ag nanoparticles can occur through reduced graphene oxide (RGO), ${ }^{[152]}$ numerous groups have integrated semiconductors and metals with graphene. Metals in these structures behave as electron capture centers (Figure $5 \mathrm{a}$ ), electron relay mediators (Figure $5 \mathrm{~b}$ ), or plasmonic components (Figure $5 \mathrm{c}$ ). The integration of $\mathrm{Pt} / \mathrm{TiO}_{2}{ }^{[153]} \mathrm{Pt} / \mathrm{g}$ $\mathrm{C}_{3} \mathrm{~N}_{4}{ }^{[154]} \mathrm{Pt} / \mathrm{CdS}^{[155]} \mathrm{Pt} / \mathrm{Sr}_{2} \mathrm{Ta}_{2} \mathrm{O}_{7-x} \mathrm{~N}_{x}{ }^{[156]} \mathrm{Ag} / \mathrm{ZnO} \mathrm{NRs},{ }^{[157]}$ and $\mathrm{Cu} /$ $\mathrm{TiO}_{2}{ }^{[158]}$ on graphene has been performed, and the evolution rate increases $2-5$ times relative to the rate on their counterpart references. In these cases, graphene serves to collect and transport photoinduced charges, whereas the metal particles act as an electron sink. To reveal electron transfer, three different structures, $\mathrm{Pt} /(0.5$ graphene oxide $(\mathrm{GO})+\mathrm{P} 25),(\mathrm{Pt} / \mathrm{P} 25)+$ $0.5 \mathrm{GO},(\mathrm{Pt} / 0.5 \mathrm{GO})+\mathrm{P} 25$, have been synthesized by different orders by using the same quantity of chloroplatinic acid. ${ }^{[153 b]}$ The preparation procedures influence the loading location of $\mathrm{Pt}$ as well as the electron-transfer routes. The (Pt/0.5GO) + P25 sample presents the highest $\mathrm{H}_{2}$ production rate of approximately $5921.1 \mu \mathrm{molh}^{-1} \mathrm{~g}^{-1}$, as graphene oxide induces irreversible electron transfer of the type $\mathrm{P} 25 \rightarrow \mathrm{GO} \rightarrow \mathrm{Pt}$. In the $\mathrm{CdS} / \mathrm{Pt} /$ GO composite, graphene serves as an electron collector and transporter to increase charge lifetime, which leads to a $\mathrm{H}_{2}$ production rate of $1.12 \mathrm{mmolh}^{-1}$ at a graphene content of $1.0 \mathrm{wt} \%$ and a Pt content of $0.5 \mathrm{wt} \%{ }^{[155]}$ The dispersion of

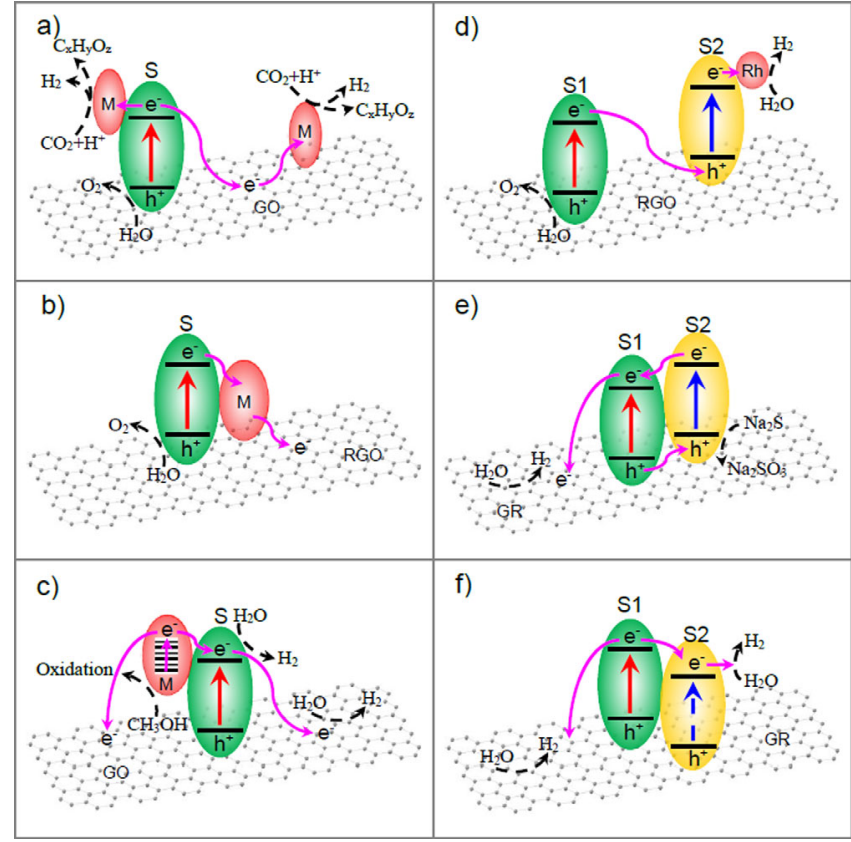

Figure 5. Charge transport in the a) semiconductor-graphene-metal electron sink system (adapted from ref. [159]), b) semiconductor-graphenemetal electron relay system (adapted from ref. [161]), and c) semiconductorgraphene-metal plasmonic effect system (adapted from ref. [163]). Charge transport in the d) semiconductor-graphene-semiconductor system (adapted from ref. [12b]), e,f) semiconductor junction-graphene systems (adapted from ref. [178] and [180]).

a noble metal ${ }^{[159]}$ or bimetal ${ }^{[160]}$ on the semiconductor-graphene composite also improves $\mathrm{CO}_{2}$ conversion. Reducing metal ions (e.g., $\mathrm{PtCl}_{6}^{2-}, \mathrm{Pd}^{2+}, \mathrm{Ag}^{+}$, and $\mathrm{AuCl}_{4}{ }^{-}$) is a simple polyol process to load metal (e.g., $\mathrm{Pt}, \mathrm{Pd}, \mathrm{Ag}$ and $\mathrm{Au}$ ) nanoparticles on reduced graphene oxide/ $/ \mathrm{TiO}_{2}$. A $2.0 \mathrm{wt} \% \mathrm{Pt}$-doped composite shows the best activity; it achieves a total $\mathrm{CH}_{4}$ yield of $1.70 \mu \mathrm{mol} \mathrm{g}_{\mathrm{cat}}{ }^{-1}{ }^{[159]}$ The Pt NPs play a critical role in trapping electrons over both the $\mathrm{TiO}_{2} / \mathrm{Pt}$ and $\mathrm{GO} / \mathrm{Pt}$ interfaces (Figure $5 \mathrm{a}$ ).

Metal nanoparticles are believed to functionalize as electron relay mediators in graphene-supported $\mathrm{Ag}_{3} \mathrm{PO}_{4} / \mathrm{Ag} / \mathrm{AgBr}^{[161]}$ and graphene oxide/ $\mathrm{Ag} / \mathrm{AgCl}$ composites (Figure $5 \mathrm{~b}$ ). ${ }^{[162]}$ $\mathrm{Ag}_{3} \mathrm{PO}_{4}$ is one of only a few materials that exhibits excellent oxidative capability for $\mathrm{O}_{2}$ evolution from water. The graphenesupported $\mathrm{Ag}_{3} \mathrm{PO}_{4} / \mathrm{Ag} / \mathrm{AgBr}$ catalyst can be prepared by the photoassisted deposition-precipitation method. ${ }^{[161]}$ The composite exhibits an $\mathrm{O}_{2}$ evolution yield $\left(76 \mu \mathrm{molh}^{-1}\right)$ that is approximately 1.3 times higher than exhibited by $\mathrm{Ag}_{3} \mathrm{PO}_{4} / \mathrm{Ag} /$ $\mathrm{AgBr}\left(48 \mu \mathrm{mol} \mathrm{h}^{-1}\right)$ and a yield that is approximately 2 times higher than that offered by pristine $\mathrm{Ag}_{3} \mathrm{PO}_{4}\left(38 \mu \mathrm{molh}^{-1}\right)$. The improved yield is attributed to $\mathrm{CB}$ depletion of $\mathrm{Ag}_{3} \mathrm{PO}_{4}$ caused by additional $\mathrm{Ag} / \mathrm{AgBr}$. This composite leads to a long lifetime of the photogenerated holes and a downward shift in the VB of $\mathrm{Ag}_{3} \mathrm{PO}_{4}$ owing to charge transfer to $\mathrm{Ag}$ and subsequently to $\mathrm{RGO}$. In the graphene oxide/Ag/AgCl composite, in which $\mathrm{GO}$ and $\mathrm{AgCl}$ act as activated photocatalysts, metallic Ag shuttles the electrons from $\mathrm{AgCl}$ to $\mathrm{GO} .{ }^{[162]}$ The electron-hole pairs of a low energy level recombine in space through $\mathrm{Ag}$ as a solid- 
state electron mediator, and the remaining charge carriers have a high energy level for redox reactions.

Graphene and RGO have also been used as supports for plasmonic catalysts, such as in $\mathrm{Au} / \mathrm{TiO}_{2} /$ graphene, $^{[163]} \mathrm{Ag} / \mathrm{TiO}_{2} /$ graphene, ${ }^{[164]} \mathrm{Au} / \mathrm{N}-\mathrm{La}_{2} \mathrm{Ti}_{2} \mathrm{O}_{7} / \mathrm{RGO}^{[165]} \mathrm{Ag} / \mathrm{Ag}_{2} \mathrm{CO}_{3} / \mathrm{RGO},{ }^{[166]}$ and graphene sheet grafted AgCl@Ag. ${ }^{[167]}$ In these cases, metal NPs are photoexcited under visible-light irradiation owing to plasmonic resonance. Charge separation is accomplished by transferring the photoexcited electrons from the metal NPs to the semiconductors. The electrons then flow into the graphene sheets in the graphene-semiconductor system (Figure $5 \mathrm{C}$ ). Both the graphene surface and the $\mathrm{CB}$ of the semiconductor function as active sites for $\mathrm{H}_{2}$ production. Such a scenario retards the recombination of electron-hole pairs and suppresses the reverse reaction by separating the redox sites. For instance, graphene-based $\mathrm{Au}-\mathrm{TiO}_{2}$ catalysts have been prepared with $\mathrm{Au} / \mathrm{TiO}_{2}-\mathrm{GO}$ composite weight ratios of $0,0.05,0.10,0.25$, and $0.50 \% .{ }^{[163]}$ In the system, the $\mathrm{H}_{2}$ evolution rate increases to $296 \mu \mathrm{m} \mathrm{h}^{-1} \mathrm{~g}^{-1}$ as the Au concentration increases up to $0.25 \%$, but an excess amount of Au NPs may act as a recombination center, which is evidenced by the lower $\mathrm{H}_{2}$ evolution rate of approximately $197 \mu \mathrm{m} \mathrm{h}^{-1} \mathrm{~g}^{-1}$ for the $0.5 \%$ sample.

\subsubsection{Semiconductor-graphene composites}

To prove the role of graphene as a support and relay material between different light absorbers (Figure $5 \mathrm{~d}$ ), the anatase/graphene/rutile, ${ }^{[168]} \mathrm{BiVO}_{4} /$ graphene/(Ru/SrTiO$\left.{ }_{3}: \mathrm{Rh}\right){ }_{1}^{[12 b, 169]}$ metal sulfide/RGO/TiO ${ }_{2}{ }^{[170]} \mathrm{ZnO} / \mathrm{RGO} / \mathrm{CdS},{ }^{[171]}$ and $\mathrm{Fe}_{2} \mathrm{~V}_{4} \mathrm{O}_{13} / \mathrm{RGO} /$ $\mathrm{CdS}^{[172]}$ catalysts have been studied. In these structures, photoexcited electrons of the n-type semiconductor are transferred to another catalyst through RGO to achieve water splitting or $\mathrm{CO}_{2}$ reduction. The interface between the different materials is the most active part for the reactions. Fast charge migration at the interface provides a huge amount of reaction opportunities for photoinduced carriers, as RGO is used as an electron mediator between $\mathrm{Ru} / \mathrm{SrTiO}_{3}: \mathrm{Rh}\left(\mathrm{H}_{2}\right)$ and $\mathrm{BiVO}_{4}\left(\mathrm{O}_{2}\right) .{ }^{[12 \mathrm{~b}]}$ The electrons of $\mathrm{BiVO}_{4}$ are transferred to the vacancies in the impurity levels of $\mathrm{Ru} / \mathrm{SrTiO}_{3}$ by $\mathrm{RGO}$. The electrons in $\mathrm{Ru} / \mathrm{SrTiO}_{3}: \mathrm{Rh}$ reduce water to $\mathrm{H}_{2}$ on the $\mathrm{Ru}$ cocatalyst, whereas the holes left on $\mathrm{BiVO}_{4}$ oxidize water to $\mathrm{O}_{2}$. The key factor that enables efficient electron transfer relies on a balance between the degree of $\mathrm{GO}$ reduction and the level of hydrophobicity. For the case in which RGO works as a carrier transport channel, the $\mathrm{ZnO}$ $\mathrm{NR} / \mathrm{RGO} / \mathrm{CdS}$ catalyst exhibits a $\mathrm{H}_{2}$ generation rate $\left(0.6 \mathrm{mmol} \mathrm{h}^{-1}\right)$ that is 3.8 times higher than of the $\mathrm{CdS} / \mathrm{ZnO}$ reference. The optimal contents of the RGO nanosheets and CdS NPs are $2 \mathrm{wt} \%$ and 20 at \%. ${ }^{[171 a]}$ An example for $\mathrm{CO}_{2}$ reduction is a system consisting of $\mathrm{Fe}_{2} \mathrm{~V}_{4} \mathrm{O}_{13}$ nanoribbon/RGO/CdS NPs grown on a stainless-steel mesh scaffold. ${ }^{[172]}$ The holes stored by $\mathrm{CdS}$ oxidize $\mathrm{H}_{2} \mathrm{O}$ to $\mathrm{O}_{2}$, whereas the electrons stored by $\mathrm{Fe}_{2} \mathrm{~V}_{4} \mathrm{O}_{13}$ reduce $\mathrm{CO}_{2}$ to $\mathrm{CH}_{4}$. As a result, the combination of $\mathrm{CdS}$ and $\mathrm{Fe}_{2} \mathrm{~V}_{4} \mathrm{O}_{13}$ increases the $\mathrm{CH}_{4}$ evolution rate to a value threefold higher than that of the $\mathrm{Fe}_{2} \mathrm{~V}_{4} \mathrm{O}_{13}$ nanoribbons, and the activity of the RGO system further increases to approximately $2.10 \mu \mathrm{molg}^{-1} \mathrm{~h}^{-1}$.
A variety of noble-metal-free cocatalysts have been integrated with graphene-semiconductor composites, such as $\mathrm{MoS}_{2}{ }^{\left[{ }^{[173]}\right.} \mathrm{Co}_{0.85} \mathrm{Se}_{1}{ }^{[174]} \mathrm{NiO}_{x \prime}{ }^{[175]} \mathrm{Ni}(\mathrm{OH})_{2}{ }^{[176]}$ and $\mathrm{RuO}_{2} \cdot{ }^{[177]}$ In these materials, not only are the electron-hole pairs separated but there are more sites available for reduction. The $\mathrm{MoS}_{2} /$ graphene $/ \mathrm{TiO}_{2}$ composite reaches a $\mathrm{H}_{2}$ production rate of $165.3 \mu \mathrm{molh}^{-1}$ when the $\mathrm{MoS}_{2} /$ graphene cocatalyst content is $0.5 \mathrm{wt} \%$ and the graphene content in this cocatalyst is $5.0 \mathrm{wt} \% .{ }^{[173 a]}$ The electrons in $\mathrm{TiO}_{2}$ are transferred to the $\mathrm{MoS}_{2}$ nanosheets through the graphene sheets and they then react with adsorbed $\mathrm{H}^{+}$ions at the edges of $\mathrm{MoS}_{2}$ to form $\mathrm{H}_{2}$. Moreover, the electrons are transferred to the $\mathrm{MoS}_{2}$ nanosheets on the surface of $\mathrm{TiO}_{2}$ or to the $\mathrm{C}$ atoms on the graphene sheets where they can react with $\mathrm{H}^{+}$to produce $\mathrm{H}_{2}$ (similar to Figure $5 \mathrm{a}$ ). Metal oxides are rarely used in pure form for $\mathrm{CO}_{2}$ reduction, whereas $\mathrm{Ni} / \mathrm{NiO}\left(\mathrm{NiO}_{x}\right)$ has been identified as an effective cocatalyst. Different amounts of graphene (0-5 wt \%) in the $\mathrm{NiO}_{x} / \mathrm{Ta}_{2} \mathrm{O}_{5} / \mathrm{RGO}$ catalyst have been tested for the conversion of $\mathrm{CO}_{2}$ in solution into $\mathrm{CH}_{3} \mathrm{OH}$ and $\mathrm{H}_{2} \cdot{ }^{[175]}$ The catalyst containing $1 \%$ graphene displays the highest conversion rate of $\mathrm{CO}_{2}$ to $\mathrm{CH}_{3} \mathrm{OH}$, and it produces 3.4 times more $\mathrm{CH}_{3} \mathrm{OH}$ ( $\approx 0.82 \mu \mathrm{mol} \mathrm{h}^{-1}$ ) than the corresponding catalyst without graphene. However, improper loading of graphene on the samples is detrimental, and this is ascribed to a trade-off between its high charge-transfer capability and its shielding effect on light absorption.

Materials with semiconductor junctions coupled to GO have been constructed, as in Figure $5 \mathrm{e}^{[178]}$ The CdS@TaON/GO catalyst shows a stable $\mathrm{H}_{2}$ production rate of $633 \mu \mathrm{molh}^{-1}$ at a GO content of $1 \mathrm{wt} \%$ and a Pt content of $0.4 \mathrm{wt} \%$; this rate is approximately 141 times higher than that shown by pristine TaON. The presence of CdS@TaON reduces electron recombination, and GO serves as an electron acceptor and transporter to increase the lifetimes of the charges. In the CdS/graphene/ $\mathrm{ZnIn}_{2} \mathrm{~S}_{4}$ porous architecture, the $3 \mathrm{wt} \% \mathrm{CdS}$ QD decorated architecture containing $0.4 \mathrm{wt} \% \mathrm{Pt}$ shows a $\mathrm{H}_{2}$ production rate of $1.9 \mathrm{mmolh}^{-1}$, which is approximately 2.7 times higher than that produced over $\mathrm{ZnIn}_{2} \mathrm{~S}_{4}{ }^{[179]}$ The rate is further increased to $2.7 \mathrm{mmolh}^{-1}$ if the composite is coupled with $1 \mathrm{wt} \%$ graphene. Injection junctions with graphene composites have also been developed, as in the $\mathrm{CuO} / \mathrm{TiO}_{2} /$ graphene, $^{[180]} \mathrm{CdS} / \mathrm{TiO}_{2} /$ graphene ${ }^{[181]}$ hierarchical CdS/1 D ZnO/2D graphene, ${ }^{[182]}$ and $\mathrm{NiS} / \mathrm{Zn}_{x} \mathrm{Cd}_{1-x} \mathrm{~S} / \mathrm{RGO}$ composites. For $\mathrm{CuO} / \mathrm{TiO}_{2} /$ graphene, the rational addition of $\mathrm{Cu}$ or graphene improves the activity of $\mathrm{TiO}_{2}{ }^{[180]}$ The maximum $\mathrm{H}_{2}$ evolution rate is $2905.0 \mu \mathrm{mol} \mathrm{g}^{-1} \mathrm{~h}^{-1}$. The electrons of $\mathrm{TiO}_{2}$ are injected into graphene or $\mathrm{CuO}$ through a percolation mechanism (Figure $5 \mathrm{f}$ ), at which they then react with $\mathrm{H}^{+}$or $\mathrm{H}_{2} \mathrm{O}$ that is adsorbed on the surface of graphene or $\mathrm{Cu}$. In contrast, in the $\mathrm{NiS} / \mathrm{Zn}_{x} \mathrm{Cd}_{1-x} \mathrm{~S} / \mathrm{RGO}$ composite, NiS is functionalized as an oxidation-active site to assemble photogenerated holes. RGO serves as an electron collector and transporter and provides reduction active sites for $\mathrm{H}_{2}$ production. ${ }^{[183]}$ The catalyst achieves a high $\mathrm{H}_{2}$ production rate of $375.7 \mu \mathrm{molh}^{-1}$ and an apparent quantum yield of $31.1 \%$ at $\lambda=$ $420 \mathrm{~nm}$. 


\subsection{Two/multiphoton electrodes (photoelectrochemical sys- tems)}

Basic PEs are fabricated from a single p-type or n-type semiconductor or from two or more semiconductors. Single-semiconductor electrodes require a band gap of at least approximately $2.3 \mathrm{eV}$ to generate the necessary voltage to split water, which leads to a maximum solar-to-fuel (STF) efficiency of $7 \%{ }^{[184]}$ To prepare more efficient PEs, a two/multiphoton scheme is desirable owing to optimal integration of narrowband-gap semiconductors, which in turn allows a wide solar spectrum to be absorbed for high photovoltage. ${ }^{[4 b, 185]}$ Two/ multiphoton electrodes can be built through various strategies such as semiconductor composites, QD sensitization, and plasmonic doping.

\subsubsection{Semiconductor-hybrid electrodes}

\subsubsection{Heterojunction electrodes}

The $\mathrm{p}-\mathrm{n}$ junction separates charges by an internal electric field induced by band bending. $\mathrm{A} \mathrm{p}-\mathrm{CaFe}_{2} \mathrm{O}_{4} / \mathrm{n}-\mathrm{TaON}$ anode has been fabricated on fluorine-doped tin oxide (FTO) glass by electrophoretic deposition of two semiconductors. ${ }^{[186]}$ Upon irradiating light from the backside of the FTO glass, TaON absorbs partial light and carriers are generated. $\mathrm{CaFe}_{2} \mathrm{O}_{4}$ absorbs the remaining light that also excites electrons. The electrons from $\mathrm{CaFe}_{2} \mathrm{O}_{4}$ (S2) move toward the substrate through $\mathrm{n}$ - $\mathrm{TaON}$ (S1), and holes from TaON migrate to the surface of $\mathrm{CaFe}_{2} \mathrm{O}_{4}$ by a potential difference (Figure $6 \mathrm{a}$ ). Thus, the anode absorbs high-energy light to excite efficient charge separations for water oxidation. The introduction of the $\mathrm{CaFe}_{2} \mathrm{O}_{4}$ overlayer on the $\mathrm{TaON}$ electrode increases the photocurrent density approximately fivefold. To improve stability, an ultrathin carbon sheath is coated on a $\mathrm{p}-\mathrm{Cu}_{2} \mathrm{O} / \mathrm{n}-\mathrm{TaON} \mathrm{NR}$ array photoanode as a surface protection layer. The passivated anode exhibits an incident photon-to-current efficiency (IPCE) of $59 \%$ at $\lambda=$ $400 \mathrm{~nm}$, shows a photocurrent of $3.06 \mathrm{~mA} \mathrm{~cm}^{-2}$, and retains approximately $87 \%$ of the initial activity after irradiation for $1 \mathrm{~h}$. Not only is the onset potential negatively shifted but the photocurrent density and photostability are also improved relative to the unpassivated anode. ${ }^{[187]}$ These improvements are due to fast transfer of electrons together with high conductivity and shielding from the electrolyte by the carbon jacket. In addition to the surface catalytic effect, bulk charge separation is achieved through introducing discrete $\mathrm{p}-\mathrm{Co}_{3} \mathrm{O}_{4}$ nanoislands onto $\mathrm{n}-\mathrm{BiVO}_{4}$. The anode offers a photocurrent of $2.71 \mathrm{mAcm}^{-2}$ at $1.23 \mathrm{~V}$, with a photoconversion efficiency of $0.659 \% .{ }^{[188]}$ The $\mathrm{p}-$ $\mathrm{n}$ junction has also been introduced in $\mathrm{Si} / \mathrm{TiO}_{2} / \mathrm{Pt}$ photocathodes for $\mathrm{CO}_{2}$ reduction. ${ }^{[189]}$ The results show good performance for the formation of methanol $\left(0.88 \mathrm{mmol} \mathrm{L}^{-1}\right)$, ethanol $\left(2.60 \mathrm{mmol} \mathrm{L}^{-1}\right)$, and acetone $\left(0.049 \mathrm{mmol} \mathrm{L}^{-1}\right)$, presenting faradaic efficiency of $96 \%$.

Integration of two n-type semiconductors is an alternative approach. The most studied materials are $\mathrm{TiO}_{2}, \mathrm{WO}_{3}, \alpha-\mathrm{Fe}_{2} \mathrm{O}_{3}$, $\mathrm{g}-\mathrm{C}_{3} \mathrm{~N}_{4}$, and $\mathrm{BiVO}_{4} . \mathrm{TiO}_{2} / \mathrm{ZnIn}_{2} \mathrm{~S}_{4}{ }^{[190]} \mathrm{N}-\mathrm{TNT} / \mathrm{TaO}_{x} \mathrm{~N}_{y}(\mathrm{~N}-\mathrm{TNT}=\mathrm{N}-$ doped $\mathrm{TiO}_{2}$ nanotube) ${ }_{1}^{[191]} \mathrm{WO}_{3} / \mathrm{BiVO}_{4}{ }^{[192]}$ coupling $\mathrm{Fe}_{2} \mathrm{O}_{3}$ with

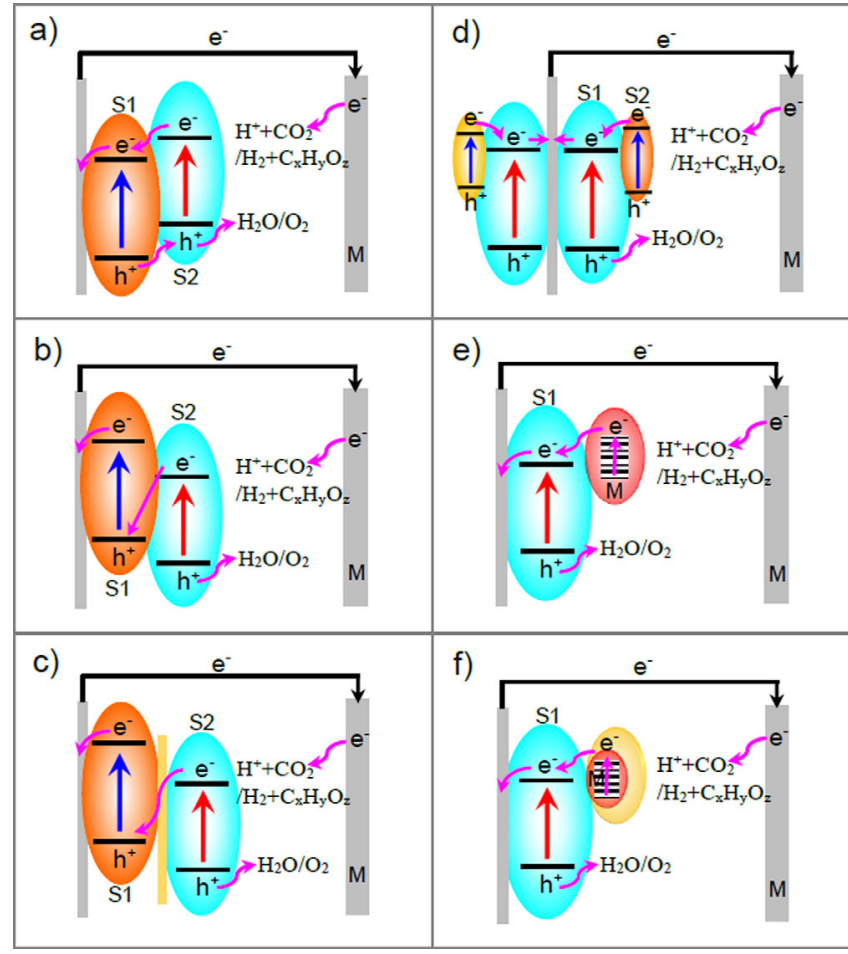

Figure 6. Charge transport at a) heterojunction photoanode (adapted from ref. [186]) and b) tunnel junction photoanode (adapted from ref. [200a]). c) Tunnel junction photoelectrode through a thin insulating layer (adapted from ref. [198]). d) Charge transport at dual-sided quantum dot cosensitized photoanode (adapted from ref. [219]). Charge transport at semiconducting photoanodes with e) a metal nanostructure or $f$ ) a core-shell metal insulator nanostructure (adapted from refs. [220e], [223b]).

$\mathrm{MgFe}_{2} \mathrm{O}_{4}{ }^{[193]}$ and $\mathrm{ZnFe}_{2} \mathrm{O}_{4}{ }^{[194]} 3 \mathrm{D} \mathrm{CoO}_{x} / \mathrm{C}_{3} \mathrm{~N}_{4} / \mathrm{Ba}-\mathrm{TaON}^{[195]}$ and $\mathrm{CoO}_{x} / \mathrm{C}_{3} \mathrm{~N}_{4} / \mathrm{WO}_{3}{ }^{[196]}$ have been explored for PEC water splitting. By coupling $\mathrm{N}$-doped TNTs with a thin $\mathrm{TaO}_{x} \mathrm{~N}_{y}$ layer, both charge-generation materials are separated at their interface owing to a potential gradient. The thin $\mathrm{TaO}_{x} \mathrm{~N}_{y}$ film serves as a passivation layer that reduces the surface-trap sites of $\mathrm{N}$ TNT. ${ }^{[191]}$ This complementary factor results in a high photocurrent and improves visible activities by approximately 3.6 times over that of the N-TNT electrode. $\mathrm{WO}_{3}$ is an indirect band-gap semiconductor $(\approx 2.6 \mathrm{eV})$ with a very low absorption coefficient, approximately $12 \%$ of the solar spectrum. To improve the performance, $\mathrm{WO}_{3} / \mathrm{BiVO}_{4}$ nanowires (NWs) have been grown on $\mathrm{FTO}$, in which $\mathrm{BiVO}_{4}$ is a primary light absorber and $\mathrm{WO}_{3}$ acts as an electron conductor. The IPCE value of the nanowire is $31 \%$ at $\lambda=420 \mathrm{~nm}$, whereas that of the planar $W_{3} /$ $\mathrm{BiVO}_{4}$ films is $9.3 \% .{ }^{[192 a]}$ The NW anode produces a photocurrent of $3.1 \mathrm{~mA} \mathrm{~cm}^{-2}$ and an IPCE of approximately $60 \%$ at $\lambda=$ 300-450 nm for water oxidation. ${ }^{[192 c]}$ In photoanode-driven $\mathrm{CO}_{2}$ reduction, the $\mathrm{Co}-\mathrm{Ci} / \mathrm{BiVO}_{4} / \mathrm{WO}_{3}$ photoanode with a $\mathrm{Cu}$ cathode system shows a stable photocurrent and $51.9 \%$ faradaic efficiency for $\mathrm{CO}$ and $\mathrm{C}_{1}-\mathrm{C}_{2}$ hydrocarbons. ${ }^{[192 \mathrm{~b}]}$

Hematite is an earth-abundant material that has a favorable band gap of $2.1 \mathrm{eV}$. Its performance is restricted by poor kinetics for water oxidation and short hole diffusion lengths (2$4 \mathrm{~nm}){ }^{[4 \mathrm{~b}, 197]}$ To compensate these shortcomings, branched Co$\mathrm{Fe}_{2} \mathrm{O}_{3} \mathrm{NR} / \mathrm{MgFe}_{2} \mathrm{O}_{4}$ has been devised as a photoanode. Driven 
by band alignment, the electrons migrate from the $\mathrm{CB}$ of $\mathrm{MgFe}_{2} \mathrm{O}_{4}$ to that of the $\mathrm{Co}-\mathrm{Fe}_{2} \mathrm{O}_{3} \mathrm{NRs}$, from which they are then transported to the $\mathrm{Ti}$ substrate along the $\mathrm{Co}-\mathrm{Fe}_{2} \mathrm{O}_{3} \mathrm{NRs}$. The holes in the VB of the impurity level of $\mathrm{Co}-\mathrm{Fe}_{2} \mathrm{O}_{3}$ are transferred to the $\mathrm{VB}$ of the impurity level of $\mathrm{MgFe}_{2} \mathrm{O}_{4}$. As a result, the anode presents a photocurrent density of approximately $3.34 \mathrm{~mA} \mathrm{~cm}^{-2}$, which is 2.69, 1.95, and 1.78 times higher than that of $\mathrm{Fe}_{2} \mathrm{O}_{3} \mathrm{NR}, \mathrm{Co}-\mathrm{Fe}_{2} \mathrm{O}_{3} \mathrm{NR}$, and $1 \mathrm{D} \mathrm{Co}-\mathrm{Fe}_{2} \mathrm{O}_{3} \mathrm{NR} / \mathrm{MgFe}_{2} \mathrm{O}_{4}{ }^{[193]}$ Relative to metal oxides, $\mathrm{g}-\mathrm{C}_{3} \mathrm{~N}_{4}$ has attracted much interest in response to visible light. The branched $\mathrm{CoO}_{x} / \mathrm{C}_{3} \mathrm{~N}_{4} / \mathrm{WO}_{3}$ anode exhibits a photocurrent density of $3.61 \mathrm{mAcm}^{-2}$, which is approximately 1.31 times greater than that of $\mathrm{WO}_{3} / \mathrm{C}_{3} \mathrm{~N}_{4}$ nanosheets. ${ }^{[196]}$ In this architecture, $\mathrm{WO}_{3}$ is an electron acceptor, and $\mathrm{CoO}_{x}$ functions as a surface oxidation catalyst.

\subsubsection{Tunnel junction electrodes}

A tunnel junction is a thin insulating layer or electric potential between light absorbers. Charge carriers can pass through the barrier by quantum tunneling. ${ }^{[198]}$ In tunnel-junction electrodes, a redox reaction occurs at the interface of the semiconductorelectrolyte. The junction interface serves as a site for the recombination of the majority of carriers (Figure $6 \mathrm{~b}$ ). There are two possibilities for charge transport from one absorber to another. In the first case, the semiconductor has different bandbending properties near the junction. A potential energy barrier across the interface blocks a minor amount of the carrier flow but permits the majority of flow towards the junction. This situation has been realized in $\mathrm{n}-\mathrm{TiO}_{2} / \mathrm{n}-\mathrm{Si} \mathrm{NW}{ }^{[199]} \mathrm{n}-\mathrm{Fe}_{2} \mathrm{O}_{3} /$ p- or n-Si NW ${ }^{[200]}$ anode, and InGaN/GaN/Si cathode. ${ }^{[201]}$ In these cases, charge carrier flow is enabled if the two semiconducting absorbers are photoexcited in a synergistic manner. The VB of the top absorber is lower than that of the underlying absorber, and holes from S1 are transported by tunneling to combine with the electrons on the CB of S2 through an extremely thin depletion layer. For instance, Si NWs absorb photons $(600 \mathrm{~nm}<\lambda<1100 \mathrm{~nm})$ that are transparent to hematite $(\lambda=300-580 \mathrm{~nm})$ and convert the energy into additional photovoltage. ${ }^{[200]}$ Band alignment at the junction reflects holes back into hematite, which helps to reduce the loss of holes. Notably, without the highly doped layers, an inadvertent $p-n$ junction would form at the interface. ${ }^{[184,202]}$ This would drive electrons and holes in the wrong directions and would cause recombination of minority carriers and reduce fuel-generation efficiencies. Alternatively, a passive or protection layer with a VB below that of the absorber allows a hole to tunnel through the thin layer or to be transported through a defect band in the layer (Figure $6 \mathrm{c}$ ). ${ }^{[198]}$ The former scheme has been realized with thin layers of $\mathrm{TiO}_{2}$ grown on $\mathrm{n}-\mathrm{Si}$ or $\mathrm{p}-\mathrm{Cu}_{2} \mathrm{O}^{[14,203]}$ or with a thin epitaxial layer of $\mathrm{SrTiO}_{3}$ grown on $\mathrm{Si}(001){ }^{[204]}$ However, the thickness of the layer needs to be controlled, as tunneling introduces a large series resistance for films thicker than a few nanometers. The latter scheme has been achieved by using amorphous $\mathrm{TiO}_{2}$ layers coated with a number of absorbers: $\mathrm{n}-\mathrm{Si}, \mathrm{n}-\mathrm{GaAs}$, and $\mathrm{n}-\mathrm{GaP}^{[205]}$ The protection layer can be as thick as $140 \mathrm{~nm}$, which rules out any tunneling effect. A thin $\mathrm{TiO}_{2}$ interlayer $(4-25 \mathrm{~nm})$ is required in a dual absorber of a $\mathrm{BiVO}_{4}(\mathrm{~S} 2)$ and $\mathrm{Si}(\mathrm{S} 1)$ anode to realize an increase in the photocurrent and a shift in the onset potential. The anode shows $1.0 \mathrm{mAcm}^{-2}$ at $1.23 \mathrm{~V}$ with an onset potential of $0.11 \mathrm{~V}$; thus, there is a 3.3-fold enhancement in current density and the onset potential is shifted in the negative direction by $300 \mathrm{mV}$ relative to that of the $\mathrm{BiVO}_{4} / \mathrm{FTO}$ photoanode. ${ }^{[206]} \mathrm{A}$ further increase in the water splitting activity can be expected by improving the interlayer conditions and by loading proper cocatalysts.

\subsubsection{Quantum-dot-sensitized electrodes}

Integrating quantum dots with bulk or nanostructured semiconductors increases the light absorbance of PEs. Thus, $\mathrm{CdS}^{[207]}$ and $\mathrm{CdSe}^{[208]}$ have been adopted as sensitizers on $\mathrm{TiO}_{2}$ nanostructures for photosynthesis. The cascade structures of $\mathrm{CdSe} /$ $\mathrm{CdS}^{[209]} \mathrm{PEDOT} / \mathrm{CdSe} / \mathrm{CdS},{ }^{[210]}$ and $\mathrm{ZnS} / \mathrm{CdSe} / \mathrm{CdS}^{[211]}$ on $\mathrm{TiO}_{2}$ PEs exhibit more enhancement in the current response than the single-sensitized PEs. The maximum photocurrent achieved by the $\mathrm{CdSe} / \mathrm{CdS} / \mathrm{TiO}_{2} \mathrm{PE}$ is $14.9 \mathrm{~mA} \mathrm{~cm}^{-2}$, which is three times that of the $\mathrm{CdS} / \mathrm{TiO}_{2}$ and $\mathrm{CdSe} / \mathrm{TiO}_{2} \mathrm{PEs}$. If $\mathrm{CdS}$ and $\mathrm{CdSe}$ are inversely deposited on a $\mathrm{TiO}_{2}$ film to form a $\mathrm{CdS} / \mathrm{CdSe} / \mathrm{TiO}_{2}$ structure, the current density is much lower than that of the CdSe/ $\mathrm{CdS} / \mathrm{TiO}_{2}$ electrode. ${ }^{[209]}$ This is ascribed to the fact that the alignment of the Fermi levels between $\mathrm{CdSe}$ and $\mathrm{CdS}$ induces upward and downward shifts in the band edges. The energy potential levels of intermediate CdSe are higher than those of $\mathrm{CdS}$, which results in a notable barrier for the injection of electrons from the outer CdS layer and the transfer of holes out of the inner CdSe layer.

Branched $\mathrm{CdS} / \mathrm{TiO}_{2} / \mathrm{SnO}_{2}$ NRs have been studied to understand band alignment of multiple structures in the parent semiconductors. ${ }^{[212]}$ The PE induces a photocurrent density of $8.75 \mathrm{mAcm}^{-2}$ at zero bias, which is more than four times higher than that of the $\mathrm{SnO}_{2} / \mathrm{TiO}_{2}$ electrode. To verify the morphology effect of the sensitizer, a series of CdS, CdSe, and CdSeS NRs deposited onto $\mathrm{TiO}_{2}$ NW PEs have been explored. ${ }^{[208 b]}$ If the sensitizer is changed from a particle to a rod to a stump-shaped morphology, the latter two anodes have higher photocurrent densities, which comes from competition between light absorption, recombination loss, and surface area. The $\mathrm{CdSe} / \mathrm{TiO}_{2}-\mathrm{NW}$ electrode presents the highest initial photocurrent owing to the smallest band gap. The $\mathrm{CdS} / \mathrm{TiO}_{2}-$ NW anode exhibits the lowest photocurrent with the highest electron injection efficiency. The $\mathrm{CdSeS} / \mathrm{TiO}_{2}-\mathrm{NW}$ heterostructure is a favorable one in terms of the level of the photocurrent and stability.

The cascade concept has been transplanted to extend the absorption spectrum in $\mathrm{ZnO}$-based PEs, such as in $\operatorname{IrO}_{x} \cdot n \mathrm{H}_{2} \mathrm{O}$ modified $\mathrm{CdSe} / \mathrm{CdS} / \mathrm{ZnO} \quad \mathrm{NWs}^{[213]} \mathrm{CdSe} / \mathrm{CdS} / \mathrm{ZnO} \quad \mathrm{NRs}^{[214]}$ $\mathrm{ZnIn}_{2} \mathrm{~S}_{4} / \mathrm{ZnS} / \mathrm{ZnO}$ nanotube arrays, ${ }^{[215]} \mathrm{NiO} / \mathrm{CdS} @ Z n O$ composites, ${ }^{[216]} \mathrm{ZnSe} / \mathrm{CdS} / \mathrm{CdSe} / \mathrm{ZnO} \mathrm{NWs}^{\left[{ }^{[217]}\right.} \mathrm{CdSe} / \mathrm{CdS} / \mathrm{ZnO} / \mathrm{WO}_{x}$ hierarchical $\mathrm{NWs}^{[218]}$ and double-sided $\mathrm{CdS} / \mathrm{ZnO} \mid \mathrm{ZnO} / \mathrm{CdSe}$ NWs. ${ }^{[219]}$ Triple-sensitized ZnO NWs can be fabricated on FTO through a facile hydrothermal and anion-exchange reaction, followed by a chemical bath deposition approach. ${ }^{[217]}$ Through synergistic light absorption and multigraded band-gap levels 
between the materials, the PE delivers a photocurrent intensity of $5.3 \mathrm{~mA} \mathrm{~cm}^{-2}$, which exceeds that of a single- or co-sensitized $\mathrm{PE}$ and is approximately 11 times higher than that of bare $\mathrm{ZnO}$ NWs. Although the electrons of CdSe are transferred to $\mathrm{ZnO}$ through the $\mathrm{CdS}$ layer, the presence of this intermediate layer in $\mathrm{CdSe} / \mathrm{CdS} / \mathrm{ZnO}$ increases charge recombination and limits the efficiency of photoelectron collection. To overcome these drawbacks, rational separation of CdS and CdSe on each side of $\mathrm{ZnO}$ in a dual-sided PE is a wise tactic (Figure $6 \mathrm{~d}$ ). ${ }^{[219]}$ The Fermi levels of $\mathrm{CdS}, \mathrm{CdSe}$, and $\mathrm{ZnO}$ are aligned so that the CBs of $\mathrm{CdS}$ and $\mathrm{CdSe}$ are close enough to allow delocalization and transfer of the photoelectrons. The anode shows high activity for water oxidation with a photocurrent density of $12 \mathrm{~mA} \mathrm{~cm}^{-2}$.

\subsubsection{Plasmonic electrodes}

Plasmonic effects have led to compelling evidence for water splitting. The PEs affected by metal NPs can be divided into those with direct contact to the semiconductor (Figure 6e) and those separated from the semiconductor by an insulating spacer (Figure $6 \mathrm{f}$ ). As a light absorber, Au has been used to sensitize $\mathrm{TiO}_{2}$ PEs to generate additional charge carriers for water oxidation. ${ }^{[220]}$ This is due to amplification of the electric field near the semiconductor surface induced be SPR; this increases the photon absorption rate of $\mathrm{TiO}_{2}$ and improves the photoactivity. ${ }^{[221]} \mathrm{Au}$ NPs assembled with a $\mathrm{TiO}_{2}$-based photonic crystal substrate can achieve a photocurrent density of approximately $150 \mu \mathrm{Acm}^{-2}$. Matching the SPR wavelength to the photonic band gap of $\mathrm{TiO}_{2}$ boosts hot electron injection and thus enhances activity. ${ }^{[220 e, 222]}$ By manipulating the shape of the decorated Au structures, a mixture of Au NPs and NRs deposited on $\mathrm{TiO}_{2} \mathrm{NWs}$ shows water oxidation over the entire UV/Vis region $(\lambda \approx 300-800 \mathrm{~nm}) .{ }^{[220 \mathrm{~b}]} \mathrm{A}$ nanobamboo array with various metal-semiconductor segments ( $\mathrm{ZnS}-\mathrm{Ag}-\mathrm{CdS}-\mathrm{Au}-\mathrm{CdSe}$ ) has also been designed to improve charge transfer. ${ }^{[220 c]}$ The surface of each segment is in direct contact with the electrolyte, and the holes easily migrate to the semiconductor/electrolyte interface because of a shorter transfer distance in the radial direction. As a result, the architecture facilitates interfacial charge transfer and accelerates photocatalytic transformations.

Direct exposure of plasmonic metals to the electrolyte leads to their corrosion and dissolution. One attempt to address this problem relies on coating the metals with a protecting layer. ${ }^{[220 \mathrm{~d}]}$ Plasmonic Ag shows great potential for redox applications. ${ }^{[220 c, 223]}$ By loading core-shell $\mathrm{Ag}_{3}\left(\mathrm{PO}_{4}\right)_{1-x} @ \mathrm{Ag}$ onto $\mathrm{ZnO}$ NRs (Figure $6 \mathrm{f}$ ), water oxidation activity can be achieved with a maximum photocurrent of $3.1 \mathrm{mAcm}^{-2}$ and an IPCE of $60 \%$ at $\lambda=400 \mathrm{~nm}^{[223 \mathrm{~b}]}$ The SPR of Ag increases the optical absorption and the rate of electron-hole formation near the $\mathrm{Ag}_{3}\left(\mathrm{PO}_{4}\right)_{1-x} / \mathrm{ZnO}$ junction. Another strategy is to embed plasmonic metals into the semiconductor photocatalyst, ${ }^{[220 g, 224]}$ as gold NPs sandwiched between $\mathrm{TiO}_{2} \mathrm{NRs}$ and a CdS layer play a dual role in enhancing the efficiency. ${ }^{[220 \mathrm{~g}]}$ The Au NPs first serve as an electron relay that facilitates charge transfer between $\mathrm{CdS}$ and $\mathrm{TiO}_{2}$ if the QDs are photoexcited by wavelengths shorter than $525 \mathrm{~nm}$. Second, the Au NPs act as a plasmonic sensitizer, which enables the conversion at wavelengths longer than the band edge of $\mathrm{CdS}$, and this extends the wavelength from 525 to $725 \mathrm{~nm}$. The dual role of Au leads to a photocurrent of $4.07 \mathrm{~mA} \mathrm{~cm}^{-2}$ under full solar spectrum irradiation and a maximum STF of $2.8 \%$. An alternative method is to utilize layered core-shell structures, such as uniform and tapered Si@Ag NWs, ${ }^{[225]}$ which combine the geometry of the NWs with the SPR in the metal core to confine light within a thin semiconductor shell. To obtain cost-effective and scalable plasmonic light harvesting, core-multishell $\mathrm{Fe}_{2} \mathrm{O}_{3} @ \mathrm{Al} @ \mathrm{Si}$ NW structures with Al thin films as the intermediate shell have been developed with photocurrent densities comparable to those of $\mathrm{Fe}_{2} \mathrm{O}_{3} @ \mathrm{Ag} @ \mathrm{Si} N W{ }^{[226]}$ A PE with a dual absorber system consisting of $\mathrm{Si}$ and hematite reaches a photocurrent density of approximately $11.81 \mathrm{~mA} \mathrm{~cm}^{-2}$, which corresponds to a STF efficiency of $14.5 \%$.

Developing PEs with charge carriers purely generated by SPR is another promising approach. ${ }^{[227]}$ One realization of such PEs is based on Au nanostructures. Au NRs are grown by electrodeposition on a porous aluminum oxide template, which is then coated with a thin $\mathrm{TiO}_{2}$ layer for charge separation. To build an autonomous unit, tiny Pt NPs are loaded to trigger the reduction of $\mathrm{H}^{+}$after capturing the hot electrons. A cobalt cocatalyst is additionally loaded to feed the metal back with electrons. This all-in-one unit is thus built and produces $\mathrm{H}_{2}$ at a rate of $5 \times 10^{13}$ molecules $\mathrm{cm}^{-2} \mathrm{~s}^{-1}$ under 1 sun illumination. ${ }^{\text {[227a] }} \mathrm{Au}$ NRs capped with $\mathrm{TiO}_{2}$ can also be used as an effective photoanode to collect and conduct hot electrons to the platinum electrode at which $\mathrm{H}_{2}$ gas evolves. ${ }^{[227 \mathrm{~b}]}$ The resultant positive charges in the Au NRs function as holes and are extracted by OEC to produce $\mathrm{O}_{2}$ gas. The anode shows enhanced responsivity across the plasmon band, as evidenced by fuel production efficiencies that are up to 20 times higher at visible wavelengths than at ultraviolet wavelengths.

\subsection{Two-photon cells (photoelectrochemical systems)}

PEC performance has been explored extensively at the electrode level, whereas cell design has received less attention. ${ }^{[4-}$ b, 19a,b,228] It is convenient to assemble two or more light absorbers in a complete cell. Various techniques have been developed at the cell level to trade-off between light absorption and reaction potentials, such as PV-PEC cells, Z-scheme cells, PEC diodes, and all-in-one membranes. These cells consist of two electrodes, one or both of which is photoactive. Semiconductors in the cells are used either to create PV junctions or as PEs. The photoanode and cathode can be physically separated in a wired configuration or combined into a monolithic structure. ${ }^{[229]}$

\subsubsection{Wired cells}

\subsubsection{PV-PEC cells}

In single-photon cells, a semiconductor material is used as either the photoanode or the cathode with a counter electrode. At the electrolyte/semiconductor interface, charge carriers are separated and all important redox reactions occur. This 
solid/liquid junction suffers from recombination and results in a low photovoltage. A PV junction can be introduced into a PEC device to generate an additional bias to assist charge separation. ${ }^{[229,230]}$ PV-PEC devices (Figure $7 \mathrm{a}$ ) include a bottom PV and a semiconductor/electrolyte junction. This stacked structure involves the arrangement of two absorbers that need optimum energy combinations in the ranges of 0.95 to 1.20 and 1.60 to $1.80 \mathrm{eV}^{[231]}$ The classic PV materials GaAs and Galn $\mathrm{P}_{2}$ are good candidates that can be used to enable such an adaptation owing to their adjustable optoelectronic properties. A typical cell is an assembly of a GaAs $p-n$ bottom cell and a GalnP $P_{2}$ top cell with a Pt foil as the counter electrode.
The top $\mathrm{GalnP}_{2}$ layer $(\approx 1.83 \mathrm{eV})$ is designed to absorb more energetic photons, which leads to a high photovoltage. The bottom $\mathrm{p}-\mathrm{n}$ junction $(\approx 1.42 \mathrm{eV})$ absorbs less energetic photons and generates an additional photovoltage. ${ }^{[232]}$ One set of electrons and holes are recombined at the tunnel junction. The resultant photovoltage is greater than the required potential for photoelectrolysis, and this drives the water reductive reaction at the semiconductor electrode. The $\mathrm{H}_{2}$ production efficiency of the cell reaches $12.4 \%$. Conditioning the absorber interface further with $\mathrm{RuO}_{2}$ increases the potential of the device with a STF efficiency of approximately $14 \% \cdot{ }^{[232 a]}$ However, the

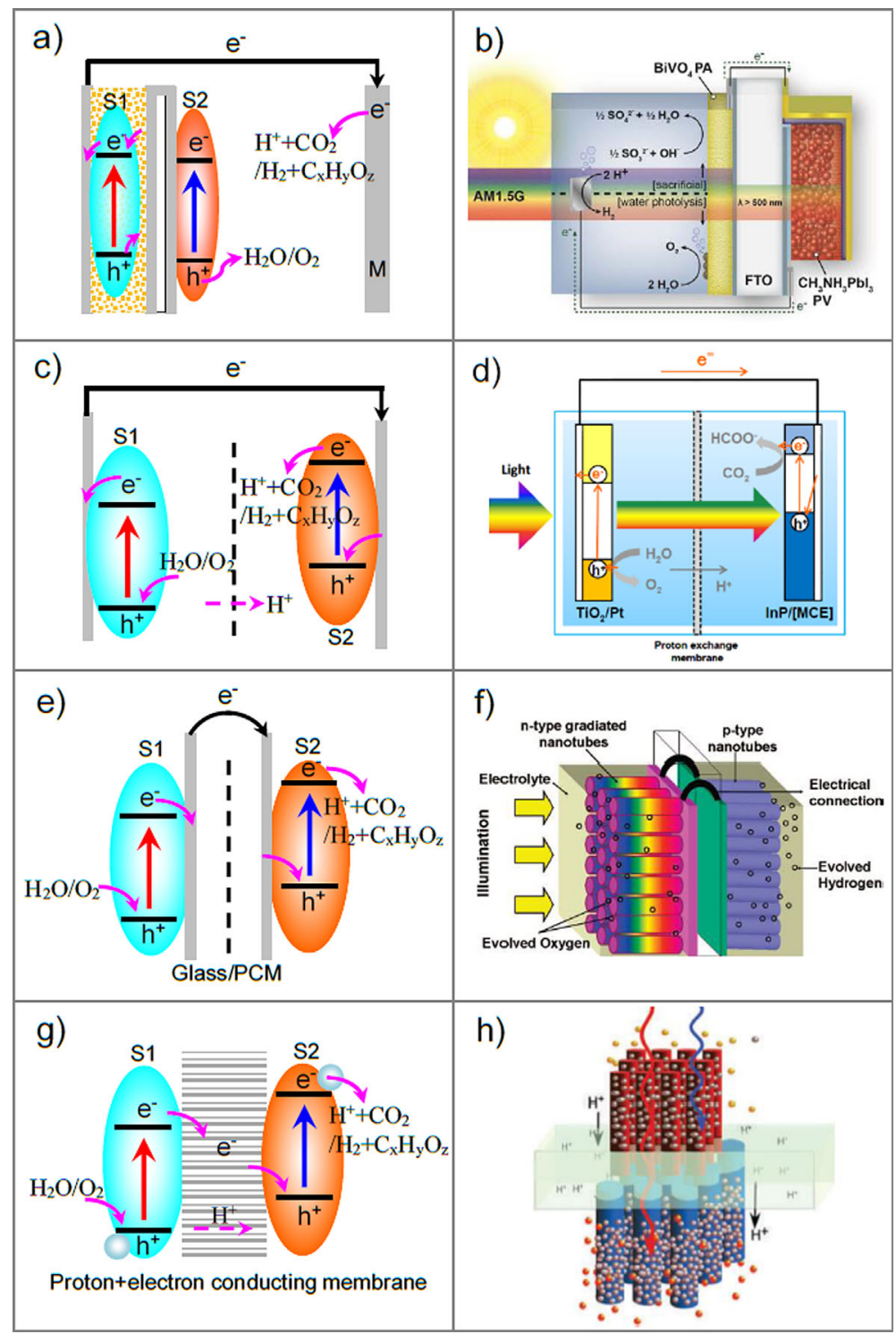

Figure 7. a) PV-PEC cell and b) example of a tandem $\mathrm{BiVO}_{4}-\mathrm{CH}_{3} \mathrm{NH}_{3} \mathrm{Pbl}_{3}$ device for solar fuels generation (reprinted with permission from ref. [238a], copyright 2015 American Chemical Society). c) Z-Scheme PEC cell and its example d) with a two-electrode configuration comprising translucent Pt-loaded TiO ${ }_{2}$ and [MCE2A + MCE4]-modified InP (reprinted with permission from ref. [251], copyright 2011 American Chemical Society). e) PEC diode and the example of f) a self-biased diode consisting of an n-type compositionally graded nanotube photoanode and a p-type nanotube cathode (reprinted with permission from ref. [253g], copyright 2009 American Chemical Society). g) All-in-one membrane and its example h) the blue portion of sunlight is absorbed by the semiconductor oxide photoanode (red color), at which water is oxidized to release protons. The red portion of light passing through is absorbed by the Si nanorod photocathode (blue color), which drives the protons and electrons to produce hydrogen. The membrane is permeable to the generated protons and conduct electrons between the electrodes (reprinted from ref. [262], copyright 2009 Nature Publishing Group). 
use of expensive and scarce light-absorbing materials limits practical application of this device.

In the search for low-costing materials, various devices have been built with silicon materials. ${ }^{[15,233]}$ The combination of a W$\mathrm{BiVO}_{4}$ photoanode with a double-junction silicon (a-Si:H/nc$\mathrm{Si}: \mathrm{H}) \mathrm{PV}$ device offers a benchmark efficiency of $5.2 \% .{ }^{[233 \mathrm{e}]}$ In this cell, photons are filtered by the front $\mathrm{BiVO}_{4}$ anode, at which a gradient $\mathrm{W}$-doping profile is introduced to enhance charge separation. Then, the remaining photons are absorbed by the PV structure. A junction cathode has also been made from hydrogenated amorphous and microcrystalline silicon (a$\mathrm{Si}: \mathrm{H} / \mu \mathrm{c}-\mathrm{Si}: \mathrm{H}) .^{[233 a, b]}$ Such a system has the added advantage of absorbing sunlight at different wavelengths. By adjusting the photocurrent of the structure, the maximum STF efficiency reaches up to $13.26 \% .{ }^{[233 f]}$ Another method is to introduce an external bias through the PV cells. By connecting the OEC to the p-type terminal and the HEC to the n-type terminal of the PV module, the voltage and current of the system are constrained to the same value, that is, they are equal. In this case, the STF efficiency can reach $>10 \%$ by a series interconnected PV module (c-Si or CIGS). ${ }^{[234]}$

A series of dye-sensitized solar cell (DSC)-PEC cells have also been fabricated by Grätzel et al, ${ }^{[235]}$ Mora-Seró et al, ${ }^{[236]}$ and Park $^{[237]}$ et al. In these devices, the PE functions as a light absorber, and typical materials include $\mathrm{WO}_{3}, \mathrm{Fe}_{2} \mathrm{O}_{3}$, and $\mathrm{CdS} / \mathrm{TiO}_{2}$. Incident light beams are transmitted from the photoanode to the underlying DSCs. In DSCs, wide-band-gap semiconductors are combined with visible-light-absorbing dyes. The photoanode and the DSCs are complementarily designed to exploit a substantial part of the solar spectrum. The STF efficiencies are $1.17\left(\mathrm{Fe}_{2} \mathrm{O}_{3} / \mathrm{DSC}\right)$ and $3.10 \%\left(\mathrm{WO}_{3} / \mathrm{DSC}\right)$. Recently, watersplitting assemblies composed of a photoelectrode (e.g., $\mathrm{BiVO}_{4}, \mathrm{Fe}_{2} \mathrm{O}_{3}, \mathrm{TiO}_{2}$, and $\mathrm{Cu}_{2} \mathrm{O}$ ) and a $\mathrm{CH}_{3} \mathrm{NH}_{3} \mathrm{Pbl}_{3}$ perovskite solar cell have been developed. ${ }^{[238]}$ The tandem configuration (Figure $7 \mathrm{~b}$ ) allows efficient photon management with the photoelectrode harvesting visible light and the underlying solar cell capturing lower energy visible-infrared wavelengths in a single-pass excitation; this results in a STF efficiency of $2.5 \% .{ }^{[238 a]}$ Moreover, the PV module might even be the sole supplier of the bias; for example, two perovskite solar cells connected in series serve as an external power source for photolysis with a STF efficiency of $12.3 \% .^{[239]}$ However, because of the presence of hygroscopic amine salts and the distorted crystal structure, perovskites are susceptible to light, temperature, and aqueous environments, which not only restrict their long-term stability but also weaken their direct use as photoanodes. $^{[240]}$

\subsubsection{Z-scheme cells}

Given that water splitting entails two half-reactions, it seems natural to use two light absorbers in a two-PE system in which the photocathode and photoanode are connected in series. The redox reaction is separated into two half-reactions (Zscheme cell in Figure $7 \mathrm{c}) .^{[241]}$ The majority of carriers recombine at the photocathode/anode interface, whereas a minority of carriers in the two semiconductors move towards the semi- conductor/electrolyte interface to carry out the individual halfreactions. The better options for the anode and cathode are ntype and p-type materials. Such a combination of two band gaps produces a wide electrochemical window. Relative to PVPEC cells, this cell offers advantages including a simple fabrication process, a low operation voltage, and relatively high efficiency. However, one-electron transfer in this system requires the absorption of two photons.

A Z-scheme cell with carbon-doped TNTs $\left(\mathrm{TiO}_{2-x} \mathrm{C}_{x}\right)$ as the anode (S1) and Pt NPs incorporated in TNTs as the cathode (S2) delivers a photocurrent of approximately $2.5-2.8 \mathrm{~mA} \mathrm{~cm}^{-2}$ and can run continuously for approximately $80 \mathrm{~h}$ for visiblelight water splitting. ${ }^{[22]}$ Following this route, various Z-scheme cells have been built, such as $\mathrm{n}-\mathrm{TiO}_{2} \mathrm{NRs} / \mathrm{FTO}$ (S1) and C/p-

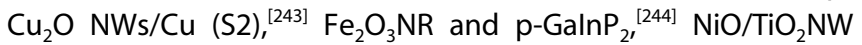
and $\mathrm{Pt} \mathrm{NP} / \mathrm{Si} \mathrm{NW}^{[245]} \mathrm{TiO}_{2}$ /indium tin oxide (ITO) and $\mathrm{Bi}$ $\mathrm{O}_{1-x} \mathrm{Cl}_{1-\mathrm{y}} / \mathrm{ITO}^{[246]} \mathrm{ZnS} / \mathrm{CdS} / \mathrm{TiO}_{2} / \mathrm{TCO}$ and $\mathrm{MoS}_{2} / \mathrm{CdS} / \mathrm{TiO}_{2} /$ $\mathrm{TCO}^{[247]} \mathrm{CdS} / \mathrm{TiO}_{2} \mathrm{NRs}$ and $\mathrm{CdSe} / \mathrm{NiO},{ }^{[241 \mathrm{~b}]}$ and $\mathrm{BiVO}_{4}$ and $\mathrm{Cu}_{2}{ }{ }^{[248]}$ The cells normally exhibit STF efficiencies in the range of approximately $0.1 \%$ or less. A self-driven cell with $\mathrm{CdS} / \mathrm{TiO}_{2} \mathrm{NR}$ as the anode and $\mathrm{CdSe} / \mathrm{NiO}$ as the cathode shows a maximum efficiency of $0.17 \%$ for overall water splitting. Average gas evolution rates of $2.24 \quad\left(\mathrm{H}_{2}\right)$ and 1.07 $\left(\mathrm{O}_{2}\right) \mu \mathrm{molh}^{-1} \mathrm{~cm}^{-2}$ are achieved with approximately $95 \%$ faradic efficiency. ${ }^{[24 \mathrm{~b}]}$ A higher STF efficiency of approximately $0.91 \%$ is obtained by using a hematite anode and an amorphous $\mathrm{Si}$ cathode with $\mathrm{NiFeO}_{x}$ and $\mathrm{Pt} / \mathrm{TiO}_{2}$ overlayers. ${ }^{[249]} \mathrm{Re}-$ cently, a dual PE device consisting of a metal nitride NW anode and a Si/InGaN NW cathode has been reported to provide a power conversion efficiency of $2 \% .{ }^{[241 a]}$ Pairing the PE with a PV as Z-scheme electrodes further improves the configuration. Overall water splitting with a STF efficiency of approximately $2.5 \%$ is achieved by a device consisting of an anode (FeOOH/Mo:BiVO $/ 4$ FTO) and a Ni/Si-cell/FTO cathode. ${ }^{[250]}$

Reduction of $\mathrm{CO}_{2}$ to formate by using $\mathrm{H}_{2} \mathrm{O}$ as an electron donor and a proton source has been realized in a Z-scheme device (Figure $7 \mathrm{~d}$ ). ${ }^{[251]}$ In this device, the conjugating p-type InP/Ru complex polymer and $\mathrm{TiO}_{2} / \mathrm{Pt}$ are used as the working and counter electrodes. The selectivity for formate production is above $70 \%$, and the STF efficiency is $0.03-0.04 \%$. However, reduction of $\mathrm{CO}_{2}$ by using a p-type semiconductor requires a large bias potential, as the VB potentials of these semiconductor are not positive enough to oxidize water. ${ }^{[251]}$ Some ntype semiconductors are stable in aqueous solutions and are active under visible light with a relatively low bias potential. PEC systems with n-type $\mathrm{WO}_{3}$ as the photoanode and $\mathrm{Cu}$ or $\mathrm{SnO}_{x} / \mathrm{Sn}$ as the cathode electrocatalyst have been demonstrated to achieve $\mathrm{CO}_{2}$ reduction at low bias potentials. ${ }^{[252]} \mathrm{A}$ highly calorific product such as methane, which requires eight electrons, is obtained at a faradaic efficiency of $67 \%$ with a total $\mathrm{CO}_{2}$ reduction faradaic efficiency of $71.6 \%$ on a $\mathrm{Cu}$ cathode. For the $\mathrm{SnO}_{x} / \mathrm{Sn}$ cathode, a combined $(\mathrm{CO}+\mathrm{HCOOH})$ faradaic efficiency of $44.3 \%$ is obtained at $+0.8 \mathrm{~V}$. This verifies that judicious integration of a light-absorbing anode and a cathode cocatalyst can accomplish the reduction of $\mathrm{CO}_{2}$ with high efficiency. 


\subsubsection{Monolithic cells}

\subsubsection{Photoelectrochemical diodes}

Tandem absorbers have been applied in self-biasing systems. ${ }^{[97,184,253]}$ The photoanode (S1) and photocathode (S2) can be integrated into a monolithic structure (so-called diode) either by stacking the two electrodes on the same substrate or by joining them together by a PCM (Figure 7e). This monolithic cell has been observed to generate $\mathrm{H}_{2}$ by simply loading it in any water container. ${ }^{[254]}$ The products are separated on both sides of the assembly. Such a strategy is successful in meterscale panels, for which ionic transport over macroscopic distances is assumed to experience a tremendous ohmic loss. The trade-off between proton-transport distance and product separation limits the panel size. Haussener et al. have calculated the size of the standalone device and have concluded that to avoid excessive overpotentials the typical electrode size should not exceed approximately $10 \mathrm{~mm} \cdot{ }^{[255]}$

The photochemical diode was first reported in $1977 . .^{[253 \mathrm{~d}]}$ Later, an assembly of Si-PV junctions was built to produce hydrogen at $7.8 \%$ efficiency. ${ }^{[256]} \mathrm{A}$ similar device with earth-abundant catalysts has been examined in a neutral electrolyte with an efficiency of $2.5 \% .{ }^{[253 j]}$ Two-photon diodes based on metaloxide nanotubes have recently been reported. ${ }^{[97,253 f, 9,257]} \mathrm{A}$ n$\mathrm{TiO}_{2}$ nanotubes/p-Cu-Ti-O nanotubes PEC diode has been integrated with glass substrates oriented back to back. Light is incident on the UV-absorbing $\mathrm{n}-\mathrm{TiO}_{2}$ side and the visible light passes to the $\mathrm{p}-\mathrm{Cu}-\mathrm{Ti}-\mathrm{O}$ side. The $\mathrm{TiO}_{2}$ side of the diode is kept in $1 \mathrm{M} \mathrm{KOH}$ and the $\mathrm{Cu}-\mathrm{Ti}-\mathrm{O}$ side is kept in $0.1 \mathrm{M} \mathrm{Na} \mathrm{HPO}_{4}$ with a salt bridge linking the two sides. The reactions are powered by incident light to generate fuel with $\mathrm{O}_{2}$ evolved from the $\mathrm{TiO}_{2}$ side and $\mathrm{H}_{2}$ evolved from the $\mathrm{p}-\mathrm{Cu}-\mathrm{Ti}-\mathrm{O}$ side. A photocurrent density of $0.25 \mathrm{~mA} \mathrm{~cm}^{-2}$ is obtained with a photoconversion efficiency of $0.3 \% .{ }^{[253 f]}$ The same group further proposes a ternary oxide nanotube array with a gradient composition to absorb light over different wavelengths (Figure $7 \mathrm{f}$ ). ${ }^{[253 g]}$ Analysis shows that the use of a large-band-gap material in the photocathode instead of in the photoanode is desirable. ${ }^{[184]}$

To promote $\mathrm{CO}_{2}$ reduction, a PEC diode has been designed in which the anode and cathode are separated by a PCM. The anode consists of doped TNTs for light harvesting, electron transport, and proton diffusion. The cathodic $\mathrm{CO}_{2}$ reduction is based on $\mathrm{Fe} / \mathrm{N}$-doped carbon nanotubes deposited over a carbon cloth $^{[253]}$ or Pt-modified RGO loaded on nickel foam. ${ }^{[253 c, \text { e] }}$ Although these devices are able to limit charge recombination, reduce the energy input, and increase the efficiency of $\mathrm{CO}_{2}$ reduction, a bias of approximately $2.0 \mathrm{~V}$ is required on the basis of the redox reduction to separate the electrons and holes. The thin-film PV provides sufficient potential for the reactions, and a standalone device has shown a conversion efficiency of approximately $4.5 \% .{ }^{[258]}$ Unassisted twophoton devices with a wireless or wired configuration have been reported to produce solar formate with a $\operatorname{lnP} /[\mathrm{RuCP}]$ semiconductor/metal-complex cathode and $\mathrm{SrTiO}_{3}$ anode. ${ }^{[253 b, h, 259]}$ Electron transfer over the devices leads to STF efficiencies of 0.14 and $0.08 \%$ in the wired and wireless configura- tions, respectively. This indicates that the design of the band configuration is crucial for solar formate production.

\subsubsection{All-in-one membranes}

If photoactive components are extremely small NWs or NPs, they can be imbedded in a membrane as an integral part of the interface (Figure 7g). ${ }^{[260]}$ Two types of such all-in-one membranes have been reported: a multifunctional membrane embedded with Si microwires and fuel-cell-like cells comprising porous electrodes. ${ }^{[19 a, b, 261]}$ This concept offers assemblies with good light-harvesting capabilities and the possibility to tune each side individually. One or both electrodes can be exposed to the gas phase, and even flue gas or atmospheric $\mathrm{CO}_{2}$ can be used as the input stream for the cathode side. The efficiency does not decrease if the size of cell increases. ${ }^{[19 a]}$ However, the membrane is easily poisoned in acidic or alkaline media. Thus, there is a strong need for research on multifunctional interfaces.

The Joint Center for Artificial Photosynthesis has developed a multifunctional membrane embedded with Si microwires. The concept modules use two different semiconductors, a wider band-gap anode material, and a narrower band-gap cathode material to yield a potential $>1.23 \mathrm{~V}$, which is necessary for water photolysis. Cocatalysts distributed along the semiconductor surface facilitate the reactions at low overpotentials, and two PEs are connected by a thin poly(3,4-ethylenedioxythiophene)-polystyrene sulfonate (PEDOT-PSS) layer (Figure 7h). ${ }^{[262]}$ A crucial component is a Nafion proton-exchange polymer membrane. ${ }^{[261 c, 263]}$ The membrane serves as a structural support for the silicon microwires, allows efficient proton transport while avoiding product crossover, offers an electric interconnection between the anode and cathode, and also is transparent for red wavelength photons. A second concept module, built by using experience obtained from fuel cells, imposes less stringent requirements on the interface. In such an assembly, the carbon-based gas-diffusion electrode is coated with semiconductor nanoparticles, and the counter electrode consists of metal nanoparticles deposited on a carbon substrate. ${ }^{[261 d, e]}$ A similar concept has been adopted to design active heterostructures that consist of a semiconductor light absorber for oxidation and alumina-coated cocatalysts for reduction. A free-floating device produces $\mathrm{H}_{2}$ at a stable rate over $24 \mathrm{~h}$ with visible light as the only input and a STF efficiency of approximately $0.9 \%$. $^{\text {[261a] }}$

PEs loaded with suitable cocatalysts are important for redox reactions, and integrating the components together into a standalone device is an enormous challenge. ${ }^{[8 c, 19 a, 261 c]} \mathrm{A} \mathrm{p}$ type Si nanopillar loaded with $\left[\mathrm{Mo}_{3} \mathrm{~S}_{4}\right]$ clusters has been embedded in a PCM for harvesting low-energy photons in the solar spectrum. The assembly is an efficient photocathode for hydrogen generation in an aqueous $1.0 \mathrm{M} \mathrm{HClO}_{4}$ solution, and it can achieve a photocurrent density as high as $9 \mathrm{mAcm}^{-2}$ with zero overpotential. ${ }^{[16]}$ This is sufficient to achieve a STF efficiency of $10 \%$ in a two-photon cell. The measured amount of hydrogen roughly matches half the number of electrons passed through the circuit, which confirms that the photocur- 
rent is indeed due to photocatalytic hydrogen evolution and is not from reduction of the $\mathrm{Mo}_{3} \mathrm{~S}_{4}$ clusters. Although these promising devices have been demonstrated, none of the current cells fulfill the requirements for practical application. Device modeling and thin-film deposition techniques are necessary methods to build future assemblies. ${ }^{[255,264]}$

\section{Summary and Outlook}

We reviewed general strategies to construct two-photon semiconducting structures toward solar-fuel applications. Particularly, we focused our discussion on essential models that dictate the performance of this technique: the indirect combination of two semiconductors by a redox couple, direct coupling of two semiconductors, multicomponent structures with a solid conductive mediator, and composite photoelectrodes together with two-photon cells. Photocatalytic and photoelectrochemical examples were selected to demonstrate these concepts from a system-level angle, and this included semiconductor particles in aqueous solution, heterogeneous photoelectrodes, and complete devices for water splitting or $\mathrm{CO}_{2}$ conversion. Various charge-extraction schemes in solution contact systems, multicomponent structures, nanostructured photoelectrodes and photovoltaic-photoelectrochemical devices, Z-scheme cells, and monolithic cells were reviewed. Successful creation of these structures will enable us to better control local photochemical environments and will be helpful to deepen the comprehension of charge transport and utilization in the processes.

Apparent quantum yields based on various photocatalytic systems were extracted from selected articles and are shown in Figure $8 \mathrm{a}$, and the solar-to-fuel conversion rates of related photoelectrochemical systems are plotted in Figure $8 \mathrm{~b}$. It would be more reasonable to compare the efficiencies and product yields over various systems, but such data is not readily available. The values presented are to show typical yields and are dependent upon many variables such as materials and structures, light intensity and wavelength, electrical bias, and electrolyte. In general, the rational design of functional structures that are analogous to biological systems is a promising way to improve activity. By steering charge transport, one can rationally design semiconducting structures according to specific demands. Solid-state two- or three-component semiconducting structures exhibit better performance than solutioncontact structures. Optimization of the three-component structure should create great opportunity for further improvements.
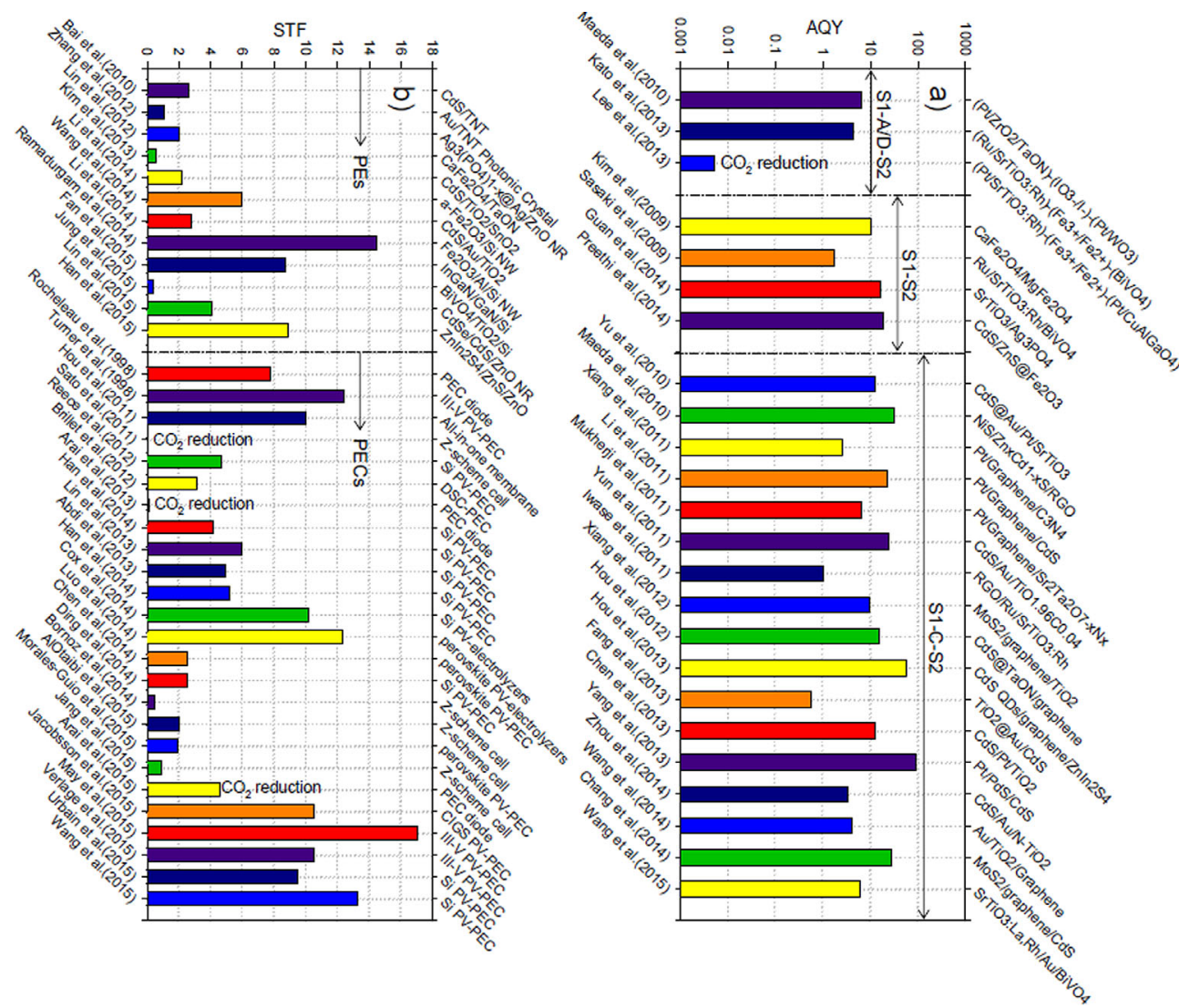

Figure 8. a) The reported apparent quantum yields on a semilogarithmic scale for photocatalytic fuel generation. b) The reported solar-to-fuel conversion efficiencies of photoelectrosynthesis. Values were taken from references given in the article. Note: Apparent quantum yields $A Q Y \%=($ number of reacted electrons) $/$ (number of incident photons) $\times 100 \%=$ (number of evolved hydrogen molecules $\times 2$ )/(number of incident photons) $\times 100 \%$. Solar-to-fuel (STF) conversion efficiency $=$ (output energy of hydrogen evolved) $/($ energy of incident solar light $) \times 100 \%=\left[I_{\text {ph }}\left(1.23-V_{\text {bias }}\right) \eta_{\mathrm{F}}\right] / P_{\text {in }}=[($ mean rate of products produced in $\left.\left.\mathrm{mmols}^{-1}\right) \times 273 \mathrm{~kJ} \mathrm{~mol}^{-1}\right] /\left[\left(\right.\right.$ light intensity in $\left.\mathrm{mW} \mathrm{cm}{ }^{-2}\right) \times\left(\right.$ area in $\left.\left.\mathrm{cm}^{2}\right)\right] \times 100 \%$, in which $I_{\mathrm{ph}}$ is the short-circuit photocurrent density (mA $\left.\mathrm{cm}^{-2}\right), \eta_{\mathrm{F}}$ is the faradaic efficiency and is defined as the moles of electrons consumed in the formation of the reaction product over the total moles of electrons transferred from the anode to the cathode, and $P_{\text {in }}$ is the incident light power intensity on the $\mathrm{PE}\left(\mathrm{mW} \mathrm{cm}^{-2}\right)$. 
Reported STF efficiencies of PEC structures vary from below 1 to $18 \%$; only a few multijunction PEC cells demonstrate a value above $10 \%$. Compositionally integrating different materials [e.g., p-type or n-type semiconductor(s)/graphene/ metals/quantum dots, etc.] with various building blocks (from nanoparticles, 1D nanowires/nanorods/nanotubes, 2D nanosheets to $3 \mathrm{D}$ porous or complex nanostructure) to build spatially functional structures was shown to improve light absorption and to facilitate microscopic charge transfer. Metals both in direct contact with the light absorber and in a separate but electrically connected cell serve as electron sinks and catalysts. The engineering of special interfaces to form efficient interactions such as heterojunctions and Schottky and ohmic junctions offers an effective tool to enhance charge separation and to extend charge lifetimes. Strategies to separate charges in Zscheme catalysts and surface passivation layers require further study to understand the mechanism. The roles of plasmonic and high-energy hot electrons represent recent breakthroughs concerning our understanding of charge transfer, and more work should be paid to fully realize their potential.

Although great effort has been devoted to finding combinations of materials to steer charge transport for photosynthetic systems, much of this domain has yet to be explored. Future prospects are likely to focus on essential interface properties of the junctions and on the design of well-defined structures for optimal control of the rate, yield, and energetics of the charge carrier flow at the nanoscale so that the complete structures can achieve maximum conversion of solar energy into chemical fuels. Novel structure designs and controlled synthesis and assembly through advanced manufacturing processes such as wet-chemical synthesis with micro/nanofabrication, deposition of low-costing materials, and large-scale self-assembly will be required to meet the technology goals. This work is helpful to understand the mechanism of charge transport in semiconducting structures, and the complied information can be used to evaluate progress in the solar-fuel field and to target a research direction for future development.

\section{Acknowledgements}

The authors acknowledge financial support from the Norwegian Research Council-Independent Projects - Mathematics, Physical Science and Technology (FRINATEK) Programme (231416/F20) and the European Economic Area (EEA)-Poland (237761) Program. G.H.L. is also thankful for support from the Nature Science Foundation of China (51576002) and the Leading Talent Team in Universities of Anhui Province.

\section{Keywords: charge transport - heterojunctions photosynthesis $\cdot$ semiconductors $\cdot$ solar fuels}

[1] a) S. Chu, A. Majumdar, Nature 2012, 488, 294-303; b) N. S. Lewis, D. G. Nocera, Proc. Natl. Acad. Sci. USA 2006, 103, 15729-15735.

[2] N. S. Lewis, Science 2016, 351, aad1920.

[3] a) W. Tu, Y. Zhou, Z. Zou, Adv. Mater. 2014, 26, 4607-4626; b) Y. Tachibana, L. Vayssieres, J.R. Durrant, Nat. Photonics 2012, 6, 511-518; c) J. L. White, M. F. Baruch, J. E. Pander, III, Y. Hu, I. C. Fortmeyer, J. E.
Park, T. Zhang, K. Liao, J. Gu, Y. Yan, T. W. Shaw, E. Abelev, A. B. Bocarsly, Chem. Rev. 2015, 115, 12888-12935; d) Y. Ma, X. Wang, Y. Jia, X. Chen, H. Han, C. Li, Chem. Rev. 2014, 114, 9987-10043; e) www.rsc.org/solarfuels, 2012; f) X. Li, J. Yu, J. Low, Y. Fang, J. Xiao, X. Chen, J. Mater. Chem. A 2015, 3, 2485-2534; g) G. Liu, N. Hoivik, K. Wang, H. Jakobsen, Sol. Energy Mater. Sol. Cells 2012, 105, 53-68; h) A. Fujishima, K. Honda, Nature 1972, 238, 37-38; i) T. Inoue, A. Fujishima, S. Konishi, K. Honda, Nature 1979, 277, 637-638.

[4] a) J. Ran, J. Zhang, J. Yu, M. Jaroniec, S. Z. Qiao, Chem. Soc. Rev. 2014, 43, 7787-7812; b) S. J. A. Moniz, S. A. Shevlin, D. J. Martin, Z.-X. Guo, J. Tang, Energy Environ. Sci. 2015, 8, 731-759; c) A. Kudo, Y. Miseki, Chem. Soc. Rev. 2009, 38, 253-278; d) K. Sivula, R. van de Krol, Nat. Rev. Mater. 2016, 1, 15010.

[5] a) P. D. Tran, L. H. Wong, J. Barber, J. S. C. Loo, Energy Environ. Sci. 2012, 5, 5902; b) X. Chen, S. Shen, L. Guo, S. S. Mao, Chem. Rev. 2010, 110,6503-6570; c) H. Zhou, Y. Qu, T. Zeid, X. Duan, Energy Environ. Sci. 2012, 5, 6732 .

[6] a) A. V. Akimov, A. J. Neukirch, O. V. Prezhdo, Chem. Rev. 2013, 113 4496-4565; b) S. C. Warren, K. Voitchovsky, H. Dotan, C. M. Leroy, M. Cornuz, F. Stellacci, C. Hebert, A. Rothschild, M. Grätzel, Nat. Mater. 2013, 12, 842-849; c) B. A. Pinaud, J. D. Benck, L. C. Seitz, A. J. Forman, Z. Chen, T. G. Deutsch, B. D. James, K. N. Baum, G. N. Baum, S. Ardo, H. Wang, E. Miller, T. F. Jaramillo, Energy Environ. Sci. 2013, 6, 1983.

[7] P. Liao, E. A. Carter, Chem. Soc. Rev. 2013, 42, 2401-2422.

[8] a) S. Dahl, I. Chorkendorff, Nat. Mater. 2012, 11, 100-101; b) Z. Huang, C. Xiang, H.-J. Lewerenz, N. S. Lewis, Energy Environ. Sci. 2014, 7, 1207-1211; c) J. R. McKone, N. S. Lewis, H. B. Gray, Chem. Mater. 2014, 26, 407-414.

[9] a) G. F. Moore, G. W. Brudvig, Annu. Rev. Condens. Matter Phys. 2011, 2, $303-327$; b) H. Zhou, X. Li, T. Fan, F. E. Osterloh, J. Ding, E. M. Sabio, D. Zhang, Q. Guo, Adv. Mater. 2010, 22, 951 -956; c) J. J. Concepcion, R. L. House, J. M. Papanikolas, T. J. Meyer, Proc. Natl. Acad. Sci. USA 2012, 109, 15560-15564; d) S. Bensaid, G. Centi, E. Garrone, S. Perathoner, G. Saracco, ChemSusChem 2012, 5, 500-521.

[10] a) K. Maeda, R. Abe, K. Domen, J. Phys. Chem. C 2011, 115, 3057-3064; b) D. J. Martin, P. J. Reardon, S. J. Moniz, J. Tang, J. Am. Chem. Soc. 2014, 136, 12568-12571.

[11] a) F. Peng, Q. Zhou, D. Zhang, C. Lu, Y. Ni, J. Kou, J. Wang, Z. Xu, Appl. Catal. B 2015, 165, 419-427; b) W. Yan, Y. Zhang, W. Xie, S. Sun, J. Ding, J. Bao, C. Gao, J. Phys. Chem. C 2014, 118, 6077-6083.

[12] a) H. Tada, T. Mitsui, T. Kiyonaga, T. Akita, K. Tanaka, Nat. Mater. 2006, 5, 782-786; b) A. Iwase, Y. H. Ng, Y. Ishiguro, A. Kudo, R. Amal, J. Am. Chem. Soc. 2011, 133, 11054-11057.

[13] Y. Hou, F. Zuo, A. Dagg, P. Feng, Nano Lett. 2012, 12, 6464-6473.

[14] A. Paracchino, V. Laporte, K. Sivula, M. Grätzel, E. Thimsen, Nat. Mater. 2011, 10, 456-461.

[15] F. F. Abdi, L. Han, A. H. Smets, M. Zeman, B. Dam, R. van de Krol, Nat. Commun. 2013, 4, 2195.

[16] Y. Hou, B. L. Abrams, P. C. Vesborg, M. E. Bjorketun, K. Herbst, L. Bech, A. M. Setti, C. D. Damsgaard, T. Pedersen, O. Hansen, J. Rossmeisl, S. Dahl, J. K. Norskov, I. Chorkendorff, Nat. Mater. 2011, 10, 434-438.

[17] a) R. Abe, J. Photochem. Photobiol. C 2010, 11, 179-209; b) K. Maeda, ACS Catal. 2013, 3, 1486-1503.

[18] a) P. Zhou, J. Yu, M. Jaroniec, Adv. Mater. 2014, 26, 4920-4935; b) H. Li, Y. Zhou, W. Tu, J. Ye, Z. Zou, Adv. Funct. Mater. 2015, 25, 998-1013.

[19] a) J. Rongé, T. Bosserez, D. Martel, C. Nervi, L. Boarino, F. Taulelle, G. Decher, S. Bordiga, J. A. Martens, Chem. Soc. Rev. 2014, 43, 7963-7981; b) K. S. Joya, Y. F. Joya, K. Ocakoglu, R. van de Krol, Angew. Chem. Int. Ed. 2013, 52, 10426-10437; Angew. Chem. 2013, 125, 10618-10630; c) Z. Xing, X. Zong, J. Pan, L. Wang, Chem. Eng. Sci. 2013, 104, $125-$ 146.

[20] H. Park, H.-i. Kim, G.-h. Moon, W. Choi, Energy Environ. Sci. 2016, 9, $411-433$.

[21] a) K. Kalyanasundaram, M. Graetzel, Curr. Opin. Biotechnol. 2010, 21, 298-310; b) J. Barber, P. D. Tran, J. R. Soc. Interface 2013, 10, 20120984; c) J. Barber, Chem. Soc. Rev. 2009, 38, 185-196.

[22] A. D. Handoko, K. Li, J. Tang, Curr. Opin. Chem. Eng. 2013, 2, 200-206.

[23] R. Marschall, Adv. Funct. Mater. 2014, 24, $2421-2440$.

[24] Y.-P. Yuan, L.-W. Ruan, J. Barber, S. C. Joachim Loo, C. Xue, Energy Environ. Sci. 2014, 7, 3934-3951.

[25] A. Kudo, MRS Bull. 2011, 36, 32-38. 
[26] A. J. Bard, J. Photochem. 1979, 10, 59-75.

[27] a) R. Abe, M. Higashi, K. Domen, ChemSusChem 2011, 4, 228-237; b) K. Maeda, M. Higashi, D. L. Lu, R. Abe, K. Domen, J. Am. Chem. Soc. 2010, 132, 5858-5868.

[28] M. Tabata, K. Maeda, M. Higashi, D. Lu, T. Takata, R. Abe, K. Domen, Langmuir 2010, 26, $9161-9165$

[29] a) K. Maeda, D. Lu, K. Domen, ACS Catal. 2013, 3, 1026-1033; b) M. Higashi, R. Abe, T. Takata, K. Domen, Chem. Mater. 2009, 21, 1543-1549.

[30] S. Hara, M. Yoshimizu, S. Tanigawa, L. Ni, B. Ohtani, H. Irie, J. Phys. Chem. C 2012, 116, 17458-17463.

[31] a) R. Abe, K. Shinmei, N. Koumura, K. Hara, B. Ohtani, J. Am. Chem. Soc 2013, 135, 16872-16884; b) R. Abe, K. Shinmei, K. Hara, B. Ohtani, Chem. Commun. 2009, 3577-3579.

[32] a) J. Yang, D. Wang, H. Han, C. Li, Acc. Chem. Res. 2013, 46, 1900 1909 ; b) Y. Sasaki, A. Iwase, H. Kato, A. Kudo, J. Catal. 2008, 259, $133-$ 137.

[33] H. Kato, Y. Sasaki, N. Shirakura, A. Kudo, J. Mater. Chem. A 2013, 1, 12327.

[34] Y. Sasaki, H. Kato, A. Kudo, J. Am. Chem. Soc. 2013, 135, 5441-5449.

[35] B. Fujihara, T. Ohno, M. Matsumura, J. Chem. Soc. Faraday Trans. 1998 94, 3705-3709.

[36] S. W. Bae, S. M. Ji, S. J. Hong, J.W. Jang, J. S. Lee, Int. J. Hydrogen Energy 2009, 34, 3243-3249.

[37] a) C.-C. Lo, C.-W. Huang, C.-H. Liao, J. C. S. Wu, Int. J. Hydrogen Energy 2010, 35, 1523-1529; b) W.-H. Lee, C.-H. Liao, M.-F. Tsai, C.-W. Huang J. C. S. Wu, Appl. Catal. B 2013, 132-133, 445-451; c) S.-C. Yu, C.-W. Huang, C.-H. Liao, J. C. S. Wu, S.-T. Chang, K.-H. Chen, J. Membr. Sci. 2011, 382, $291-299$

[38] a) W. Fan, Q. Zhang, Y. Wang, Phys. Chem. Chem. Phys. 2013, 15, 2632 2649 ; b) S. Bai, J. Jiang, Q. Zhang, Y. Xiong, Chem. Soc. Rev. 2015, 44, $2893-2939$.

[39] X. Yao, T. Liu, X. Liu, L. Lu, Chem. Eng. J. 2014, 255, 28-39.

[40] a) H. N. Kim, T. W. Kim, I. Y. Kim, S.-J. Hwang, Adv. Funct. Mater. 2011, 21, 3111-3118; b) D. W. Jing, L. J. Guo, J. Phys. Chem. C 2007, 111, $13437-13441$.

[41] a) J. Ryu, S. H. Lee, D. H. Nam, C. B. Park, Adv. Mater. 2011, 23, 1883 1888; b) L. Long, X. Yu, L. Wu, J. Li, X. Li, Nanotechnology 2014, 25 , 035603; c) C. Li, J. Yuan, B. Han, L. Jiang, W. Shangguan, Int. J. Hydrogen Energy 2010, 35, 7073-7079.

42] Z. Zheng, W. Xie, Z. S. Lim, L. You, J. Wang, Sci. Rep. 2014, 4, 5721.

[43] X. Guan, L. Guo, ACS Catal. 2014, 4, 3020-3026.

[44] J. Lv, T. Kako, Z. S. Li, Z. G. Zou, J. H. Ye, J. Phys. Chem. C 2010, 114, 6157-6162.

[45] a) Z. Wang, A. Shakya, J. Gu, S. Lian, S. Maldonado, J. Am. Chem. Soc 2013, 135, 9275-9278; b) K. Zheng, K. Žídek, M. Abdellah, W. Zhang, P. Chábera, N. Lenngren, A. Yartsev, T. Pullerits, J. Phys. Chem. C 2014, $118,18462-18471$

[46] X. Li, H. Liu, D. Luo, J. Li, Y. Huang, H. Li, Y. Fang, Y. Xu, L. Zhu, Chem Eng. J. 2012, 180, $151-158$.

[47] C. Wang, R. L. Thompson, P. Ohodnicki, J. Baltrus, C. Matranga, J. Mater Chem. 2011, 21, 13452.

[48] M. Abou Asi, C. He, M. Su, D. Xia, L. Lin, H. Deng, Y. Xiong, R. Qiu, X.-z. Li, Catal. Today 2011, 175, 256-263.

[49] M. F. Ehsan, T. He, Appl. Catal. B 2015, 166-167, 345-352.

[50] M. F. Ehsan, M. N. Ashiq, F. Bi, Y. Bi, S. Palanisamy, T. He, RSC Adv. 2014 4, 48411-48418.

[51] K. Tvrdy, P. A. Frantsuzov, P. V. Kamat, Proc. Natl. Acad. Sci. USA 2011 $108,29-34$

[52] a) E. Najafi, T. D. Scarborough, J. Tang, A. Zewail, Science 2015, 347 164-167; b) S. Ida, A. Takashiba, S. Koga, H. Hagiwara, T. Ishihara, J. Am. Chem. Soc. 2014, 136, $1872-1878$.

[53] A. Kezzim, N. Nasrallah, A. Abdi, M. Trari, Energy Convers. Manage. 2011, 52, 2800-2806

[54] H. Xu, S. Ouyang, L. Liu, D. Wang, T. Kako, J. Ye, Nanotechnology 2014 25, 165402.

[55] A. Kubacka, M. J. Muñoz-Batista, M. Fernández-García, S. Obregón, G. Colón, Appl. Catal. B 2015, 163, 214-222.

[56] S. I. In, D. D. Vaughn, 2nd, R. E. Schaak, Angew. Chem. Int. Ed. 2012, 51 , 3915-3918; Angew. Chem. 2012, 124, 3981-3984.

[57] J. Zhang, S. Z. Qiao, L. Qi, J. Yu, Phys. Chem. Chem. Phys. 2013, 15, $12088-12094$.
[58] A. Nashim, K. Parida, J. Mater. Chem. A 2014, 2, 18405-18412.

[59] H. G. Kim, P. H. Borse, W. Choi, J. S. Lee, Angew. Chem. Int. Ed. 2005, 44 4585-4589; Angew. Chem. 2005, 117, $4661-4665$.

[60] H. G. Kim, P. H. Borse, J. S. Jang, E. D. Jeong, O. S. Jung, Y. J. Suh, J. S Lee, Chem. Commun. 2009, 5889-5891.

[61] J. Zhang, M. Zhang, R. Q. Sun, X. Wang, Angew. Chem. Int. Ed. 2012, 51, 10145-10149; Angew. Chem. 2012, 124, 10292-10296.

[62] Y. Wang, B. Li, C. Zhang, L. Cui, S. Kang, X. Li, L. Zhou, Appl. Catal. B 2013, 130-131, 277-284.

[63] G. Xi, S. Ouyang, J. Ye, Chem. Eur. J. 2011, 17, 9057-9061.

[64] L. Xu, J. Guan, L. Gao, Z. Sun, Catal. Commun. 2011, 12, 548-552.

[65] J. Chen, S. Shen, P. Guo, M. Wang, P. Wu, X. Wang, L. Guo, Appl. Catal. B 2014, $152-153,335-341$.

[66] S.-W. Cao, X.-F. Liu, Y.-P. Yuan, Z.-Y. Zhang, Y.-S. Liao, J. Fang, S. C. J. Loo, T. C. Sum, C. Xue, Appl. Catal. B 2014, 147, 940-946.

[67] S. Zhou, Y. Liu, J. Li, Y. Wang, G. Jiang, Z. Zhao, D. Wang, A. Duan, J. Liu, Y. Wei, Appl. Catal. B 2014, 158-159, 20-29.

[68] Y. He, Y. Wang, L. Zhang, B. Teng, M. Fan, Appl. Catal. B 2015, 168-169, $1-8$.

[69] a) L. Xu, E. M. P. Steinmiller, S. E. Skrabalak, J. Phys. Chem. C 2012, 116, $871-877$; b) N. Siedl, S. O. Baumann, M. J. Elser, O. Diwald, J. Phys. Chem. C 2012, 116, 22967-22973.

[70] J. Yan, G. Wu, N. Guan, L. Li, Appl. Catal. B 2014, 152-153, 280-288.

[71] P. Dhanasekaran, H. G. Salunke, N. M. Gupta, J. Phys. Chem. C 2012 $116,12156-12164$.

[72] Q. Tian, W. Wu, L. Sun, S. Yang, M. Lei, J. Zhou, Y. Liu, X. Xiao, F. Ren, C. Jiang, V. A. Roy, ACS Appl. Mater. Interfaces 2014, 6, 13088-13097.

[73] J. Sun, X. Li, Q. Zhao, J. Ke, D. Zhang, J. Phys. Chem. C 2014, 118, $10113-10121$

[74] V. Preethi, S. Kanmani, Int. J. Hydrogen Energy 2014, 39, 1613-1622.

[75] E. A. Kozlova, D. V. Markovskaya, S. V. Cherepanova, A. A. Saraev, E. Y. Gerasimov, T. V. Perevalov, V. V. Kaichev, V. N. Parmon, Int. J. Hydrogen Energy 2014, 39, 18758-18769.

[76] X. Wang, J. Chen, X. Guan, L. Guo, Int. J. Hydrogen Energy 2015, 40, $7546-7552$

[77] J.-P. Zou, S.-L. Lei, J. Yu, S.-L. Luo, X.-B. Luo, X.-H. Tang, W.-L. Dai, J. Sun G.-C. Guo, C.-T. Au, Appl. Catal. B 2014, 150-151, 466-471.

[78] T. P. Lyubina, D. V. Markovskaya, E. A. Kozlova, V. N. Parmon, Int. J. Hydrogen Energy 2013, 38, 14172-14179.

[79] Z.-J. Jiang, D. F. Kelley, J. Phys. Chem. C 2012, 116, 12958-12968.

[80] D. Perera, R. Lorek, R. S. Khnayzer, P. Moroz, T. O'Connor, D. Khon, G. Diederich, E. Kinder, S. Lambright, F. N. Castellano, M. Zamkov, J. Phys. Chem. C 2012, 116, 22786-22793.

[81] S. Balachandran, N. Prakash, K. Thirumalai, M. Muruganandham, M. Sillanpää, M. Swaminathan, Ind. Eng. Chem. Res. 2014, 53, 8346-8356.

[82] J. Su, X.-X. Zou, G.-D. Li, X. Wei, C. Yan, Y.-N. Wang, J. Zhao, L.-J. Zhou, J.-S. Chen, J. Phys. Chem. C 2011, 115, 8064-8071.

[83] X. Li, J. Chen, H. Li, J. Li, Y. Xu, Y. Liu, J. Zhou, J. Nat. Gas Chem. 2011 $20,413-417$.

[84] a) H. Bai, Z. Liu, D. D. Sun, H. Du, J. Am. Ceram. Soc. 2013, 96, $942-$ $949 ;$ b) J. Ng, S. Xu, X. Zhang, H. Y. Yang, D. D. Sun, Adv. Funct. Mater. 2010, 20, 4287-4294.

[85] a) L. Huang, X. Wang, J. Yang, G. Liu, J. Han, C. Li, J. Phys. Chem. C 2013, 117, 11584-11591; b) P. Tongying, V. V. Plashnitsa, N. Petchsang, F. Vietmeyer, G. J. Ferraudi, G. Krylova, M. Kuno, J. Phys. Chem. Lett. 2012, 3, 3234-3240; c) J. Huang, K. L. Mulfort, P. Du, L. X. Chen, J. Am Chem. Soc. 2012, 134, 16472-16475.

[86] A. Thibert, F. A. Frame, E. Busby, M. A. Holmes, F. E. Osterloh, D. S Larsen, J. Phys. Chem. Lett. 2011, 2, 2688-2694.

[87] Z. Pan, H. Zhang, K. Cheng, Y. Hou, J. Hua, X. Zhong, ACS Nano 2012 6, $3982-3991$

[88] X. Yang, J. Xu, T. Wong, Q. Yang, C. S. Lee, Phys. Chem. Chem. Phys. 2013, 15, 12688-12693.

[89] E. Khon, K. Lambright, R. S. Khnayzer, P. Moroz, D. Perera, E. Butaeva, S. Lambright, F. N. Castellano, M. Zamkov, Nano Lett. 2013, 13, 2016 2023.

[90] K. Wu, Q. Li, Y. Jia, J. R. McBride, Z. X. Xie, T. Lian, ACS Nano 2015, 9 , $961-968$.

[91] a) G. Song, F. Xin, X. Yin, J. Colloid Interface Sci. 2015, 442, 60-66; b) F. $\mathrm{Xu}, \mathrm{W}$. Xiao, B. Cheng, J. Yu, Int. J. Hydrogen Energy 2014, 39, $15394-$ 
15402; c) X. Wang, G. Liu, Z. G. Chen, F. Li, L. Wang, G. Q. Lu, H. M. Cheng, Chem. Commun. 2009, 3452-3454.

[92] X. Wang, G. Liu, G. Q. Lu, H.-M. Cheng, Int. J. Hydrogen Energy 2010 35, 8199-8205.

[93] a) Y. Sasaki, H. Nemoto, K. Saito, A. Kudo, J. Phys. Chem. C 2009, 113, 17536-17542; b) Q. Jia, A. Iwase, A. Kudo, Chem. Sci. 2014, 5, 1513.

[94] L. J. Zhang, S. Li, B. K. Liu, D. J. Wang, T. F. Xie, ACS Catal. 2014, 4, $3724-3729$.

[95] H. Katsumata, Y. Tachi, T. Suzuki, S. Kaneco, RSC Adv. 2014, 4, 21405.

[96] Y. Peng, Z. Guo, J. Yang, D. Wang, W. Yuan, J. Mater. Chem. A 2014, 2, 6296.

[97] C. Liu, J. Tang, H. M. Chen, B. Liu, P. Yang, Nano Lett. 2013, 13, 2989 2992.

[98] D. O. Scanlon, C. W. Dunnill, J. Buckeridge, S. A. Shevlin, A. J. Logsdail, S. M. Woodley, C. R. Catlow, M. J. Powell, R. G. Palgrave, I. P. Parkin, G. W. Watson, T. W. Keal, P. Sherwood, A. Walsh, A. A. Sokol, Nat. Mater. 2013, 12, $798-801$

[99] a) G. Marcì, E. I. García-López, L. Palmisano, Catal. Commun. 2014, 53, 38-41; b) S. Qin, F. Xin, Y. Liu, X. Yin, W. Ma, J. Colloid Interface Sci. 2011, 356, 257-261; c) Y. He, L. Zhang, M. Fan, X. Wang, M. L. Walbridge, Q. Nong, Y. Wu, L. Zhao, Sol. Energy Mater. Sol. Cells 2015, 137, 175-184.

[100] a) Y. Liu, G. Ji, M. A. Dastageer, L. Zhu, J. Wang, B. Zhang, X. Chang, M. A. Gondal, RSC Adv. 2014, 4, 56961-56969; b) C. Liu, N. P. Dasgupta, P. Yang, Chem. Mater. 2014, 26, 415-422.

[101] a) H. Li, Y. Gao, Y. Zhou, F. Fan, Q. Han, Q. Xu, X. Wang, M. Xiao, C. Li, Z. Zou, Nano Lett. 2016, DOI: 10.1021/acs.nanolett.6b02094; b) H. Zhou, T. X. Fan, D. Zhang, ChemCatChem 2011, 3, 513-528.

[102] J. C. White, P. K. Dutta, J. Phys. Chem. C 2011, 115, 2938-2947.

[103] a) S. Linic, P. Christopher, D. B. Ingram, Nat. Mater. 2011, 10, 911-921; b) C. Clavero, Nat. Photonics 2014, 8, 95-103.

[104] a) K. Wu, Z. Chen, H. Lv, H. Zhu, C. L. Hill, T. Lian, J. Am. Chem. Soc. 2014, 136, 7708-7716; b) J. S. Jang, S. H. Choi, H. G. Kim, J. S. Lee, J. Phys. Chem. C 2008, 112, 17200-17205.

[105] a) H. Park, W. Choi, M. R. Hoffmann, J. Mater. Chem. 2008, 18, 2379; b) J. Chen, H. Su, Y. Liu, Y. Zeng, W. Zhang, J. Gu, W. M. Lau, D. Zhang, Int. J. Hydrogen Energy 2013, 38, 8639-8647.

[106] K. Li, B. Chai, T. Peng, J. Mao, L. Zan, ACS Catal. 2013, 3, 170-177.

[107] Y. Zhu, Z. Chen, T. Gao, Q. Huang, F. Niu, L. Qin, P. Tang, Y. Huang, Z. Sha, Y. Wang, Appl. Catal. B 2015, 163, 16-22.

[108] J. Yang, H. Yan, X. Wang, F. Wen, Z. Wang, D. Fan, J. Shi, C. Li, J. Catal. 2012, 290, 151-157.

[109] J. Fang, L. Xu, Z. Zhang, Y. Yuan, S. Cao, Z. Wang, L. Yin, Y. Liao, C. Xue, ACS Appl. Mater. Interfaces 2013, 5, 8088-8092.

[110] Y.-C. Chen, Y.-C. Pu, Y.-J. Hsu, J. Phys. Chem. C 2012, 116, 2967-2975.

[111] R. Zhang, J. Wang, P. Han, J. Alloys Compd. 2015, 637, 483-488.

[112] D. Wang, T. Hisatomi, T. Takata, C. Pan, M. Katayama, J. Kubota, K. Domen, Angew. Chem. Int. Ed. 2013, 52, 11252-11256; Angew. Chem. 2013, 125, $11462-11466$.

[113] a) T. O'Connor, M. S. Panov, A. Mereshchenko, A. N. Tarnovsky, R. Lorek D. Perera, G. Diederich, S. Lambright, P. Moroz, M. Zamkov, ACS Nano 2012, 6, 8156-8165; b) K. P. Acharya, R. S. Khnayzer, T. O'Connor, G. Diederich, M. Kirsanova, A. Klinkova, D. Roth, E. Kinder, M. Imboden, M. Zamkov, Nano Lett. 2011, 11, 2919-2926.

[114] S. Xie, Y. Wang, Q. Zhang, W. Fan, W. Deng, Y. Wang, Chem. Commun. 2013, 49, $2451-2453$.

[115] Q. Kang, T. Wang, P. Li, L. Liu, K. Chang, M. Li, J. Ye, Angew. Chem. Int. Ed. 2015, 54, 841-845; Angew. Chem. 2015, 127, 855-859.

[116] a) Q. Wang, X. Yang, D. Liu, L. Chi, J. Hou, Electrochim. Acta 2012, 83, $140-145$; b) K. Xie, Q. Wu, Y. Wang, W. Guo, M. Wang, L. Sun, C. Lin, Electrochem. Commun. 2011, 13, 1469-1472.

[117] Q. C. Xu, Y. H. Ng, Y. Zhang, J. S. Loo, R. Amal, T. T. Tan, Chem. Commun. 2011, 47, $8641-8643$

[118] Q. Wang, T. Hisatomi, S. S. K. Ma, Y. Li, K. Domen, Chem. Mater. 2014 $26,4144-4150$

[119] Q. Wang, Y. Li, T. Hisatomi, M. Nakabayashi, N. Shibata, J. Kubota, K. Domen, J. Catal. 2015, 328, 308-315.

[120] Q. Wang, T. Hisatomi, Q. Jia, H. Tokudome, M. Zhong, C. Wang, Z. Pan, T. Takata, M. Nakabayashi, N. Shibata, Y. Li, I. D. Sharp, A. Kudo, T. Yamada, K. Domen, Nat. Mater. 2016, 15, 611-615.
[121] Y. Yamada, C. K. Tsung, W. Huang, Z. Huo, S. E. Habas, T. Soejima, C. E. Aliaga, G. A. Somorjai, P. Yang, Nat. Chem. 2011, 3, 372-376.

[122] S. Sun, X. Chang, L. Dong, Y. Zhang, Z. Li, Y. Qiu, J. Solid State Chem. 2011, 184, 2190-2195.

[123] X. Hu, X. Zhou, R. Wang, C. Hu, J. Qu, Appl. Catal. B 2014, 154-155, 44-50.

[124] a) M. R. Elahifard, S. Rahimnejad, S. Haghighi, M. R. Gholami, J. Am. Chem. Soc. 2007, 129, 9552-9553; b) Y. Zhang, Z.-R. Tang, X. Fu, Y.-J. Xu, Appl. Catal. B 2011, 106, 445-452.

[125] a) Y. Hou, X. Li, Q. Zhao, G. Chen, C. L. Raston, Environ. Sci. Technol. 2012, 46, 4042-4050; b) Y. Hou, X. Li, Q. Zhao, X. Quan, G. Chen, J. Mater. Chem. 2011, 21, 18067.

[126] L. Zhang, K.-H. Wong, Z. Chen, J. C. Yu, J. Zhao, C. Hu, C.-Y. Chan, P.-K. Wong, Appl. Catal. A 2009, 363, $221-229$.

[127] Y. Yang, W. Guo, Y. Guo, Y. Zhao, X. Yuan, Y. Guo, J. Hazard. Mater. 2014, 271, 150-159.

[128] G. Tian, Y. Chen, X. Meng, J. Zhou, W. Zhou, K. Pan, C. Tian, Z. Ren, H. $\mathrm{Fu}$, ChemPlusChem 2013, 78, 117-123.

[129] Z. Chen, W. Wang, Z. Zhang, X. Fang, J. Phys. Chem. C 2013, 117, $19346-19352$.

[130] Y. Bu, Z. Chen, C. Sun, Appl. Catal. B 2015, 179, 363-371.

[131] H. Lin, J. Cao, B. Luo, B. Xu, S. Chen, Catal. Commun. 2012, 21, 91 - 95

[132] J. Song, Y. Shi, M. Ren, G. Hu, Appl. Phys. A 2014, 116, 2139-2147.

[133] R. Kobayashi, S. Tanigawa, T. Takashima, B. Ohtani, H. Irie, J. Phys. Chem. C 2014, 118, 22450-22456.

[134] Y. He, L. Zhang, B. Teng, M. Fan, Environ. Sci. Technol. 2015, 49, 649

[135] H. G. Kim, E. D. Jeong, P. H. Borse, S. Jeon, K. Yong, J. S. Lee, W. Li, S. H. Oh, Appl. Phys. Lett. 2006, 89, 064103.

[136] a) L. Ding, H. Zhou, S. Lou, J. Ding, D. Zhang, H. Zhu, T. Fan, Int. J. Hydrogen Energy 2013, 38, 8244-8253; b) H. Zhao, M. Wu, J. Liu, Z. Deng, Y. Li, B.-L. Su, Appl. Catal. B 2016, 184, 182-190.

[137] H. Zhou, L. Ding, T. Fan, J. Ding, D. Zhang, Q. Guo, Appl. Catal. B 2014, $147,221-228$.

[138] H. Zhou, J. Pan, L. Ding, Y. Tang, J. Ding, Q. Guo, T. Fan, D. Zhang, Int. J. Hydrogen Energy 2014, 39, $16293-16301$

[139] M. Kim, Y. K. Kim, S. K. Lim, S. Kim, S.-I. In, Appl. Catal. B 2015, 166 $167,423-431$.

[140] a) H. J. Yun, H. Lee, N. D. Kim, D. M. Lee, S. Yu, J. Yi, ACS Nano 2011, 5, 4084-4090; b) S. Yu, S. Y. Lee, J. Yeo, J. W. Han, J. Yi, J. Phys. Chem. C 2014, 118, 29583-29590.

[141] Z. B. Yu, Y. P. Xie, G. Liu, G. Q. Lu, X. L. Ma, H.-M. Cheng, J. Mater. Chem A 2013, 1, 2773.

[142] X. Wang, G. Liu, L. Wang, Z.-G. Chen, G. Q. M. Lu, H.-M. Cheng, Adv. Energy Mater. 2012, 2, 42-46.

[143] Q. Zhai, S. Xie, W. Fan, Q. Zhang, Y. Wang, W. Deng, Y. Wang, Angew. Chem. Int. Ed. 2013, 52, 5776-5779; Angew. Chem. 2013, 125, 58885891.

[144] Y. C. Wei, J. Q. Jiao, Z. Zhao, W. J. Zhong, J. M. Li, J. Liu, G. Y. Jiang, A. J. Duan, J. Mater. Chem. A 2015, 3, 11074-11085.

[145] a) K. Maeda, K. Teramura, D. Lu, N. Saito, Y. Inoue, K. Domen, Angew. Chem. Int. Ed. 2006, 45, 7806-7809; Angew. Chem. 2006, 118, 7970 7973; b) T. Ikeda, A. Xiong, T. Yoshinaga, K. Maeda, K. Domen, T. Teranishi, J. Phys. Chem. C 2013, 117, 2467-2473; c) M. Yoshida, K. Takanabe, K. Maeda, A. Ishikawa, J. Kubota, Y. Sakata, Y. Ikezawa, K. Domen J. Phys. Chem. C 2009, 113, 10151-10157.

[146] W. Li, C. Feng, S. Dai, J. Yue, F. Hua, H. Hou, Appl. Catal. B 2015, 168 $169,465-471$.

[147] O. K. Varghese, M. Paulose, T. J. Latempa, C. A. Grimes, Nano Lett. 2009, 9, $731-737$.

[148] a) B. Y. Zheng, H. Zhao, A. Manjavacas, M. McClain, P. Nordlander, N. J. Halas, Nat. Commun. 2015, 6, 7797; b) R. Long, K. Mao, M. Gong, S. Zhou, J. Hu, M. Zhi, Y. You, S. Bai, J. Jiang, Q. Zhang, X. Wu, Y. Xiong, Angew. Chem. Int. Ed. 2014, 53, 3205-3209; Angew. Chem. 2014, 126, 3269-3273; c) L. Weng, H. Zhang, A. O. Govorov, M. Ouyang, Nat. Commun. 2014, 5, 4792 .

[149] a) J. Zhang, C. Niu, J. Ke, L. Zhou, G. Zeng, Catal. Commun. 2015, 59, 30-34; b) Z. Li, J. Liu, D. Wang, Y. Gao, J. Shen, Int. J. Hydrogen Energy 2012, 37, 6431-6437; c) X. Wang, S. Li, Y. Ma, H. Yu, J. Yu, J. Phys. Chem. C 2011, 115, 14648-14655; d) J. Hou, Z. Wang, C. Yang, W. Zhou, S. Jiao, H. Zhu, J. Phys. Chem. C 2013, 117, 5132-5141; e) S. Yu, 
Y. H. Kim, S. Y. Lee, H. D. Song, J. Yi, Angew. Chem. Int. Ed. 2014, 53, 11203-11207; Angew. Chem. 2014, 126, 11385-11389; f) B. D. Mankidy, B. Joseph, V. K. Gupta, Nanotechnology 2013, 24, 405402; g) H. Cheng, J. Hou, H. Zhu, X.-M. Guo, RSC Adv. 2014, 4, 41622-41630; h) J. Hou, C. Yang, Z. Wang, Q. Ji, Y. Li, G. Huang, S. Jiao, H. Zhu, Appl. Catal. B 2013, 142-143, 579-589; i) L. Ye, J. Liu, C. Gong, L. Tian, T. Peng, L. Zan, ACS Catal. 2012, 2, 1677-1683; j) W.-J. Ong, L. K. Putri, L.-L. Tan, S.-P. Chai, S.-T. Yong, Appl. Catal. B 2016, 180, 530-543.

[150] a) A. K. Geim, Science 2009, 324, 1530-1534; b) K. S. Novoselov, V. I. Fal'ko, L. Colombo, P. R. Gellert, M. G. Schwab, K. Kim, Nature 2012, 490, $192-200$.

[151] a) G. Xie, K. Zhang, B. Guo, Q. Liu, L. Fang, J. R. Gong, Adv. Mater. 2013, 25, 3820-3839; b) W. Tu, Y. Zhou, Z. Zou, Adv. Funct. Mater. 2013, 23, $4996-5008$.

[152] I. V. Lightcap, T. H. Kosel, P. V. Kamat, Nano Lett. 2010, 10, 577-583.

[153] a) H. Li, X. Cui, Int. J. Hydrogen Energy 2014, 39, 19877-19886; b) L. Zhang, Z. Xi, M. Xing, J. Zhang, Int. J. Hydrogen Energy 2013, 38, 9169 9177.

[154] Q. Xiang, J. Yu, M. Jaroniec, J. Phys. Chem. C 2011, 115, 7355-7363.

[155] Q. Li, B. Guo, J. Yu, J. Ran, B. Zhang, H. Yan, J. R. Gong, J. Am. Chem. Soc. 2011, 133, 10878-10884

[156] A. Mukherji, B. Seger, G. Q. Lu, L. Z. Wang, ACS Nano 2011, 5, $3483-$ 3492.

[157] P. Gao, Z. Liu, D. D. Sun, J. Mater. Chem. A 2013, 1, 14262.

[158] X.-J. Lv, S.-X. Zhou, C. Zhang, H.-X. Chang, Y. Chen, W.-F. Fu, J. Mater. Chem. 2012, 22, 18542

[159] L.-L. Tan, W.-J. Ong, S.-P. Chai, A. R. Mohamed, Appl. Catal. B 2015, $166-167,251-259$

[160] J. Hou, H. Cheng, O. Takeda, H. Zhu, Angew. Chem. Int. Ed. 2015, 54, 8480-8484; Angew. Chem. 2015, 127, 8600-8604.

[161] Y. Hou, F. Zuo, Q. Ma, C. Wang, L. Bartels, P. Feng, J. Phys. Chem. C 2012, 116, 20132-20139.

[162] Y. Min, G. He, Q. Xu, Y. Chen, J. Mater. Chem. A 2014, 2, 1294-1301.

[163] Y. Wang, J. Yu, W. Xiao, Q. Li, J. Mater. Chem. A 2014, 2, 3847.

[164] Y. Yang, E. Liu, H. Dai, L. Kang, H. Wu, J. Fan, X. Hu, H. Liu, Int. J. Hydrogen Energy 2014, 39, 7664-7671.

[165] F. Meng, S. K. Cushing, J. Li, S. Hao, N. Wu, ACS Catal. 2015, 5, $1949-$ 1955.

[166] S. Song, B. Cheng, N. Wu, A. Meng, S. Cao, J. Yu, Appl. Catal. B 2016 $181,71-78$.

[167] H. Zhang, X. Fan, X. Quan, S. Chen, H. Yu, Environ. Sci. Technol. 2011, 45, $5731-5736$.

[168] Y. Yan, C. Wang, X. Yan, L. Xiao, J. He, W. Gu, W. Shi, J. Phys. Chem. C 2014, 118, 23519-23526.

[169] T. M. Suzuki, A. Iwase, H. Tanaka, S. Sato, A. Kudo, T. Morikawa, J. Mater. Chem. A 2015, 3, 13283-13290.

[170] K. Iwashina, A. Iwase, Y. H. Ng, R. Amal, A. Kudo, J. Am. Chem. Soc. 2015, 137, 604-607.

[171] a) X. Wang, X. Yao, Carbon 2014, 77, 667-674; b) X. Wang, L. Yin, G. Liu, Chem. Commun. 2014, 50, 3460-3463.

[172] P. Li, Y. Zhou, H. Li, Q. Xu, X. Meng, X. Wang, M. Xiao, Z. Zou, Chem. Commun. 2015, 51, 800-803.

[173] a) Q. Xiang, J. Yu, M. Jaroniec, J. Am. Chem. Soc. 2012, 134, 65756578 ; b) Y. Li, H. Wang, S. Peng, J. Phys. Chem. C 2014, 118, $19842-$ 19848 ; c) K. Chang, Z. Mei, T. Wang, Q. Kang, S. Ouyang, J. Ye, ACS Nano 2014, 8, 7078-7087; d) W. Han, C. Zang, Z. Huang, H. Zhang, L. Ren, X. Qi, J. Zhong, Int. J. Hydrogen Energy 2014, 39, 19502-19512; e) Y.-J. Yuan, J.-R. Tu, Z.-J. Ye, D.-Q. Chen, B. Hu, Y.-W. Huang, T.-T. Chen, D.-P. Cao, Z.-T. Yu, Z.-G. Zou, Appl. Catal. B 2016, 188, 13-22.

[174] S. Cao, Y. Chen, L. Kang, Z. Lin, W.-F. Fu, J. Mater. Chem. A 2015, 3, $18711-18717$

[175] X.-J. Lv, W.-F. Fu, C.-Y. Hu, Y. Chen, W.-B. Zhou, RSC Adv. 2013, 3, 1753.

[176] Z. Yan, X. Yu, A. Han, P. Xu, P. Du, J. Phys. Chem. C 2014, 118, $22896-$ 22903.

[177] Z. Mou, S. Yin, M. Zhu, Y. Du, X. Wang, P. Yang, J. Zheng, C. Lu, Phys. Chem. Chem. Phys. 2013, 15, 2793-2799.

[178] J. Hou, Z. Wang, W. Kan, S. Jiao, H. Zhu, R. V. Kumar, J. Mater. Chem. 2012, 22, 7291.

[179] J. Hou, C. Yang, H. Cheng, Z. Wang, S. Jiao, H. Zhu, Phys. Chem. Chem. Phys. 2013, 15, 15660-15668.
[180] B. Wang, Q. Sun, S. Liu, Y. Li, Int. J. Hydrogen Energy 2013, 38, 7232 7240.

[181] N. Zhang, Y. Zhang, X. Pan, M.-Q. Yang, Y.-J. Xu, J. Phys. Chem. C 2012, $116,18023-18031$.

[182] C. Han, Z. Chen, N. Zhang, J. C. Colmenares, Y.-J. Xu, Adv. Funct. Mater. 2015, 25, 221-229.

[183] J. Zhang, L. Qi, J. Ran, J. Yu, S. Z. Qiao, Adv. Energy Mater. 2014, 4, 1301925.

[184] B. Seger, I. E. Castelli, P. C. K. Vesborg, K. W. Jacobsen, O. Hansen, I. Chorkendorff, Energy Environ. Sci. 2014, 7, 2397-2413.

[185] a) M. G. Walter, E. L. Warren, J. R. McKone, S. W. Boettcher, Q. Mi, E. A. Santori, N. S. Lewis, Chem. Rev. 2010, 110, 6446-6473; b) S. Choudhary, S. Upadhyay, P. Kumar, N. Singh, V. R. Satsangi, R. Shrivastav, S. Dass, Int. J. Hydrogen Energy 2012, 37, 18713-18730; c) Z. Li, W. Luo, M. Zhang, J. Feng, Z. Zou, Energy Environ. Sci. 2013, 6, 347-370.

[186] E. S. Kim, N. Nishimura, G. Magesh, J. Y. Kim, J.W. Jang, H. Jun, J. Kubota, K. Domen, J. S. Lee, J. Am. Chem. Soc. 2013, 135, 5375-5383.

[187] J. Hou, C. Yang, H. Cheng, S. Jiao, O. Takeda, H. Zhu, Energy Environ. Sci. 2014, 7, 3758-3768.

[188] X. Chang, T. Wang, P. Zhang, J. Zhang, A. Li, J. Gong, J. Am. Chem. Soc. 2015, 137, 8356-8359.

[189] T. T. Guaraldo, J. F. d. Brito, D. Wood, M. V. B. Zanoni, Electrochim. Acta 2015, 185, 117-124.

[190] M. A. Mahadik, P. S. Shinde, M. Cho, J. S. Jang, Appl. Catal. B 2016, 184, $337-346$.

[191] H.-i. Kim, D. Monllor-Satoca, W. Kim, W. Choi, Energy Environ. Sci. 2015, 8, 247-257.

[192] a) P. M. Rao, L. Cai, C. Liu, I. S. Cho, C. H. Lee, J. M. Weisse, P. Yang, X. Zheng, Nano Lett. 2014, 14, 1099-1105; b) J. H. Kim, G. Magesh, H. J. Kang, M. Banu, J. H. Kim, J. Lee, J. S. Lee, Nano Energy 2015, 15, $153-$ 163; c) J. Su, L. Guo, N. Bao, C. A. Grimes, Nano Lett. 2011, 11, 1928 1933; d) A. Loiudice, J. K. Cooper, L. H. Hess, T. M. Mattox, I. D. Sharp, R. Buonsanti, Nano Lett. 2015, 15, 7347-7354.

[193] Y. Hou, F. Zuo, A. Dagg, P. Feng, Angew. Chem. Int. Ed. 2013, 52, $1248-$ 1252; Angew. Chem. 2013, 125, 1286- 1290.

[194] K. J. McDonald, K.-S. Choi, Chem. Mater. 2011, 23, 4863-4869.

[195] J. Hou, H. Cheng, O. Takeda, H. Zhu, Energy Environ. Sci. 2015, 8, $1348-1357$.

[196] Y. Hou, F. Zuo, A. P. Dagg, J. Liu, P. Feng, Adv. Mater. 2014, 26, $5043-$ 5049.

[197] M. T. Mayer, Y. Lin, G. Yuan, D. Wang, Acc. Chem. Res. 2013, 46, 15581566.

[198] L. Chen, J. Yang, S. Klaus, L. J. Lee, R. Woods-Robinson, J. Ma, Y. Lum, J. K. Cooper, F. M. Toma, L. W. Wang, I. D. Sharp, A. T. Bell, J. W. Ager, J. Am. Chem. Soc. 2015, 137, 9595-9603.

[199] Y. J. Hwang, A. Boukai, P. Yang, Nano Lett. 2009, 9, 410-415.

[200] a) M. T. Mayer, C. Du, D. Wang, J. Am. Chem. Soc. 2012, 134, $12406-$ 12409; b) X. Wang, K. Q. Peng, Y. Hu, F. Q. Zhang, B. Hu, L. Li, M. Wang, X. M. Meng, S. T. Lee, Nano Lett. 2014, 14, 18-23.

[201] S. Fan, B. AlOtaibi, S. Y. Woo, Y. Wang, G. A. Botton, Z. Mi, Nano Lett. 2015, 15, $2721-2726$.

[202] J. Chen, L. Zhang, Z. Lam, H. B. Tao, Z. Zeng, H. B. Yang, J. Luo, L. Ma, B. Li, J. Zheng, S. Jia, Z. Wang, Z. Zhu, B. Liu, J. Am. Chem. Soc. 2016, $138,3183-189$.

[203] Y. W. Chen, J. D. Prange, S. Duhnen, Y. Park, M. Gunji, C. E. Chidsey, P. C. Mclntyre, Nat. Mater. 2011, 10, 539-544.

[204] L. Ji, M. D. McDaniel, S. Wang, A. B. Posadas, X. Li, H. Huang, J. C. Lee, A. A. Demkov, A. J. Bard, J. G. Ekerdt, E. T. Yu, Nat. Nanotechnol. 2015, $10,84-90$.

[205] a) S. Hu, M. R. Shaner, J. A. Beardslee, M. Lichterman, B. S. Brunschwig, N. S. Lewis, Science 2014, 344, 1005-1009; b) Y. Lin, C. Battaglia, M Boccard, M. Hettick, Z. Yu, C. Ballif, J. W. Ager, A. Javey, Nano Lett. 2013, 13, 5615-5618.

[206] H. Jung, S. Y. Chae, C. Shin, B. K. Min, O. S. Joo, Y. J. Hwang, ACS Appl. Mater. Interfaces 2015, 7, 5788-5796.

[207] a) J. Bai, J. Li, Y. Liu, B. Zhou, W. Cai, Appl. Catal. B 2010, 95, 408-413; b) G. Ai, H. Li, S. Liu, R. Mo, J. Zhong, Adv. Funct. Mater. 2015, 25, 5706- 5713 .

[208] a) J. Hensel, G. Wang, Y. Li, J. Z. Zhang, Nano Lett. 2010, 10, 478-483; b) J. Luo, L. Ma, T. He, C. F. Ng, S. Wang, H. Sun, H. J. Fan, J. Phys Chem. C 2012, 116, 11956-11963. 
[209] Y.-L. Lee, C.-F. Chi, S.-Y. Liau, Chem. Mater. 2010, 22, 922 - 927.

[210] N. Srinivasan, Y. Shiga, D. Atarashi, E. Sakai, M. Miyauchi, Appl. Catal. B 2015, 179, 113-121

[211] S. Cheng, W. Fu, H. Yang, L. Zhang, J. Ma, H. Zhao, M. Sun, L. Yang, J. Phys. Chem. C 2012, 116, 2615-2621.

[212] a) X. Li, Z. Zhang, L. Chen, Z. Liu, J. Cheng, W. Ni, E. Xie, B. Wang, J. Power Sources 2014, 269, 866-872; b) C. Gao, Z. Zhang, X. Li, L. Chen Y. Wang, Y. He, F. Teng, J. Zhou, W. Han, E. Xie, Sol. Energy Mater. Sol. Cells 2015, 141, $101-107$.

[213] M. Seol, J.-W. Jang, S. Cho, J. S. Lee, K. Yong, Chem. Mater. 2013, 25, $184-189$.

[214] C.-J. Lin, L.-C. Kao, Y. Huang, M. A. Bañares, S. Y.-H. Liou, Int. J. Hydrogen Energy 2015, 40, 1388-1393.

[215] J. Han, Z. Liu, K. Guo, B. Wang, X. Zhang, T. Hong, Appl. Catal. B 2015 $163,179-188$

[216] Y. Li, X. Zhang, S. Jiang, H. Dai, X. Sun, Y. Li, Sol. Energy Mater. Sol. Cells $2015,132,40-46$.

[217] H. Xu, R. Mo, C. Cheng, G. Ai, Q. Chen, S. Yang, H. Li, J. Zhong, RSC Adv. 2014, 4, 47429-47435.

[218] H. Kim, M. Seol, J. Lee, K. Yong, J. Phys. Chem. C 2011, 115, $25429-$ 25436.

[219] G. Wang, X. Yang, F. Qian, J. Z. Zhang, Y. Li, Nano Lett. 2010, 10, 1088 1092.

[220] a) W. Hou, S. B. Cronin, Adv. Funct. Mater. 2013, 23, 1612-1619; b) Y. C. Pu, G. Wang, K. D. Chang, Y. Ling, Y. K. Lin, B. C. Fitzmorris, C. M. Liu, X Lu, Y. Tong, J. Z. Zhang, Y. J. Hsu, Y. Li, Nano Lett. 2013, 13, 3817-3823; c) X. Wang, C. Liow, A. Bisht, X. Liu, T. C. Sum, X. Chen, S. Li, Adv. Mater 2015, 27, 2207-2214; d) I. Thomann, B. A. Pinaud, Z. Chen, B. M. Clemens, T. F. Jaramillo, M. L. Brongersma, Nano Lett. 2011, 11, 3440-3446; e) Z. Zhang, L. Zhang, M. N. Hedhili, H. Zhang, P. Wang, Nano Lett. 2013, 13, 14-20; f) S. C. Warren, E. Thimsen, Energy Environ. Sci. 2012, 5, 5133-5146; g) J. Li, S. K. Cushing, P. Zheng, T. Senty, F. Meng, A. D. Bristow, A. Manivannan, N. Wu, J. Am. Chem. Soc. 2014, 136, $8438-$ 8449 .

[221] Z. Liu, W. Hou, P. Pavaskar, M. Aykol, S. B. Cronin, Nano Lett. 2011, 11, $1111-1116$

[222] X. Zhang, Y. Liu, S.-T. Lee, S. Yang, Z. Kang, Energy Environ. Sci. 2014, 7 , 1409.

[223] a) X. Zhang, Y. Li, J. Zhao, S. Wang, Y. Li, H. Dai, X. Sun, J. Power Sources 2014, 269, 466-472; b) Y.-G. Lin, Y.-K. Hsu, Y.-C. Chen, S.-B. Wang, J. T. Miller, L.-C. Chen, K.-H. Chen, Energy Environ. Sci. 2012, 5, 8917

[224] C. Li, X. T. Zhu, H. F. Zhang, Z. C. Zhu, B. Liu, C. W. Cheng, Adv. Mater Interfaces 2015, 2, 1500428

[225] a) S. A. Mann, E. C. Garnett, Nano Lett. 2013, 13, 3173-3178; b) L. Zhou, X. Yu, J. Zhu, Nano Lett. 2014, 14, 1093-1098.

[226] S. Ramadurgam, T. G. Lin, C. Yang, Nano Lett. 2014, 14, 4517-4522.

[227] a) S. Mubeen, J. Lee, N. Singh, S. Kramer, G. D. Stucky, M. Moskovits, Nat. Nanotechnol. 2013, 8, 247-251; b) J. Lee, S. Mubeen, X. Ji, G. D. Stucky, M. Moskovits, Nano Lett. 2012, 12, 5014-5019; c) H. J. Kim, S. H. Lee, A. A. Upadhye, I. Ro, M. I. Tejedor-Tejedor, M. A. Anderson, W. B. Kim, G. W. Huber, ACS Nano 2014, 8, 10756-10765

[228] L. J. Minggu, W. R. Wan Daud, M. B. Kassim, Int. J. Hydrogen Energy 2010, 35, 5233-5244.

[229] A. C. Nielander, M. R. Shaner, K. M. Papadantonakis, S. A. Francis, N. S Lewis, Energy Environ. Sci. 2015, 8, 16-25.

[230] a) M. S. Prévot, K. Sivula, J. Phys. Chem. C 2013, 117, 17879-17893; b) T. J. Jacobsson, V. Fjallstrom, M. Edoff, T. Edvinsson, Energy Environ. Sci. 2014, 7, 2056-2070; c) X. Peng, C. He, X. Fan, Q. Liu, J. Zhang, H. Wang, Int. J. Hydrogen Energy 2014, 39, 14166-14171.

[231] a) M. M. May, H. J. Lewerenz, D. Lackner, F. Dimroth, T. Hannappel, Nat. Commun. 2015, 6, 8286; b) S. Hu, N. S. Lewis, J. W. Ager, J. Yang, J. R. McKone, N. C. Strandwitz, J. Phys. Chem. C 2015, 119, $24201-24228$ c) E. Verlage, S. Hu, R. Liu, R. J. R. Jones, K. Sun, C. Xiang, N. S. Lewis, H. A. Atwater, Energy Environ. Sci. 2015, 8, 3166-3172.

[232] O. Khaselev, Science 1998, 280, 425-427.

[233] a) W. Calvet, E. Murugasen, J. Klett, B. Kaiser, W. Jaegermann, F. Finger, S. Hoch, M. Blug, J. Busse, Phys. Chem. Chem. Phys. 2014, 16, $12043-$ 12050; b) F. Urbain, V. Smirnov, J.-P. Becker, A. Lambertz, F. Yang, J. Ziegler, B. Kaiser, W. Jaegermann, U. Rau, F. Finger, Energy Environ. Sci. 2016, 9, 145-154; c) L. Han, I. A. Digdaya, T. W. F. Buijs, F. F. Abdi, Z. Huang, R. Liu, B. Dam, M. Zeman, W. A. Smith, A. H. M. Smets, J. Mater.
Chem. A 2015, 3, 4155-4162; d) L. Han, F. F. Abdi, P. Perez Rodriguez, B. Dam, R. van de Krol, M. Zeman, A. H. Smets, Phys. Chem. Chem. Phys. 2014, 16, 4220-4229; e) L. Han, F. F. Abdi, R. van de Krol, R. Liu, Z. Huang, H. J. Lewerenz, B. Dam, M. Zeman, A. H. Smets, ChemSusChem 2014, 7, 2832-2838; f) H. P. Wang, K. Sun, S. Y. Noh, A. Kargar, M. L. Tsai, M. Y. Huang, D. Wang, J. H. He, Nano Lett. 2015, 15, 2817-2824.

[234] a) C. R. Cox, J. Z. Lee, D. G. Nocera, T. Buonassisi, Proc. Natl. Acad. Sci. USA 2014, 111, 14057-14061; b) M. T. Winkler, C. R. Cox, D. G. Nocera, T. Buonassisi, Proc. Natl. Acad. Sci. USA 2013, 110, E1076-E1082; c) T. J. Jacobsson, V. Fjällström, M. Edoff, T. Edvinsson, Sol. Energy Mater. Sol. Cells 2015, 134, 185-193.

[235] a) J. Brillet, M. Cornuz, F. L. Formal, J.-H. Yum, M. Grätzel, K. Sivula, J. Mater. Res. 2010, 25, 17-24; b) J. Brillet, J.-H. Yum, M. Cornuz, T. Hisatomi, R. Solarska, J. Augustynski, M. Graetzel, K. Sivula, Nat. Photonics 2012, 6, 824-828.

[236] V. González-Pedro, I. Zarazua, E. M. Barea, F. Fabregat-Santiago, E. de La Rosa, I. Mora-Seró, S. Giménez, J. Phys. Chem. C 2014, 118, 891-895.

[237] a) K. Shin, J.-B. Yoo, J. H. Park, J. Power Sources 2013, 225, 263-268, b) J. K. Kim, K. Shin, S. M. Cho, T.-W. Lee, J. H. Park, Energy Environ. Sci. 2011, 4, 1465.

[238] a) Y. S. Chen, J. S. Manser, P. V. Kamat, J. Am. Chem. Soc. 2015, 137 974-981; b) C. G. Morales-Guio, M. T. Mayer, A. Yella, S. D. Tilley, M. Grätzel, X. Hu, J. Am. Chem. Soc. 2015, 137, 9927-9936; c) X. Zhang, B. Zhang, K. Cao, J. Brillet, J. Chen, M. Wang, Y. Shen, J. Mater. Chem. A 2015，3，21630-21636; d) Gurudayal, D. Sabba, M. H. Kumar, L. H. Wong, J. Barber, M. Grätzel, N. Mathews, Nano Lett. 2015, 15, $3833-$ 3839; e) P. Dias, M. Schreier, S. D. Tilley, J. S. Luo, J. Azevedo, L. Andrade, D. Q. Bi, A. Hagfeldt, A. Mendes, M. Grätzel, M. T. Mayer, Adv. Energy Mater. 2015, 5, 1501537.

[239] J. Luo, J. H. Im, M. T. Mayer, M. Schreier, M. K. Nazeeruddin, N. G. Park S. D. Tilley, H. J. Fan, M. Grätzel, Science 2014, 345, 1593-1596.

[240] P. Da, M. Cha, L. Sun, Y. Wu, Z. S. Wang, G. Zheng, Nano Lett. 2015, 15, $3452-3457$.

[241] a) B. AlOtaibi, S. Fan, S. Vanka, M. G. Kibria, Z. Mi, Nano Lett. 2015, 15 6821-6828; b) H. B. Yang, J. Miao, S. F. Hung, F. Huo, H. M. Chen, B. Liu, ACS Nano 2014, 8, 10403-10413.

[242] S. K. Mohapatra, M. Misra, V. K. Mahajan, K. S. Raja, J. Phys. Chem. C 2007, 111, 8677-8685

[243] Z. Wu, G. Zhao, Y. Zhang, J. Liu, Y. N. Zhang, H. Shi, J. Mater. Chem. A 2015, 3, 3416-3424.

[244] H. Wang, J. A. Turner, J. Electrochem. Soc. 2010, 157, F173.

[245] Y. Wang, J. Tang, Z. Peng, Y. Wang, D. Jia, B. Kong, A. A. Elzatahry, D. Zhao, G. Zheng, Nano Lett. 2014, 14, 3668-3673.

[246] Y. Fujishima, S. Okamoto, M. Yoshiba, T. Itoi, S. Kawamura, Y. Yoshida, Y. Ogura, Y. Izumi, J. Mater. Chem. A 2015, 3, 8389-8404.

[247] R. Raja, P. Sudhagar, A. Devadoss, C. Terashima, L. K. Shrestha, K Nakata, R. Jayavel, K. Ariga, A. Fujishima, Chem. Commun. 2015, 51, $522-525$.

[248] P. Bornoz, F. F. Abdi, S. D. Tilley, B. Dam, R. van de Krol, M. Grätzel, K. Sivula, J. Phys. Chem. C 2014, 118, 16959-16966.

[249] J.-W. Jang, C. Du, Y. Ye, Y. Lin, X. Yao, J. Thorne, E. Liu, G. McMahon, J. Zhu, A. Javey, J. Guo, D. Wang, Nat. Commun. 2015, 6, 7447

[250] C. Ding, W. Qin, N. Wang, G. Liu, Z. Wang, P. Yan, J. Shi, C. Li, Phys. Chem. Chem. Phys. 2014, 16, 15608-15614.

[251] S. Sato, T. Arai, T. Morikawa, K. Uemura, T. M. Suzuki, H. Tanaka, T. Kajino, J. Am. Chem. Soc. 2011, 133, 15240-15243.

[252] G. Magesh, E. S. Kim, H. J. Kang, M. Banu, J. Y. Kim, J. H. Kim, J. S. Lee, J. Mater. Chem. A 2014, 2, 2044.

[253] a) S. Hu, C. Xiang, S. Haussener, A. D. Berger, N. S. Lewis, Energy Environ. Sci. 2013, 6, 2984; b) J. Zhao, X. Wang, Z. Xu, J. S. C. Loo, J. Mater Chem. A 2014, 2, 15228; c) J. Cheng, M. Zhang, G. Wu, X. Wang, J. Zhou, K. Cen, Sol. Energy Mater. Sol. Cells 2015, 132, 606-614; d) A. J. Nozik, Appl. Phys. Lett. 1977, 30, 567; e) J. Cheng, M. Zhang, G. Wu, X. Wang, J. Zhou, K. Cen, Environ. Sci. Technol. 2014, 48, 7076-7084 f) G. K. Mor, O. K. Varghese, R. H. T. Wilke, S. Sharma, K. Shankar, T. J. Latempa, K.-S. Choi, C. A. Grimes, Nano Lett. 2008, 8, 1906-1911; g) K. Shankar, J. I. Basham, N. K. Allam, O. K. Varghese, G. K. Mor, X. J. Feng, M. Paulose, J. A. Seabold, K. S. Choi, C. A. Grimes, J. Phys. Chem. C 2009, 113, 6327-6359; h) T. Arai, S. Sato, T. Kajino, T. Morikawa, Energy Environ. Sci. 2013, 6, 1274; i) C. Ampelli, G. Centi, R. Passalacqua, S Perathoner, Energy Environ. Sci. 2010, 3, 292; j) S. Y. Reece, J. A. Hamel, 
K. Sung, T. D. Jarvi, A. J. Esswein, J. J. Pijpers, D. G. Nocera, Science 2011, 334, 645-648; k) Y. Zhong, K. Ueno, Y. Mori, X. Shi, T. Oshikiri, K. Murakoshi, H. Inoue, H. Misawa, Angew. Chem. Int. Ed. 2014, 53, 10350-10354; Angew. Chem. 2014, 126, 10518-10522.

[254] S. Mubeen, J. Lee, N. Singh, M. Moskovits, E. W. McFarland, Energy Environ. Sci. 2013, 6, 1633.

[255] S. Haussener, C. Xiang, J. M. Spurgeon, S. Ardo, N. S. Lewis, A. Z. Weber, Energy Environ. Sci. 2012, 5, 9922.

[256] R. E. Rocheleau, E. L. Miller, A. Misra, Energy Fuels 1998, 12, 3-10.

[257] Y. Qu, L. Liao, R. Cheng, Y. Wang, Y. C. Lin, Y. Huang, X. Duan, Nano Lett. 2010, 10, $1941-1949$.

[258] a) H. S. Jeon, J. H. Koh, S. J. Park, M. S. Jee, D.-H. Ko, Y. J. Hwang, B. K. Min, J. Mater. Chem. A 2015, 3, 5835-5842; b) T. Arai, S. Sato, T. Morikawa, Energy Environ. Sci. 2015, 8, 1998-2002.

[259] S. Sato, T. Arai, T. Morikawa, Inorg. Chem. 2015, 54, 5105-5113.

[260] a) M. B. McDonald, S. Ardo, N. S. Lewis, M. S. Freund, ChemSusChem 2014, 7, 3021 -3027; b) M. B. McDonald, J. P. Bruce, K. McEleney, M. S. Freund, ChemSusChem 2015, 8, 2645-2654.
[261] a) S. Mubeen, N. Singh, J. Lee, G. D. Stucky, M. Moskovits, E. W. McFarland, Nano Lett. 2013, 13, 2110-2115; b) N. M. Vargas-Barbosa, G. M. Geise, M. A. Hickner, T. E. Mallouk, ChemSusChem 2014, 7, 3017-3020; c) J. M. Spurgeon, M. G. Walter, J. Zhou, P. A. Kohl, N. S. Lewis, Energy Environ. Sci. 2011, 4, 1772; d) J. Rongé, D. Nijs, S. Kerkhofs, K. Masschaele, J. A. Martens, Phys. Chem. Chem. Phys. 2013, 15, 9315-9325; e) S. Ichikawa, R. Doi, Catal. Today 1996, 27, $271-277$.

[262] H. B. Gray, Nat. Chem. 2009, 1, 7.

[263] a) S. L. McFarlane, B. A. Day, K. McEleney, M. S. Freund, N. S. Lewis, Energy Environ. Sci. 2011, 4, 1700; b) J. M. Spurgeon, S. W. Boettcher, M. D. Kelzenberg, B. S. Brunschwig, H. A. Atwater, N. S. Lewis, Adv. Mater. 2010, 22, 3277-3281.

[264] D. Kang, T. W. Kim, S. R. Kubota, A. C. Cardiel, H. G. Cha, K. S. Choi, Chem. Rev. 2015, 115, 12839-12887.

Received: June 10, 2016

Published online on $\mathbf{\square}$ II, 0000 


\section{REVIEWS}

G. Liu, K. Du, S. Haussener, K. Wang*

$\mathbf{\square}-\mathbf{\square}$

Charge Transport in Two-Photon Semiconducting Structures for Solar Fuels

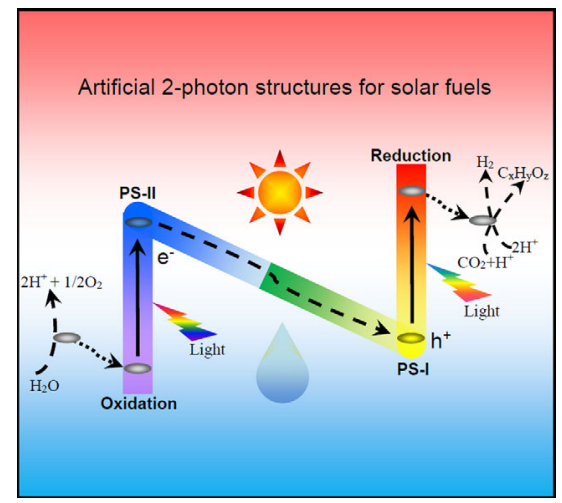

Burning bright: Progress on twophoton semiconducting structures is presented with focus on understanding of interfacial carrier dynamics. Strategies from solution-particle photocatalytic systems to nanostructured photoelectrode and photoelectrochemical devices are discussed to elucidate the mechanism of charge transport and to rationalize experimental observations. The studies compile valuable knowledge to build efficient solar-driven systems for clean energy. 